US Army Corps

of Engineers

Waterways Experiment

Station

\title{
Infragravity Waves in the Nearshore Zone
}

by Kent K. Hathaway, WES Joan Oltman-Shay, Northwest Research Associates Peter Howd, University of South Florida

Rob A. Holman, Oregon State University

Approved For Public Release; Distribution Is Unlimited

Prepared for Headquarters, U.S. Army Corps of Engineers 
The contents of this report are not to be used for advertising. publication, or promotional purposes. Citation of trade names does not constitute an official endorsement or approval of the use of such commercial products.

The findings of this report are not to be construed as an official Department of the Army position, unless so designated by other authorized documents. 


\title{
Infragravity Waves in the Nearshore Zone
}

\author{
by Kent K. Hathaway \\ U.S. Army Corps of Engineers \\ Waterways Experiment Station \\ 3909 Halls Ferry Road \\ Vicksburg, MS 39180-6199 \\ Joan Oltman-Shay
}

Northwest Research Associates

14508 NE 20th Street

Bellevue, WA 98009

Peter Howd

Department of Marine Science University of South Florida

140 7th Avenue South

St. Petersburg, FL 33701-5016

Rob A. Holman

College of Oceanography

Oregon State University

Corvallis, OR 97331-5503

Final report

Approved for public release; distribution is unlimited

Prepared for U.S. Army Corps of Engineers

Washington, DC 20314-1000 


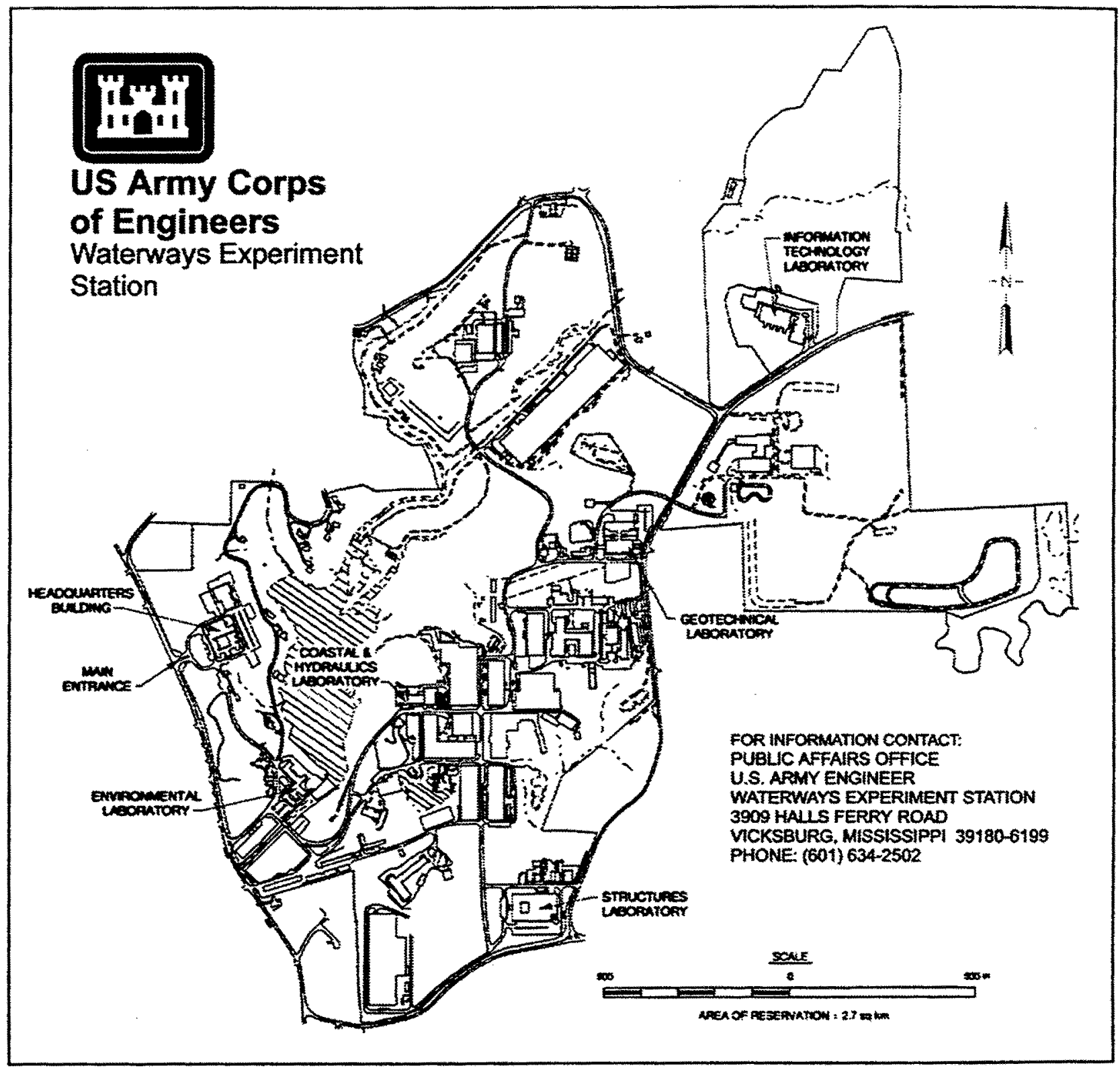

Waterways Experiment Station Cataloging-in-Publication Data

Infragravity waves in the nearshore zone / by Kent K. Hathaway ... [et al.] ; prepared for U.S. Army Corps of Engineers.

89 p. : ill. ; $28 \mathrm{~cm}$. - (Technical report ; CHL-98-30)

Includes bibliographic references.

1. Water waves. 2. Ocean waves. 3. Gravity waves. 4. Coastal engineering. I. Hathaway, Kent K. II. United States. Army. Corps of Engineers. III. U.S. Army Engineer Waterways Experiment Station. IV. Coastal and Hydraulics Laboratory (U.S. Army Engineer Waterways Experiment Station) V. Series: Technical report (U.S. Army Engineer Waterways Experiment Station) ; CHL-98-30.

TA7 W34 no.CHL-98-30 


\section{Contents}

Contents $\ldots \ldots \ldots \ldots \ldots \ldots \ldots \ldots \ldots \ldots \ldots \ldots \ldots \ldots \ldots \ldots \ldots \ldots$ iii

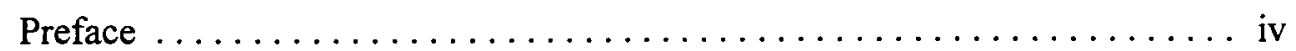

1 -Introduction $\ldots \ldots \ldots \ldots \ldots \ldots \ldots \ldots \ldots \ldots \ldots \ldots \ldots \ldots \ldots \ldots \ldots$

2-Infragravity Wave Dynamics $\ldots \ldots \ldots \ldots \ldots \ldots \ldots \ldots \ldots \ldots$

Infragravity Wave Classifications $\ldots \ldots \ldots \ldots \ldots \ldots \ldots \ldots \ldots \ldots$

Infragravity Wave Generation Mechanisms . . . . . . . . . . . . 14

Infragravity Waves on Nonplanar Beaches in the Presence of Longshore

Currents . . . . . . . . . . . . . . . . . 18

3-Infragravity Waves, Nearshore Morphology, and Sediment Transport . . . 26

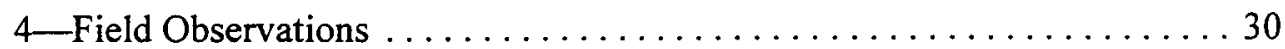

Video Analysis of Runup . . . . . . . . . . . . . . . . 32

Observations of Infragravity Waves During SAMSON and DELILAH . . 34

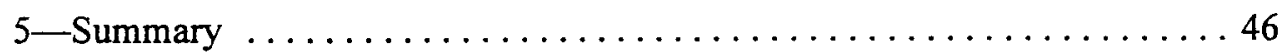

References $\ldots \ldots \ldots \ldots \ldots \ldots \ldots \ldots \ldots \ldots \ldots \ldots \ldots \ldots$

Appendix A: DELILAH Runup Spectra and Beach Profiles $\ldots \ldots \ldots$ A1

Appendix B: Photogrammetry $\ldots \ldots \ldots \ldots \ldots \ldots \ldots \ldots \ldots \ldots$ B1

Appendix C: Notation $\ldots \ldots \ldots \ldots \ldots \ldots \ldots \ldots \ldots \ldots \ldots \ldots \ldots$

SF298 


\section{Preface}

This report summarizes the present state of knowledge on infragravity motions and their significance in coastal engineering. Theoretical and observational studies are presented, most of which have been published elsewhere, however a few studies discussed in Chapter 4 are presented for the first time in this report. This report is motivated, in part, by the need to determine the significance of infragravity waves on coastal erosion and by the desire to improve coastal engineering solutions to problems associated with nearshore processes. Work was performed under the Infragravity Waves in the Nearshore Zone, Work Unit 32430, Coastal Navigation Hydrodynamics Program, authorized by Headquarters, U.S. Army Corps of Engineers (HQUSACE). Messrs. John H. Lockhart, Jr., John G. Housley, Barry W. Holliday, and John F. C. Sanda were HQUSACE Technical Monitors. Funds were provided through the Coastal Hydraulics Laboratory (CHL), U.S. Army Engineer Waterways Experiment Station (WES), under the program management of Ms. Carolyn Holmes, CHL. Director of CHL during the investigation was Dr. James R. Houston, and Assistant Director was Mr. Charles C. Calhoun, Jr.

The report was assembled by Mr. Kent Hathaway with considerable help from Ms. Judy Roughton at CHL's Field Research Facility (FRF) in Duck, NC, under the direct supervision of Mr. William A. Birkemeier, Chief, FRF, and the general supervision of Mr. Thomas W. Richardson, Chief, Coastal Sediments and Engineering Division, CHL. Analysis of infragravity data and assistance in preparing this document were provided by Dr. Joan Oltman-Shay, Northwest Research Associates, under contract number DACW39-93-0045. Additional assistance in preparing this document was provided by Dr. Peter Howd, University of South Florida, under contract number DACW39-94-K-0047.

Video images of runup data were processed in cooperation with Dr. Robert A. Holman, Oregon State University, with the help of his staff. Video data were collected with the support of the FRF staff, specifically Mr. Brian Scarborough who helped in surveying, and Ms. Roughton who digitized runup videos.

At the time of publication of this report, Director of WES was Dr. Robert W. Whalin. Commander was COL Robin R. Cababa, EN.

The contents of this report are not to be used for advertising, publication, or promotional purposes. Citation of trade names does not constitute an official endorsement or approval of the use of such commercial products. 


\section{Introduction}

The study of physical processes that govern sediment transport on beaches is a topic of vital interest to geologists, coastal engineers, and oceanographers. This research is motivated in part by the expenses incurred from coastal erosion and structure damage and by the desire to improve coastal engineering solutions to problems associated with nearshore processes. Estimation of extreme runup during storms is important for determining shoreline changes and designing coastal structures. Measurements show that runup is composed of incident wave $(0.05$ to $1 \mathrm{~Hz})$ and infragravity wave $(0.003$ to $0.05 \mathrm{~Hz})$ oscillations.

Observations of surf and runup during storms have shown the significance of infragravity waves, with the spectra often dominated by energy in this band (Holman and Bowen 1982, Guza and Thornton 1982, Holman and Sallenger 1985).

This report provides the reader with a description of infragravity motions and their significance in coastal engineering. A summary of previous investigations, both theoretical and observational, is provided as background information in Chapter 1. A description of infragravity motions and the postulated generation mechanisms is presented in Chapter 2. Particular emphasis is placed on the work of Howd, Bowen, and Holman (1992) and Oltman-Shay and Howd (1993), which noted the effects of longshore currents on infragravity edge waves. The potential significance of these waves to nearshore morphology and sediment transport is discussed in Chapter 3. Results from the SAMSON and DELILAH field experiments held at the Waterways Experiment Station, Coastal Hydraulics Laboratory's (CHL) Field Research Facility (FRF) are presented in Chapter 4 and Appendix A. The photogrammetric technique for measuring runup and subaerial beach profiles is included in Appendix B. Finally, in Chapter 5, the present knowledge of infragravity waves and the techniques used for measuring these motions are reviewed, and future research needs are discussed.

Technically, runup refers to the maximum elevation of wave excursion on the shoreline relative to mean (still) water level. This defines runup as a discrete measurement, but it is often referred to as the continuous process of water movement at the shoreface. To avoid confusion in terminology, "runup" is composed of setup due to breaking of incident wind waves and swash motion about the setup. Setup is the mean water surface elevation above still-water level, which is a well-understood phenomenon and can be predicted and modeled 
(Longuet-Higgins and Stewart 1964). Swash is defined as the continuous motion of runup relative to the setup level.

Munk (1949) and Tucker (1950) were the first to detect low-frequency waves and found a linear relation between their amplitudes and the amplitudes of the wind waves. These waves were measured with pressure recorders, $300 \mathrm{~m}$ offshore in approximately 6-m water depth, and were shown to have small amplitudes and periods of 2 to 3 minutes. Munk and Tucker observed that the waves were correlated with, but lagged behind, the incident wave groups. They concluded that the low-frequency motions were forced with the incident wave group and released as a free wave when the incident waves broke. They attributed the observed lag as the time needed for the forced motion to travel to the surf zone, and the released free wave to reflect from the beach and travel back to the wave recorder. Munk referred to his observations as "surf beat."

More recent studies have measured current velocity and water elevation variances in the surf zone and found that a significant fraction of the total energy is in the infragravity band (Guza and Thornton 1985; Sallenger and Holman 1987; Wright, Guza, and Short 1982; Bowen and Huntley 1984). Swash motions on steep-sloped (reflective) beaches, where incident waves are not fully dissipated, will have a major portion of the energy in the wind wave band (Wright et al. 1986). However, on shallow-sloped (dissipative) beaches, infragravity swash motions dominate the energy spectrum (Holman 1981, Holman and Sallenger 1985, Holman 1983). Holman and Bowen (1984) observed swash motions on an extremely dissipative beach and found 99.9 percent of the total variance in the infragravity band.

In the inner surf zone, energy spectra are often dominated by infragravity waves during high energy storm events, whereas incident wave energy will be depth limited due to dissipation in the surf zone (Figure 1). The surf zone is called "saturated" when an increase in offshore incident wave energy only serves to widen the surf zone, and local wind wave energy remains constant. However, infragravity waves do not exhibit saturation, but continue to increase in amplitude with an increase in the offshore incident wave height (Guza and Thornton 1982; Sallenger and Holman 1984; Holman and Sallenger 1985). Furthermore, beaches normally regarded as reflective can become highly dissipative during high energy storms (Wright et al. 1986).

A principal interest in infragravity waves has been to determine their importance to sediment transport and large scale morphology response (Bowen and Inman 1971, Short 1975, Holman and Bowen 1982). This interest developed in part from the observation that infragravity waves have length scales similar to typical nearshore morphologic scaling $\left(\mathrm{O}\left(10^{2}-10^{3} \mathrm{~m}\right)\right.$ ) (Wright and Short 1984, Lippmann and Holman 1990). Linear bar formation has been proposed to occur under the cross-shore nodes or antinodes of long waves (Carter, Liu, and Mei 1973; Bowen 1980; Sallenger, Holman, and Birkemeier 1985). More complex 


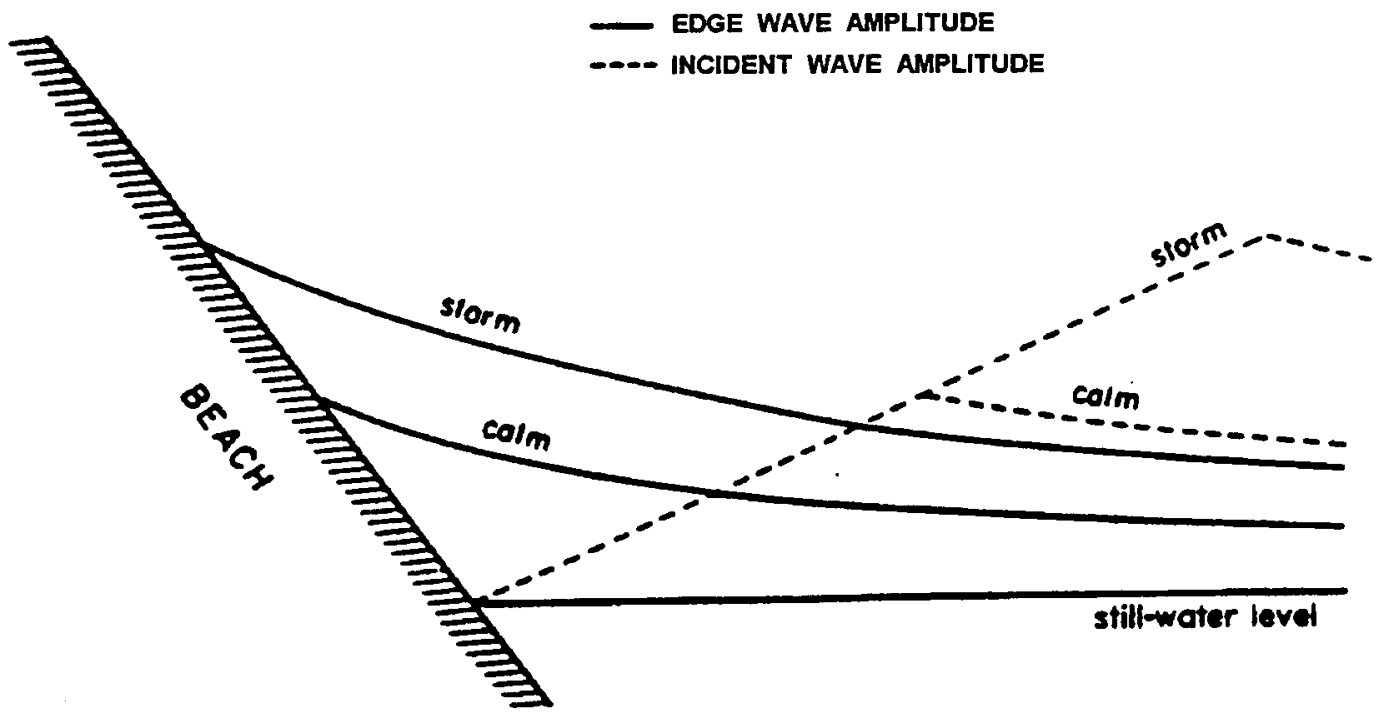

Figure 1. Schematic representation of incident wave saturation and infragravity wave resonance (after Holman, 1983)

morphology, such as crescentic and welded bars, has been attributed to the interaction of two or more long (edge) waves (Bowen and Inman 1971, Holman and Bowen 1982).

Another field in which infragravity motions are of interest is the shipping industry, where harbor oscillations with periods on the order of several minutes are common. If the infragravity wave forcing is at periods close to the natural mode of the harbor, then resonant amplification can occur. When excessive, these motions can be detrimental to mooring of ships, and transfer of cargos, and they can decrease the lifetime of mooring facilities. These oscillations also adversely influence tide measurements, particularly for tidal stations located near antinodes of the oscillation. Since tide gauges are typically designed to filter out waves at incident wave periods $(<25 \mathrm{~s})$, infragravity waves and harbor oscillations with longer periods are not filtered and contaminate the tide records. Furthermore, accurate water depth measurements (relative to a datum) cannot be made with fathometers, which is a serious problem for surveying and dredging operations. Typically a survey vessel uses the mean water level of a nearby tide gauge as a reference datum. If either the vessel or tide gauge is located near an antinode, then significant errors in survey accuracy will be recorded. 


\section{Infragravity Wave Dynamics}

\section{Infragravity Wave Classifications}

As their name suggests, infragravity waves are at frequencies below windgenerated gravity waves, or wind waves. Both wind waves and infragravity waves are gravity waves; the restoring mechanism for their motion is gravity. However, unlike wind waves, infragravity waves are not generated directly by the wind because in deep water they travel faster than the wind. It is generally accepted that infragravity waves are generated through the nonlinear interaction of wind waves, either offshore of the surf zone (Longuet-Higgins and Stewart 1964; Gallagher 1971; Sand 1982; Herbers, Elgar, and Guza 1994; Herbers et al 1995 ), and/or in the surf zone through a varying breaker location (from wave groupiness) and concomitant setup (Schäffer and Svendsen 1988; Schäffer 1990; Schäffer and Jonsson 1992; Lippmann, Holman, and Bowen 1997).

The specific frequency chosen to separate the infragravity and incident wave bands (nominally $0.05 \mathrm{~Hz}$ ) varies in the literature, generally depending on location. For example, on the east coast of the United States the $0.04-$ to $0.06-\mathrm{Hz}$ band is often considered to be included in the infragravity band, whereas this transition is often dominated by incident swell waves on the west coast. Howd, Oltman-Shay, and Holman (1991) found in the analysis of SUPERDUCK experiment data (Crowson et al. 1988) that variance from swell below $0.05 \mathrm{~Hz}$ was insignificant at this east coast site. Varying the cutoff between 0.04 and $0.06 \mathrm{~Hz}$ resulted in typical changes of \pm 5 percent in the total infragravity variance. Okihiro, Guza, and Seymour (1992) determined that a $0.04-\mathrm{Hz}$ cutoff was more appropriate for their observations in the Pacific Ocean, where long period swell is more common. Selection of an appropriate cutoff is generally a trade-off between underestimating infragravity variance to avoid the contamination from low-frequency swell and overestimating infragravity variance by including swell energy.

Infragravity waves are classified as free waves, which can be nonlocally forced and freely propagating, and forced waves, which are second-order forced waves generated by wave groups and are bound to them (Longuet-Higgins and Stewart, 1964; Figure 2). There are two types of free waves: edge waves that are 


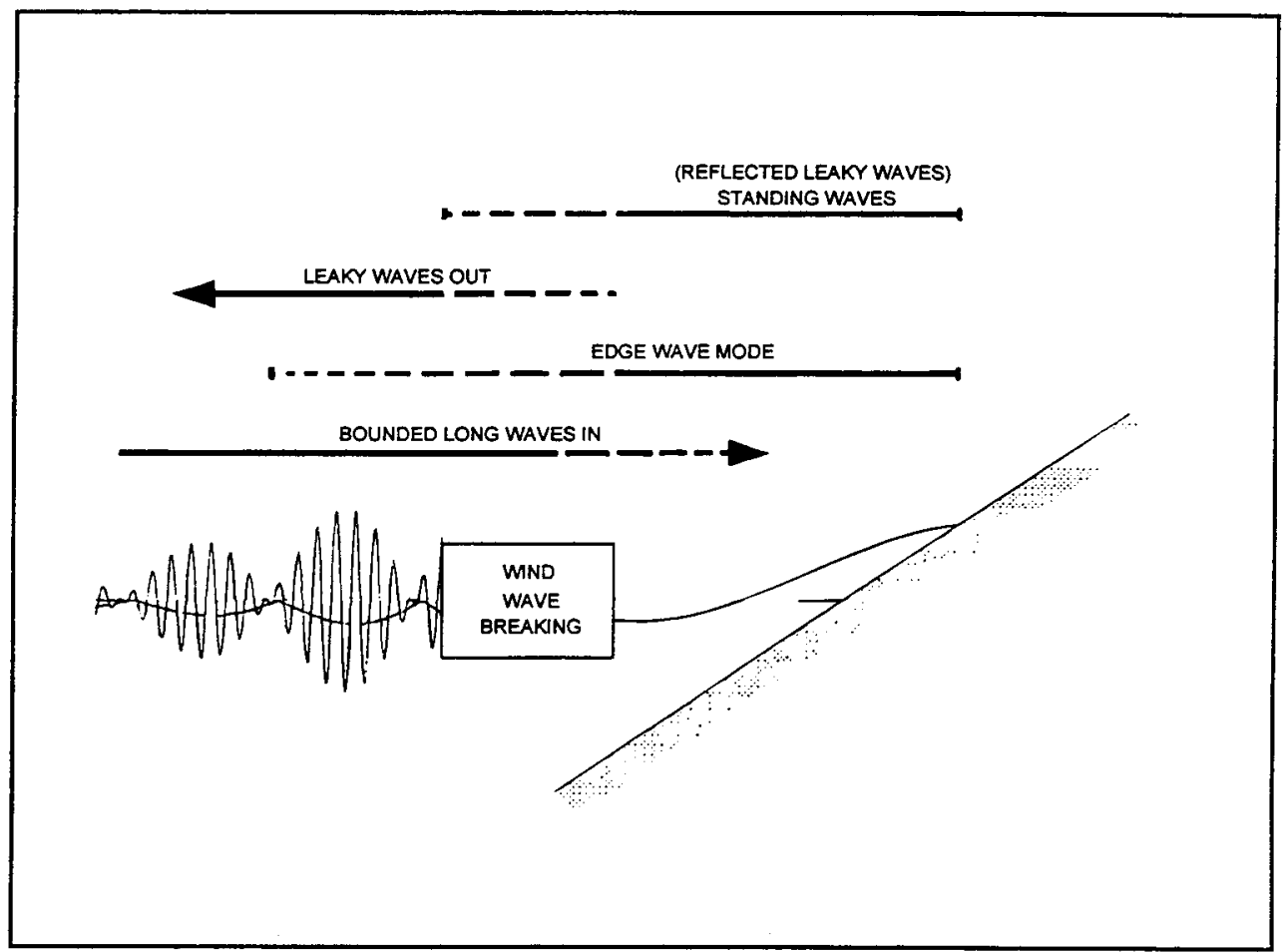

Figure 3. Schematic of infragravity wave types

refractively trapped to the shoreline and leaky waves that escape out to deep water upon reflection from the shoreline (Eckart, 1951). Edge and leaky waves are free surface gravity waves, free to propagate away from the generating source. Since forced waves are bound to wave groups and traveling at the group velocity, they are generally referred to as bound long waves (BLW).

A third type of low frequency motion was recently discovered (Oltman-Shay, Howd, and Birkemeier 1989): shear instabilities, or sometimes referred to as shear or far-infragravity waves. Tang and Dalrymple (1989) observed similar low frequency motions during the Torry Pines field experiment. These waves manifest as fluctuations in the horizontal current rather than as a surface elevation displacement, and as such are actually a vorticity phenomena. Holman and Bowen (1989) presented a theoretical basis for these motions being generated by cross-shore shear in the mean longshore current. The significance of finding these motions is the realization that low- frequency $(0.001$ to $0.03 \mathrm{~Hz})$ motion in the surf zone may not be composed entirely of surface gravity waves.

\section{Free infragravity waves}

Analytical edge wave solutions have been obtained for simplified nearshore bathymetry. Eckart (1951) found edge wave solutions to the linear shallowwater equations by assuming a planar beach with no alongshore currents. Ursell (1952) derived a more general solution for edge waves using the full linear 
equations of motion. For shallow beaches, with typical slopes less than 0.1 , Eckart's solution yields very accurate results compared to Ursell's full solution, especially for the lowest mode edge waves (Schäffer and Jonsson 1992). The general mathematical description for edge waves propagating alongshore is written as

$$
\eta(x, y, t)=a \phi(x) \cos \left(k_{y} y-\omega t\right)
$$

where

$$
\begin{aligned}
\eta & =\text { elevation } \\
x & =\text { cross-shore coordinate, } 0 \text { at shoreline, positive offshore } \\
y & =\text { longshore coordinate } \\
t & =\text { time } \\
a & =\text { edge wave shoreline amplitude } \\
\phi & =\text { cross-shore amplitude function } \\
k_{y} & =\text { longshore wave number } \\
\omega & =\text { radial frequency }
\end{aligned}
$$

Several solutions satisfy the edge wave boundary conditions for a given frequency and correspond to different edge wave modes. For Eckart's (1951) solution on a plane beach of slope $\beta$, these waves satisfy the shallow-water dispersion relation

$$
\omega^{2}=g k_{y}[(2 n+1) \tan \beta]
$$

where the mode number $n=0,1,2 \ldots$, subject to the condition that $(2 n+1) \tan \beta<1$. Thus, for a specific frequency, mode 0 edge waves have the largest longshore wave numbers (smallest longshore wavelengths) with higher modes having increasingly smaller wave numbers (larger longshore wavelengths). The possible number of edge wave modes is bound by the condition $(2 n+1) \tan \beta<1$, with the possible number of modes increasing as the beach slope decreases. This defines a cutoff for the highest possible mode since the longshore wave number is limited by the deepwater wave number $\left(k_{y}=\omega^{2} / g\right)$. Thus, a discrete set of edge wave solutions exists for longshore wave numbers $k_{y}$ in the range $\omega^{2} / g \leq\left|k_{y}\right| \leq \omega^{2} / g \beta$. If $k_{y}<\omega^{2} / g$, then the wave will enter deep water and not be refractively trapped to the shore. This is the region for leaky wave propagation, with a continuum of solutions with longshore wave numbers smaller than the deepwater cutoff (Figure 3).

Edge and leaky waves have long wavelengths relative to their amplitudes, allowing for near perfect reflection from the shoreline without breaking. These waves set up a standing wave structure with nodes and anti-nodes in the crossshore, and can be either progressive or standing in the longshore. The crossshore amplitude function $\phi(x)$ was found by Eckart (1951) for 


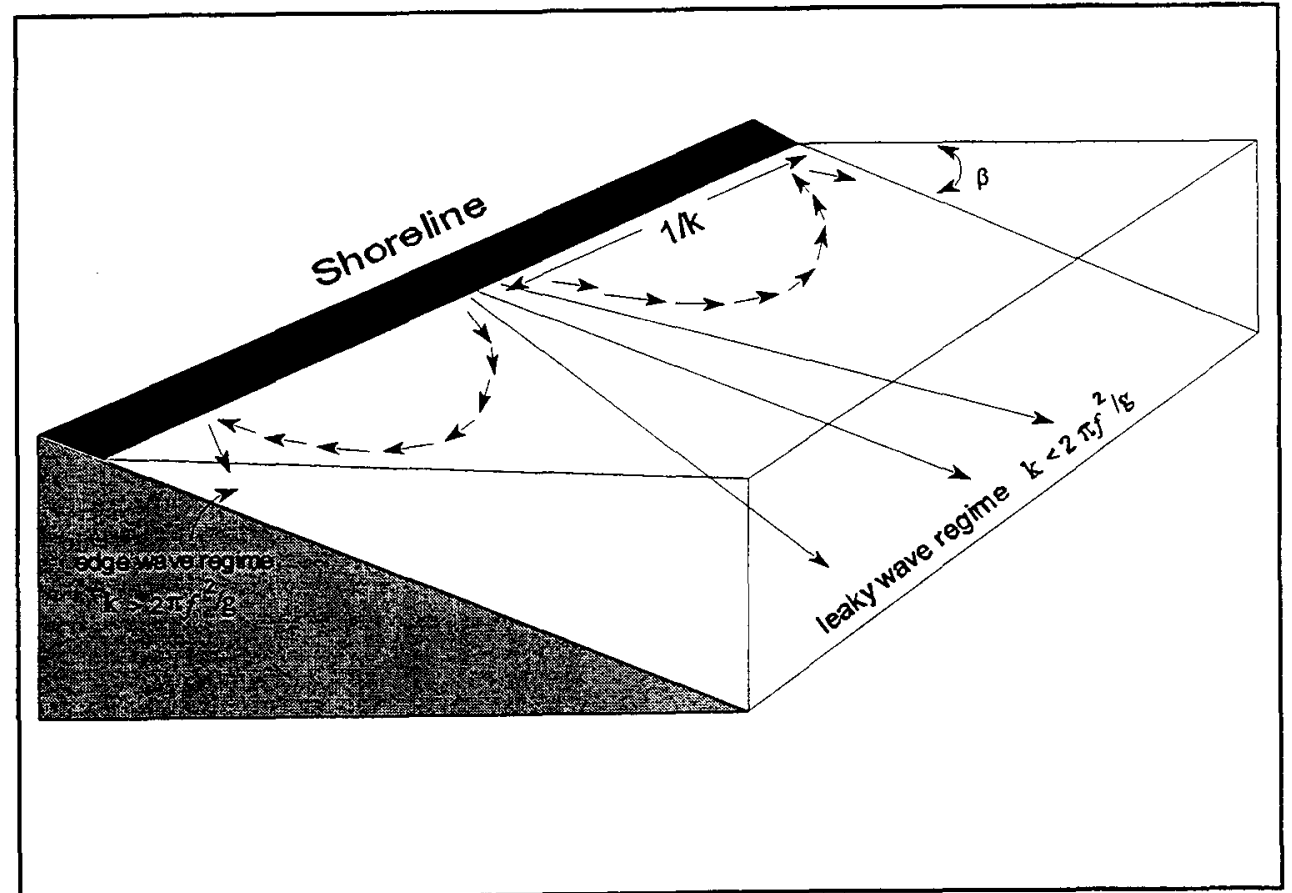

Figure 3. Refractive trapping of edge waves in shallow water and reflection of leaky waves

shallow-water edge waves of mode $n$ in the form of a Laguerre polynomial of order $n$

$$
\phi(x)=e^{-k_{y} x} L_{n}\left(2 k_{y} x\right)
$$

Eckart's longshore $(u)$ current and cross-shore $(v)$ current solutions are

$$
\begin{gathered}
u(x, y, t)=\frac{a g k_{y}}{\omega} \frac{\partial}{\partial(k x)}\left[L_{n}\left(2 k_{y}\right) e^{-k_{y} x}\right] \cos \left(k_{y} y-\omega t\right) \\
v(x, y, t)=\frac{a g k_{y}}{\omega}\left[L_{n}\left(2 k_{y}\right) e^{-k_{y} x}\right] \sin \left(k_{y} y-\omega t\right)
\end{gathered}
$$

The cross-shore structure for low-mode ( 0 to 3 ) edge waves is shown in Figure 4 in terms of a nondimensional offshore distance

$$
\chi=\frac{\omega^{2} x}{g \beta}
$$

Note the similar structure between these waves, particularly near the shore, with 


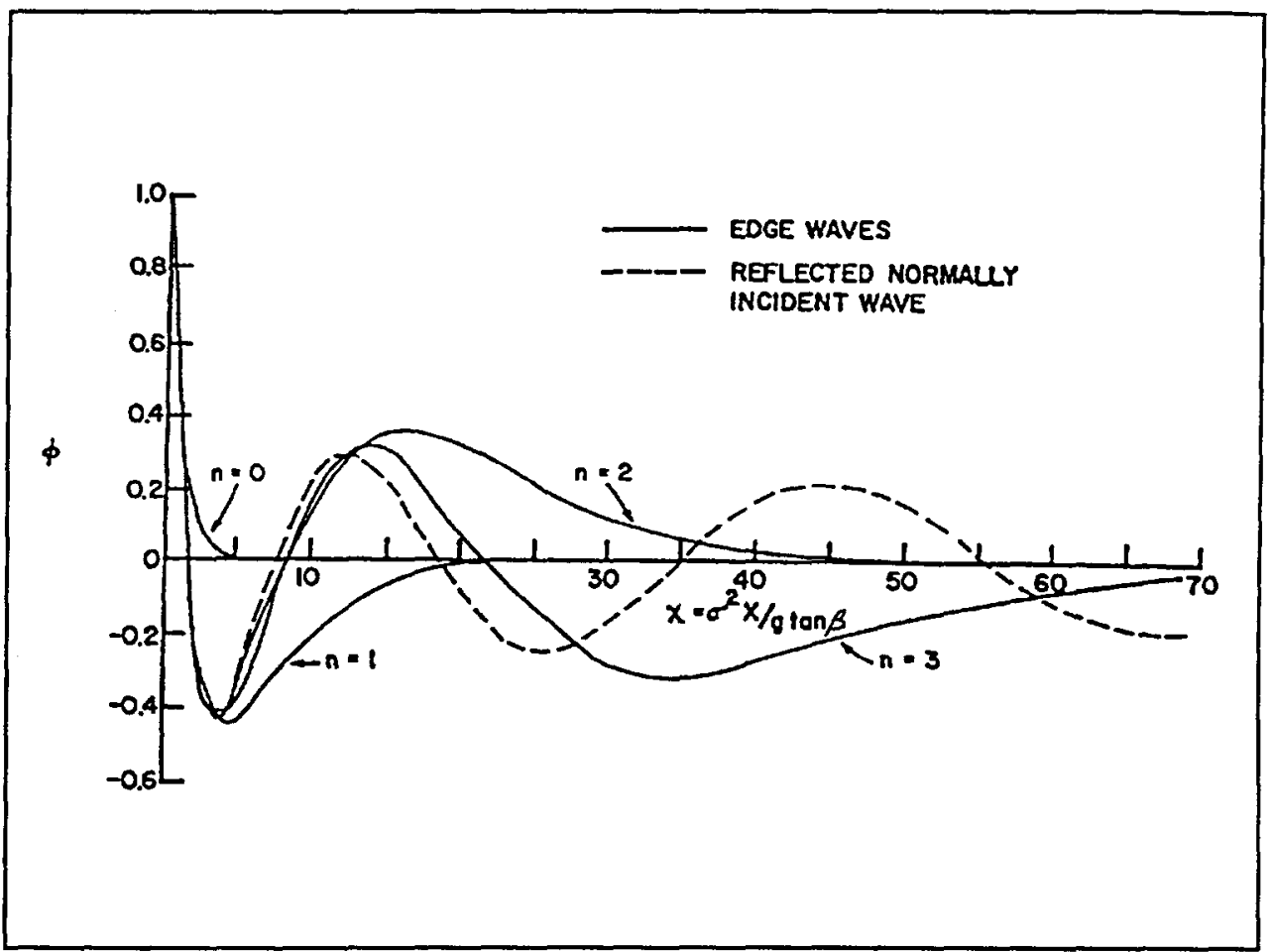

Figure 4. Cross-shore profile of low mode edge waves and leaky wave (after Holman 1983)

increasing similarity in the higher modes. Also note that these waves have their largest amplitudes at the shoreline and decay exponentially offshore with an $e$-folding distance of $k_{y}^{-1}$. Ursell's (1952) full solution has an $e$-folding of $\left(k_{y} \cos \beta\right)^{-1}$, but on shallow beaches $\cos \beta \approx 1$ and the two solutions are nearly identical.

Since on most simple beach profiles the largest elevation excursion is at the shoreline, these waves are often measured in swash oscillations. Although swash variance and spectra can be obtained from these measurements, determination of the modes is not possible using only swash data. Alongshorealigned arrays of in situ instruments are required to resolve the infragravity wave modes (Huntley, Guza, and Thornton 1981; Oltman-Shay and Guza 1987). Recent work by Bryan and Bowen (1996) and Byran, Howd and Bowen (1998) also cautions against the use of swash measurements for amplitude determination on beaches with pronounced sandbars, particularly for higher frequency edge waves, which may have maximum amplitudes in the vicinity of the bar(s).

Suhayda (1974) presented a description for the structure of normally incident leaky waves as 


$$
\eta(x, t)=a J_{0}(\sqrt{4 \chi}) \cos (\omega t)
$$

where $J_{0}$ is the zeroth order Bessel function. Leaky waves, like edge waves, are standing in the cross-shore but do not attenuate with distance offshore. Thus, they theoretically have an infinite number of nodes and antinodes extending out to deep water. These waves have a cross-shore structure similar in appearance to edge waves, particularly close to shore (Figure 4). High mode edge waves have many nodes and antinodes and can be indistinguishable from leaky waves in surf zone measurements.

Measurements of nearshore infragravity waves are for the purpose of identifying modes made with alongshore-aligned arrays of current meters. Huntley, Guza, and Thornton (1981) were the first to clearly identify edge wave modes using an alongshore array of current meters. Alongshore wave numberfrequency $\left(k_{y}-f\right)$ spectra are particularly useful for partitioning wave variance into the contributions from incident, edge, leaky, and shear waves (Oltman-Shay and Guza 1987; Oltman-Shay and Howd 1993; Howd, Oltman-Shay, and Holman 1991). The complex cross-shore standing structure of infragravity waves makes cross-shore wave number-frequency $\left(k_{x}-f\right)$ spectra, that would be observed from a cross-shore array, of little use for resolving high-mode edge and leaky waves. An Iterative Maximum Likelihood Estimator (IMLE) (Pawka 1982,1983 ) method of analyzing cross- and longshore component current data from along-shore aligned arrays has been shown highly successful at estimating $k-f$ spectra (e.g., Oltman-Shay and Guza 1987).

Typical $k-f$ spectra from the Oltman-Shay and Guza (1987) analysis of longshore-aligned array data from the Nearshore Sediment Transport Study (NSTS) field site at Torrey Pines is shown in Figure 5. The $k_{y}-f$ spectra of longshore component of flow are significantly better at resolving low mode edge waves, each mode showing up as a 'ridge' of high variance over a predictable frequency range. Cross-shore component velocity is dominated by high mode edge waves or leaky waves.

Oltman-Shay and Guza (1987) studied 15 days of data from two beaches. They found longshore current component energy was observed to consist of 70 to 90 percent low-mode $(n<2)$ edge waves. Cross-shore currents were found to contain low-mode edge waves which accounted for about 20 percent of the wave energy, but the $k_{y}-f(u)$ spectra also contained other low wave number energy from unresolvable combinations of high-mode edge waves and/or leaky waves. The observation of high modes in the $k_{y}-f(u)$ spectra does not contradict the dominance of low-modes in the $k_{y}-f(v)$ spectra because high-mode and leaky waves have their largest velocity components in the cross-shore direction. 


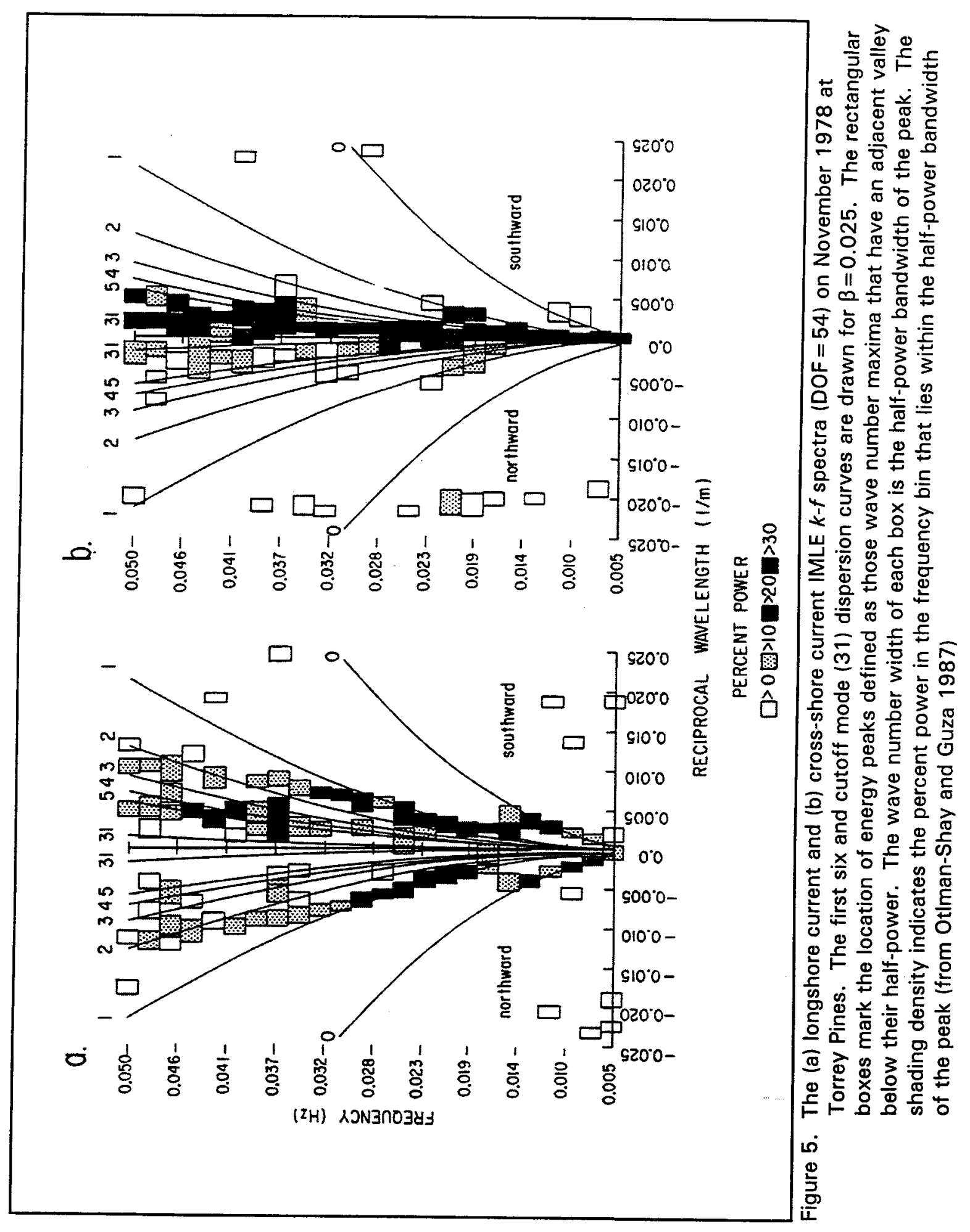




\section{Shear waves}

Oltman-Shay, Howd, and Birkemeier (1989) examined data from the alongshore aligned array of bidirectional current meters deployed during the SUPERDUCK experiment (Crowson et al. 1988) and found an energetic, longshore progressive wave in shallow water ( $1 \mathrm{~m}$ depth) that could not be gravity waves. The most energetic frequencies for these waves, observed to date, fall into the lower end of the infragravity band $(0.001<f<0.01 \mathrm{~Hz})$; hence, they were initially given the term "far-infragravity" waves (Figure 6). These motions were shown to be consistent with the Bowen and Holman (1989) model of vorticity waves or instabilities generated by cross-shore shear in the mean longshore current. This suggests that the term "shear instability" or "shear wave" is more appropriate than "far-infragravity wave" since these motions are observed as fluctuations in the mean longshore current and not as vertical displacements of the water surface.

Oltman-Shay, Howd, and Birkemeier (1989) noted that shear waves were only observed in the presence of a mean longshore current and propagate in the same direction (Figure 6). Furthermore, their alongshore wave numbers are too large to be surface gravity waves, exceeding the wave number of a mode 0 edge wave (largest free wave $k_{y}$ 's) by more than an order of magnitude.

Figure 7 demonstrates the rapid spin-up of shear waves with an increase of longshore current. Oscillation periods were near $400 \mathrm{~s}$ in the middle of the record and decreased to $200 \mathrm{~s}$ toward the end. Horizontal root mean square velocities exceeded $30 \mathrm{~cm} / \mathrm{s}$, alongshore wavelengths were typically of the order $10^{2} \mathrm{~m}$, and celerity was of the order $1 \mathrm{~m} / \mathrm{s}$. These observations were consistent with the shear instability model of Bowen and Holman (1989) which predicts a celerity of approximately $V_{\max } / 3$, where $V_{\max }$ is the peak longshore current.

The observed waves were found to have a characteristic longshore wavelength of approximately twice the width of the longshore current and to be highly coherent and homogeneous over an alongshore distance of two wavelengths.

An alternative hypothesis for the generation of shear instabilities was presented by Fowler and Dalrymple (1991) where interaction of two different wave trains produce longshore variations in energy (i.e., a longshore interference pattern, Figure 8). Tang and Dalrymple (1989) analyzed data from the Torry Pines field experiment for very low frequency $(<0.0024 \mathrm{~Hz})$ motions. They confirmed the presence of significant energy at very low frequencies $(<0.0015$ $\mathrm{Hz}$ ) that was easily distinguished from edge wave dispersion curves. These motions were found to have wavelengths similar to observed slowly migrating rip current cells. They suggested that incident wave groups forced a nearshore circulation in the form of migrating rip currents. Fowler and Dalrymple (1991) validated their proposed mechanism in a laboratory experiment using a directional wave basin. 


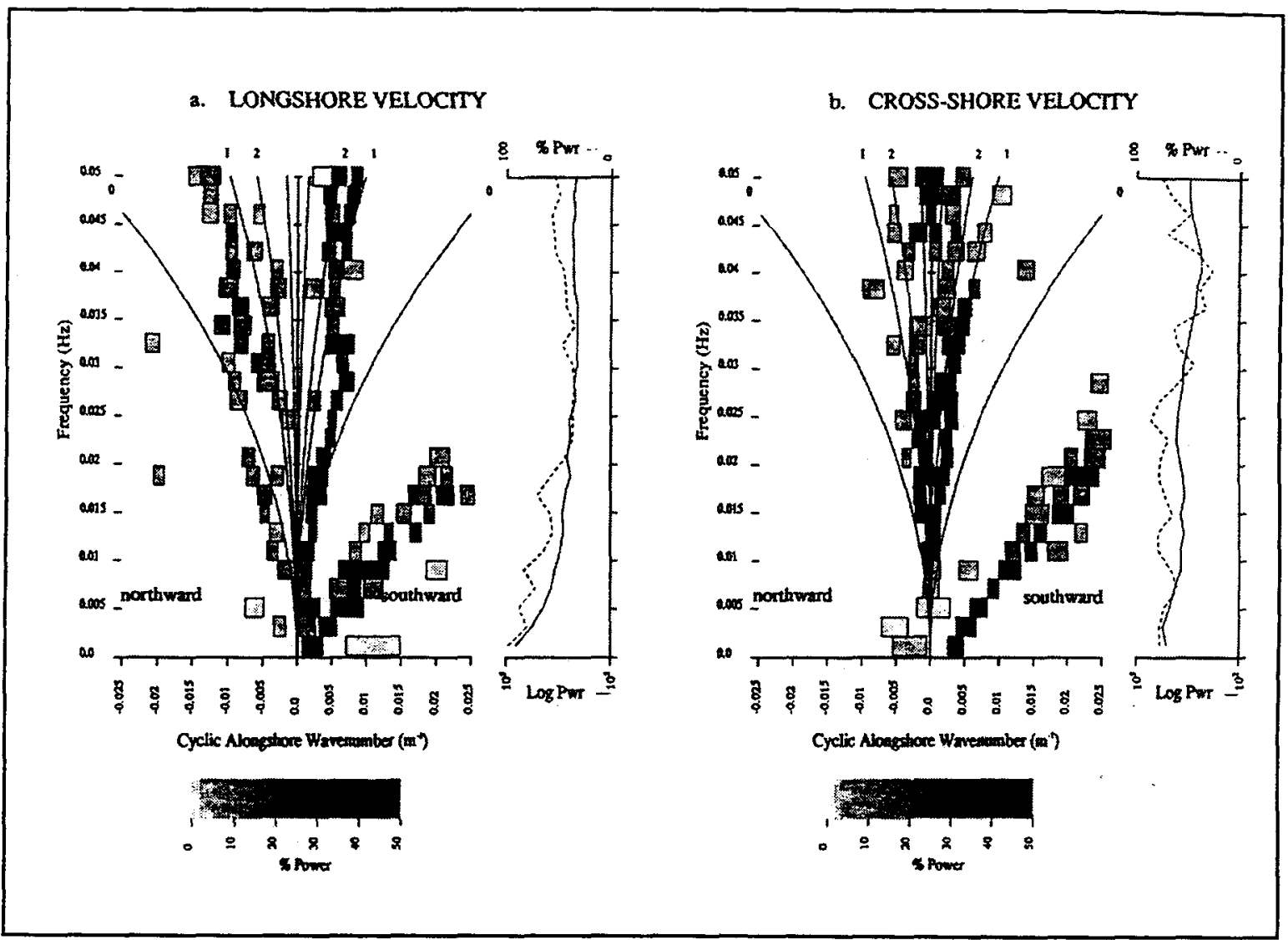

Figure 6. Typical $k$ - $f$ spectra, from NSTS experiment at Leadbetter Beach, CA . Edge wave dispersion lines are drawn for a plane-beach assumption. Note that mode 0 edge waves are better resolved in the longshore current based $k_{y}-f(v)$ spectra (top) than in the cross-shore current $k_{y}-f(u)$ spectra (bottom). The shading density indicates the percent power in the frequency bin that lies in the halfpower bandwidth of the peak (from Oltman-Shay, Howd, and Birkemeier 1989)

Research is ongoing to investigate these different mechanisms for generating shear waves, the growth and dissipation of these instabilities, and their role in modifying the incident and infragravity wave fields (e.g., Slinn et al. 1998). Modulation of the edge wave field and incident waves would be expected considering the magnitude of these shear oscillations. Clearly, the similar spatial scales of shear waves and sandbar morphology lends intrigue into their potential role in nearshore sediment dynamics. 


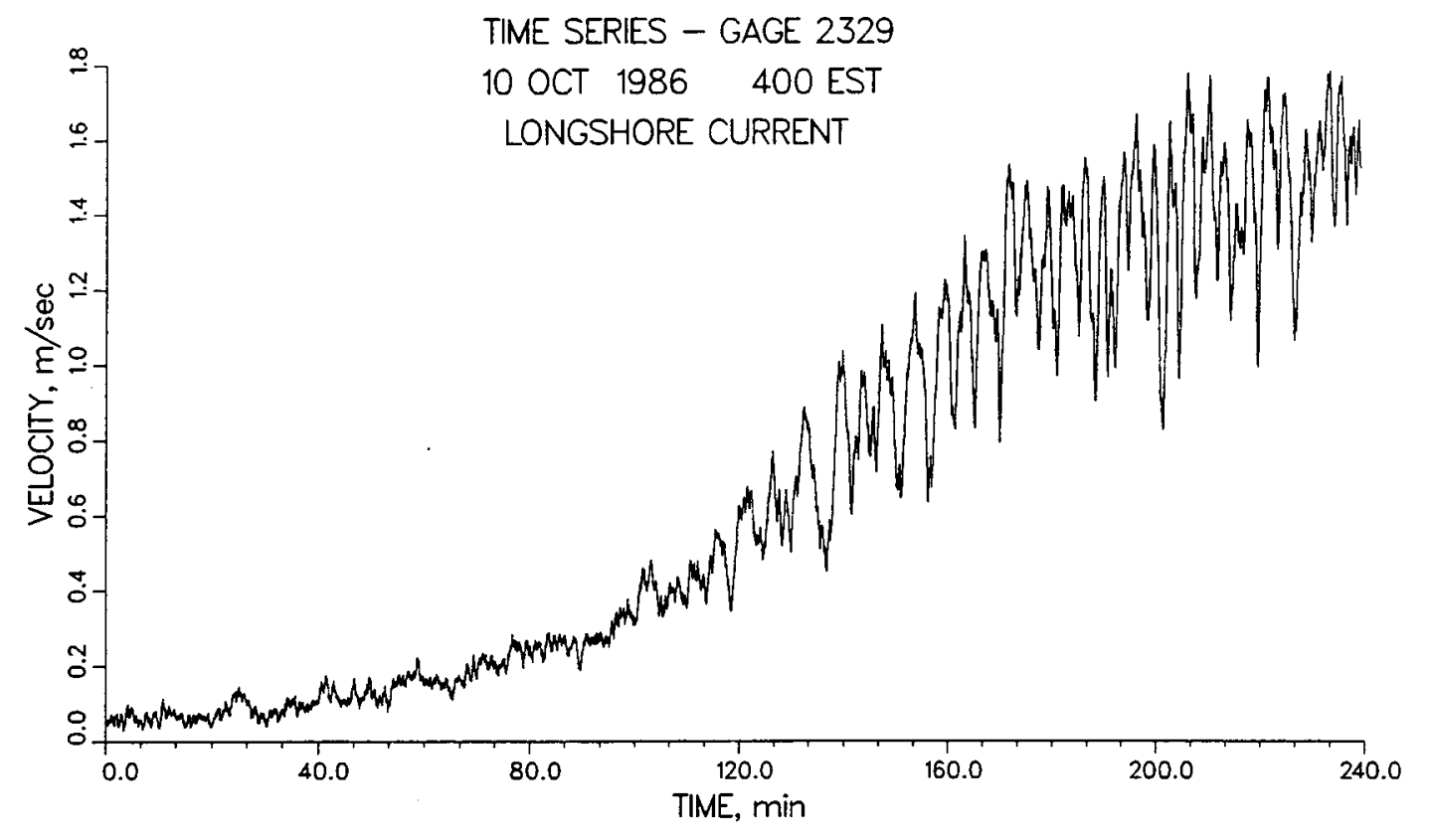

Figure 7. Longshore current showing rapid spin-up of shear waves. The time series was low-pass filtered, with a cutoff frequency of $0.04 \mathrm{~Hz}$, to remove currents at incident band frequencies

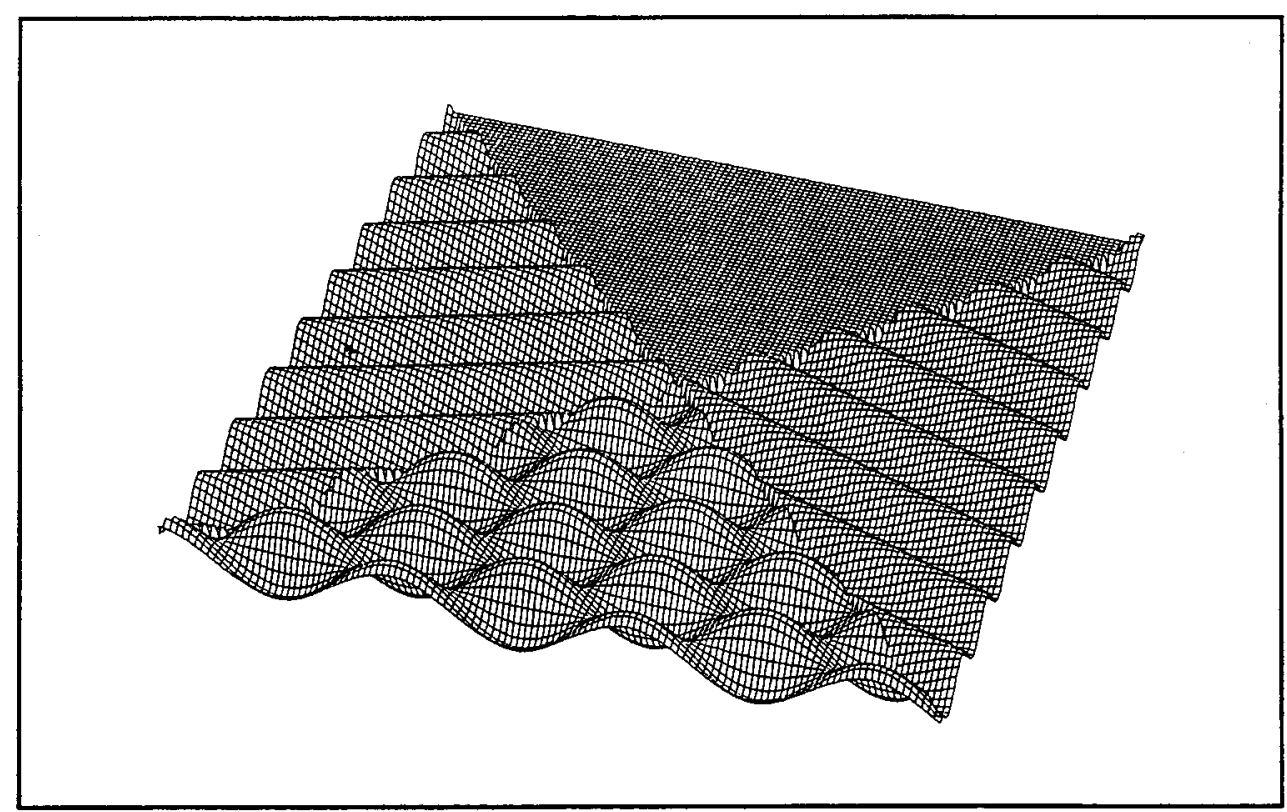

Figure 8. Schematic of two interacting wave trains creating longshore variations in energy as a proposed mechanism for generating periodic rip currents 


\section{Infragravity Wave Generation Mechanisms}

Two fundamental mechanisms have been proposed for the generation (forcing) of infragravity waves. The first is second-order bound wave generation by wave groups in intermediate water depths. Longuet-Higgins and Stewart (1962) showed theoretically that grouped-forced long waves could be generated by variations in radiation stress, which is a time-varying mean momentum flux induced by the wind waves. The second leading theory considers a forcing of low-frequency waves by a variation in the breakpoint location, which gives rise to a time variation in setup producing free long waves. Based on field observations (e.g., List 1992), it is reasonable to assume that both mechanisms have a role in the production of low-frequency motions in the nearshore region.

Longuet-Higgins and Stewart (1962) showed theoretically that groupedforced waves could be generated by variations in radiation stress $\left(S_{x x}(t)\right)$. This group forced long wave can be described by

$$
\eta(t)=-\frac{1}{\rho}\left|\frac{S_{x x}(t)}{g h-c_{g}^{2}}\right|
$$

where

$\eta(t)$ is the low-frequency surface elevation

$\rho$ is the water density

$h$ is water depth

$c_{g}$ is the group velocity

Radiation stress forces a lowering of the mean water level under high waves in the group and a corresponding rise under low waves. Thus, the bound wave is $180 \mathrm{deg}$ out of phase from the incident wind-wave group envelope. When the incident waves break, Longuet-Higgins and Stewart (1962) proposed that the bound wave is released as a free wave to either propagate seaward from the breakpoint or reflect off the shoreline and travel seaward.

The magnitudes of bound waves are reasonably well-predicted in intermediate to deep water by the bound long-wave (BLW) model (Sand 1982). However, in intermediate to shallow depths the prediction of infragravity energy becomes significantly more complicated because of the significant presence of free edge waves and because multiple generation mechanisms can be locally active (Herbers et al. 1995; Herbers, Elgar, Guza 1995). In addition to forced bound waves, break point forced waves may contribute a significant fraction of the total infragravity energy. Also, resonant amplifications of trapped edge waves that often dominate the nearshore infragravity variance are difficult to model over typical beaches, where the topography and current field can be complex. Furthermore, the transformation of bound waves as they propagate 
through the surf zone and subsequently release as free waves is poorly modeled.

Gallagher (1971) expanded on the Longuet-Higgins and Stewart (1962) twodimensional mechanism of forcing by wave groups (the BLW model) to three dimensions by considering forcing from nonlinear interactions of incident swell pairs approaching the shore at oblique angles. These triad interactions provide a mechanism for generating infragravity waves with nonzero alongshore wave numbers, allowing for resonant excitation of edge waves. Since this model neglects processes inside the surf zone it is regarded as an offshore generation mechanism. Bowen and Guza (1978) verified in the laboratory the importance of resonance on edge wave growth, concluding that resonant response was strong even through incident wave breaking. They suggested that due to resonance, edge waves would dominate the infragravity motions in the nearshore.

The generation mechanism proposed by Symonds, Huntley, and Bowen (1982) considers long waves produced from a time-varying breakpoint position induced by wave groupiness on a plane sloping beach. Their model predicts free long waves propagating seaward from the breaker zone, and shoreward, reflecting from the beach and traveling seaward. This model was based on spectra of bichromatic incident waves with periodic wave groups and excluded incident BLW forcing. Kostense (1984) verified the model in a wave flume and found good qualitative agreement. Since only two dimensions were considered and shoreline resonance was not addressed, this models the generation of leaky waves.

List (1992) proposed a finite difference model for the generation of twodimensional surf beat (leaky waves) using random wind waves as input. Contributions from both bound and breakpoint forced long waves were simulated in the time domain. His analysis of data from the DUCK85 experiment determined that the primary forcing was associated with bound long waves, which were amplified and strongly modified in the surf zone before reflecting from the shoreline as a leaky wave. He believed that the lower contribution of breakpoint forced waves, roughly half that of the bound wave, was due to radiation stress gradients in the breaker zone associated with breakpoint-forced long waves being transient. These gradients would have alternating signs within the surf zone that change at the group period, resulting in nonstationary forcing. In comparison, seaward of the surf zone, gradients from bound long waves would have a constant sign, allowing continual forcing of long waves into the breaker zone.

Schäffer (1990) extended this mechanism of breakpoint forced waves to three dimensions thus allowing for the generation of edge waves. In addition, Schäffer and Svendsen (1988) included incident BLW forcing and the propagation of wave groupiness through the surf zone.

Lippmann, Holman and Bowen (1997) also formulated a theoretical surf zone mechanism for driving edge waves based on variations in the breakpoint location for a plane sloping beach (following Symonds, Huntley, and Bowen 1982). 
Model comparisons were made with forcing outside the surf zone from nonlinear interactions of incident wave pairs (after Gallagher 1971). Conceptually, their development can be likened to a directional wavemaker, with the time and space variation in the breakpoint (determined by modulation scales in the incident wave field) forcing the generation of edge waves through similarly varying gradients in the components of the radiation stress. They concluded, based on their model, that this surf zone mechanism would be 2 to 10 times more important than the offshore forcing.

Recent observations of infragravity waves outside the surf zone have considerably advanced understanding of the relationship between incident wave conditions, the generation of infragravity waves, and the relative contributions of leaky versus high mode edge waves (Elgar et al. 1992; Herbers, Elgar, and Guza 1994; Herbers et al. 1995; Herbers, Elgar, and Guza 1995). This series of papers uses data primarily from an array of 24 bottom-mounted pressure transducers deployed in 13-m water depths approximately $2 \mathrm{~km}$ offshore of the Field Research Facility.

The primary conclusions of Elgar et al. (1992) concerned the relationship between incident wave climate and the bound and free infragravity waves. They found that the total infragravity wave energy was well correlated with the local swell (incident) wave energy, suggesting local forcing was important. Using bispectral analysis they were able to demonstrate that anomalous amplification of infragravity wave energy between 13- and 8-m depths was associated with the growth of the bound wave component of the infragravity band. This growth was most important during storm events and most evident in the high frequency end of the infragravity band. Bound waves provided between 70 and 100 percent of the storm infragravity wave energy in $8-\mathrm{m}$ depths and between 30 and 50 percent at the deeper $13-\mathrm{m}$ site. During low wave conditions less that 10 percent of the infragravity wave energy was in the form of bound waves. Ruessink (1998) had similar results from measurements made on a gently sloping multi-bar beach.

Herbers, Elgar, and Guza (1994) provide a thorough test of the second-order nonlinear theory governing the forcing of bound infragravity waves. Their results confirm that theory can accurately predict the total bound wave contributions, which ranged from 0.1 to 30 percent of the total infragravity energy. As in Elgar et al. (1992), the highest contributions were noted during storms when both the total infragravity energy and incident waves were also large. Less success was had with predicting the bound wave energy levels in specific frequency bands, with errors of up to a factor of 50 observed. They attribute this to statistical uncertainties in the estimates of the incident wave directional spectrum and in the bispectral-based estimates of bound wave energy.

In a companion paper (Herbers et al. 1995), the sources and variability of free infragravity waves on continental shelves are studied using data from depth ranges of $8 \mathrm{~m}$ to $204 \mathrm{~m}$ on morphologically variable continental shelves along both the Atlantic and Pacific coastlines of the United States. Consistent with previous studies, they found bound infragravity waves to be important (but not 
dominant) in shallow water or during large storm events. The magnitude of the free infragravity waves varied dramatically with wave conditions, as expected, and also with the configuration of the shelf. For instance, energy levels on wide, sandy continental shelves, such as off the FRF, were found to have free wave energy levels 2-4 times greater than those on a narrow shelf under similar incident wave conditions, suggesting a sensitivity to the refractive characteristics of the shelf and the distance over which nonlinear interactions occur during shoaling.

Herbers, Elgar, and Guza (1995) again use their data from the 13-m site at the FRF to investigate the forcing and propagation of infragravity waves. Much of their analysis is based on comparison of energy fluxes of waves progressing either on or off-shore, and either direction along the beach. In general terms they found that during storms the outgoing infragravity wave energy flux is several times larger than the shoreward energy flux, arguing for a surf-zone origin of the waves, and significant energy dissipation on the continental shelf. The opposite holds during low swell conditions, with shoreward energy flux commonly exceeding the offshore flux, suggesting non-locally generated motions may be important during those time periods. Examination of the partitioning of the energy fluxes is very helpful in focusing the future needs for infragravity wave research on generation and dissipative mechanisms.

Okihiro, Guza, and Seymour (1993) and Okihiro and Guza (1996) report on observations and model studies of the forcing and amplification of harbor seiches at infragravity frequencies. The three harbors they studied were all small with surface areas of approximately $1 \mathrm{~km}^{2}$, and water depths ranging from 5 to $12 \mathrm{~m}$. All were located in the Pacific, two in Hawaii and one in California. The sources of seiche energy were determined by correlation analysis between offshore swell (recorded just seaward of harbor entrances) and pressure sensors from within the harbors. They found, for these harbors, that below a frequency of $\sim 0.0015 \mathrm{~Hz}$ the seiche and swell energies were only weakly correlated. This frequency band contained the grave mode of oscillation and appeared to be excited by meteorological events and tsunamis. In contrast, seiche energy at frequencies above this cutoff (i.e., the infragravity frequencies) are highly correlated with swell energy. They also noted secondary dependencies on swell frequency (increasing correlation with longer period waves) and more energetic seiching at high tide. Swell-driven seiches dominated over the lower frequency seiche band when waves were high, as could be expected.

Amplification of the sieche motions was found to depend on the seiche frequency and was largest for the grave mode. However the harbors they studied all showed a decrease in grave-mode amplification with increasing overall seiche energy. Significant seiche heights were reported to be approximately $10-15$ percent of the offshore significant wave height when it exceeds $2 \mathrm{~m}$. 


\section{Infragravity Waves on Nonplanar Beaches in the Presence of Longshore Currents}

Analytical descriptions of edge wave dynamics have primarily been restricted to two beach types, one with plane parallel contours (Eckart 1951, Ursell 1952) and one with an exponential profile (Ball 1967). Solutions for beaches with irregular bathymetry are typically found with numerical models (e.g., Howd, Bowen, and Holman 1992; Falques and Iranzo 1992). Holman and Bowen (1979) presented numerical solutions for complex beach profiles, showing that a plane beach assumption could yield estimates of edge wavelength with \pm 100 percent error. They emphasized the importance of profile changes with varying stages of the tide, and the subsequent effects on edge wave amplitudes and modifications to the nodal structure. Kirby, Dalrymple, and Liu (1981) also used a numerical solution to study the effects of nonplanar bathymetry on the crossshore structure of edge wave nodes and antinodes. They found that for a barred topography, an edge wave elevation antinode would be attracted to the bar crest, resulting in a cross-shore velocity node at the bar and providing a mechanism for bar stabilization.

Recently, Howd, Bowen, and Holman (1992) examined edge wave solutions for the effects of mean alongshore currents, allowing for slow cross-shore variations in the longshore current and in the depth (mild slope assumption). They demonstrated that longshore currents can significantly modify edge wave refraction in the nearshore waveguide, altering both the edge wave dispersion relation and the cross-shore nodal structure. These waveguide modifications are similar to those produced by sandbars (Kirby, Dalrymple, and Liu 1981). Edge waves opposing the longshore current are refractively focussed to the bar (Figure 9). However, edge waves traveling in the same direction as the longshore current will diverge in the longshore current maximum, similar to their divergence in a trough where the local celerity is a maximum. Thus, as seen in Figure 9, a barred topography will symmetrically modify progressive edge waves whereas the mean longshore current will have a different effect depending on the direction of travel.

Howd, Oltman-Shay, and Holman (1991) introduced a hypothesis on the role edge waves in strong longshore currents would have on the formation and migration of linear sandbars. They suggested the concept of an "effective beach profile" associated with the modification of edge waves by the cross-shore structure of the longshore current. This model was described in more detail by Howd, Bowen, and Holman (1992). A summary of their work is included here to illustrate the effect of longshore currents on edge wave solutions (see also Oltman-Shay and Howd 1993).

Howd, Bowen, and Holman (1992) numerically modeled the nearshore waveguide using the invisid shallow-water equations of momentum and mass, including alongshore currents with the total velocity vector 


\section{MODIFICATIONS TO THE NEARSHORE WAVE GUIDE}

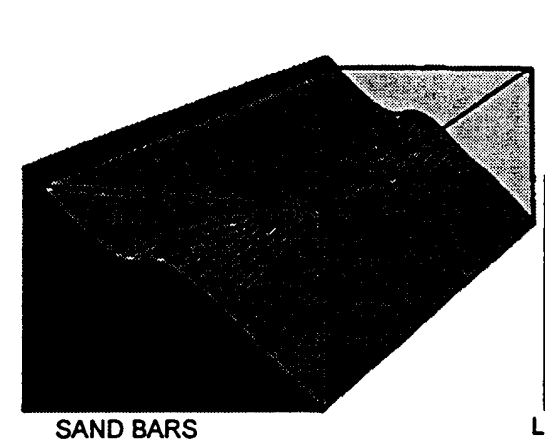

DEPTH MINIMUM AT CREST VELOCITY MINIMUM AT CREST REFRACTIVE FOCUSSING ON CREST RESPONSE SAME BOTH DIRECTIONS

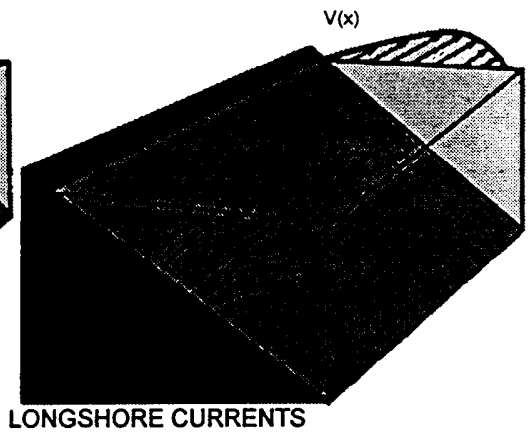

\section{CELERITY * $V(x)$}

VELOCITY MIN/MAX AT V MAXIMUM

REFRACTIVE FOCUSSING INTO CURRENT REFRACTIVE DEFOCUSSING WTH CURRENT

Figure 9. Modification of edge waves by longshore currents

$U(x, y, t)=[u(x, y, t), v(x, y, t)+V(x)]$, where $x$ and $y$ are the cross-shore and alongshore coordinates, $u$ and $v$ are the edge wave velocity components, and $V$ is the mean alongshore current. It is assumed $V \gg u, v$ and that depth $h$ and $V$ are slowly varying in $x$ alone. The linear shallow-water equations take the form

$$
\begin{gathered}
\frac{\partial u}{\partial t}+V \frac{\partial u}{\partial y}=-g \frac{\partial \eta}{\partial x} \\
\frac{\partial v}{\partial t}+u \frac{\partial V}{\partial x}+V \frac{\partial v}{\partial y}=-g \frac{\partial \eta}{\partial y} \\
\frac{\partial \eta}{\partial t}+\nabla(\eta V+h U)=0
\end{gathered}
$$

The edge wave solution assumes a wave-like form for $u, v$, and $\eta$, as

$$
\begin{aligned}
& u=u^{\prime}(x) e^{\left(k_{y} y-\omega t\right)} \\
& v=v^{\prime}(x) e^{\left(k_{y} y-\omega t\right)}
\end{aligned}
$$




$$
\eta=\eta^{\prime}(x) e^{\left(k_{y} y-\omega t\right)}
$$

Substituting Equations 12-14 into the shallow-water Equations 9-11 results in

$$
\begin{gathered}
\alpha u^{\prime}=-g \frac{\partial \eta}{\partial x} \\
\alpha v^{\prime}=\frac{\partial V}{\partial x} u^{\prime}-g k \eta^{\prime} \\
\alpha \eta^{\prime}=\frac{\partial\left(h u^{\prime}\right)}{\partial x}-k h v^{\prime}
\end{gathered}
$$

where $\alpha=\left(k_{y} V-\omega\right)$. These equations can be manipulated to obtain two second-order differential equations in terms of $\eta$ and $u$

$$
\begin{gathered}
\frac{\partial}{\partial x}\left[\left(\frac{g h}{\alpha}\right)\left(\frac{\partial \eta}{\partial x}\right)\right]+\eta\left(1-\frac{k_{y}^{2} g h}{\alpha^{2}}\right)=0 \\
\frac{\partial}{\partial x}\left[\frac{\gamma}{\left(1-\gamma^{2}\right)} \frac{\partial}{\partial x}\left(\frac{h u}{\alpha}\right)\right]-\gamma^{2} k_{y}^{2}\left(\frac{h u}{\alpha}\right)=0
\end{gathered}
$$

where

$$
\gamma^{2}=\frac{\alpha^{2}}{k_{y}^{2} g h}
$$

In the case of no alongshore currents $(V=0)$, Equation 18 can be written in the form of Eckart's (1951) edge wave equation

$$
\frac{\partial}{\partial x}\left(g h \frac{\partial \eta}{\partial x}\right)+\eta\left(\omega^{2}+g h k_{y}^{2}\right)=0
$$
as

The effective beach profile is defined by Howd, Bowen, and Holman (1992)

$$
h^{\prime}(x)=\frac{h(x)}{\left[1-\frac{V(x)}{c}\right]^{2}}
$$


where $c=\omega / k_{y}$ is the edge wave celerity. Rewriting Equation 21 in terms of $h^{\prime}(x)$ gives

$$
\frac{\partial}{\partial x}\left(g h^{\prime} \frac{\partial \eta}{\partial x}\right)+\eta\left(\omega^{2}+g h^{\prime} k_{y}^{2}\right)=0
$$

which is functionally equivalent to the classical edge wave equation but now carries with it the modifications of edge wave characteristics due to mean longshore currents and topography.

Edge waves traveling into the current experience an increase in $\left|k_{y}\right|$ and compress the nodal structure toward the shore. The effect is opposite for edge waves progressing with the current, the magnitude of $\left|k_{y}\right|$ decreases and the nodal structure shifts offshore. This change in dispersion has interesting implications for the possible effects on nearshore morphology. Without currents, edge waves of identical frequency and mode traveling in opposite directions would have identical, but opposite sign $k_{y}$. Bowen and Inman (1971) suggested that when these edge waves are phase-locked, the associated velocity fields could generate crescentic bars. The results of Howd, Bowen, and Holman (1992) imply that addition of alongshore currents would change the $\left|k_{y}\right|$

magnitudes and the associated edge wave drift velocities to a more complicated pattern. This could result in more complex morphology changes, such as welded bars, as proposed by Holman and Bowen (1982) for edge wave interactions of different modes.

Edge wave solutions for beaches with alongshore currents or depth profiles without analytical solutions can be found by manipulating Equations 15-17 to obtain two coupled first-order equations (Howd, Bowen, and Holman 1992; Oltman-Shay and Howd 1993)

$$
\begin{gathered}
\frac{\partial \eta^{\prime}}{\partial x}=-\frac{\alpha}{g} u^{\prime} \\
\frac{\partial u^{\prime}}{\partial x}=\frac{\alpha}{h}\left(1-\frac{g k_{y}^{2} h}{\alpha^{2}}\right) \eta^{\prime}+\left[\left(\frac{k_{y}}{\alpha}\right)\left(\frac{\partial V}{\partial x}\right)-\left(\frac{1}{h}\right)\left(\frac{\partial h}{\partial x}\right)\right] u^{\prime}
\end{gathered}
$$

Howd, Bowen, and Holman (1992) solved these equations using a numerical method, the Runge-Kutta method, where the initial values at the shoreline are

$$
\eta_{x}^{\prime}(0)=-\frac{\omega^{2}}{g \beta_{1} \eta^{\prime}(0)}
$$




$$
\begin{gathered}
u_{x}^{\prime}(0)=-\frac{g \eta^{\prime}(0)}{\omega}\left\{\frac{1}{2}\left[k_{y}^{2}+\left(\frac{\omega^{2}}{g \beta_{1}}\right)^{2}\right]+\left(\frac{\omega^{2}}{g \beta_{1}}\right)\left(\frac{\beta_{2}}{\beta_{1}}\right)+\left(\frac{\omega k_{y} V_{x}}{g \beta_{1}}\right)\right\} \\
\left|u^{\prime}(0)\right|=\frac{\omega}{\beta_{1}}\left|\eta^{\prime}(0)\right| \\
\left|v^{\prime}(0)\right|=\left|\frac{g k_{y}}{\omega} \eta^{\prime}(0)-\frac{V_{x} u^{\prime}(0)}{\omega}\right|
\end{gathered}
$$

where $\beta_{1}$ is the beach slope at the shoreline and $\beta_{2}$ is the beach curvature at the shoreline. Solutions assume $u^{\prime}$ and $v^{\prime}$ are bounded and approach 0 for the offshore boundary condition. Howd, Bowen, and Holman (1992) tested the model with analytical solutions using planar and exponential profiles and determined numerical estimates of wave number were accurate to 0.1 percent.

Oltman-Shay and Howd (1993) compared the Howd, Bown, and Holman (1992) numerical model solutions and the plane-beach analytical solutions with observations from the two NSTS beaches, Torrey Pines and Leadbetter. They found that numerical and analytical estimates of edge wave shoreline variance differed by only 10 to 40 percent (e.g., Table 1 ). However, they also found that effect of mean longshore current, an asymmetry in the up and downstream $k_{y}-f$ dispersion curves (e.g., Figure 10), and the effect of a concave steepening of the foreshore in the depth profile, manifesting as a steepening of the dispersion curve from that of a plane beach solution (e.g., Figure 11), were observed and well predicted by the numerical solutions using the measured cross-shore profiles of mean alongshore current. 


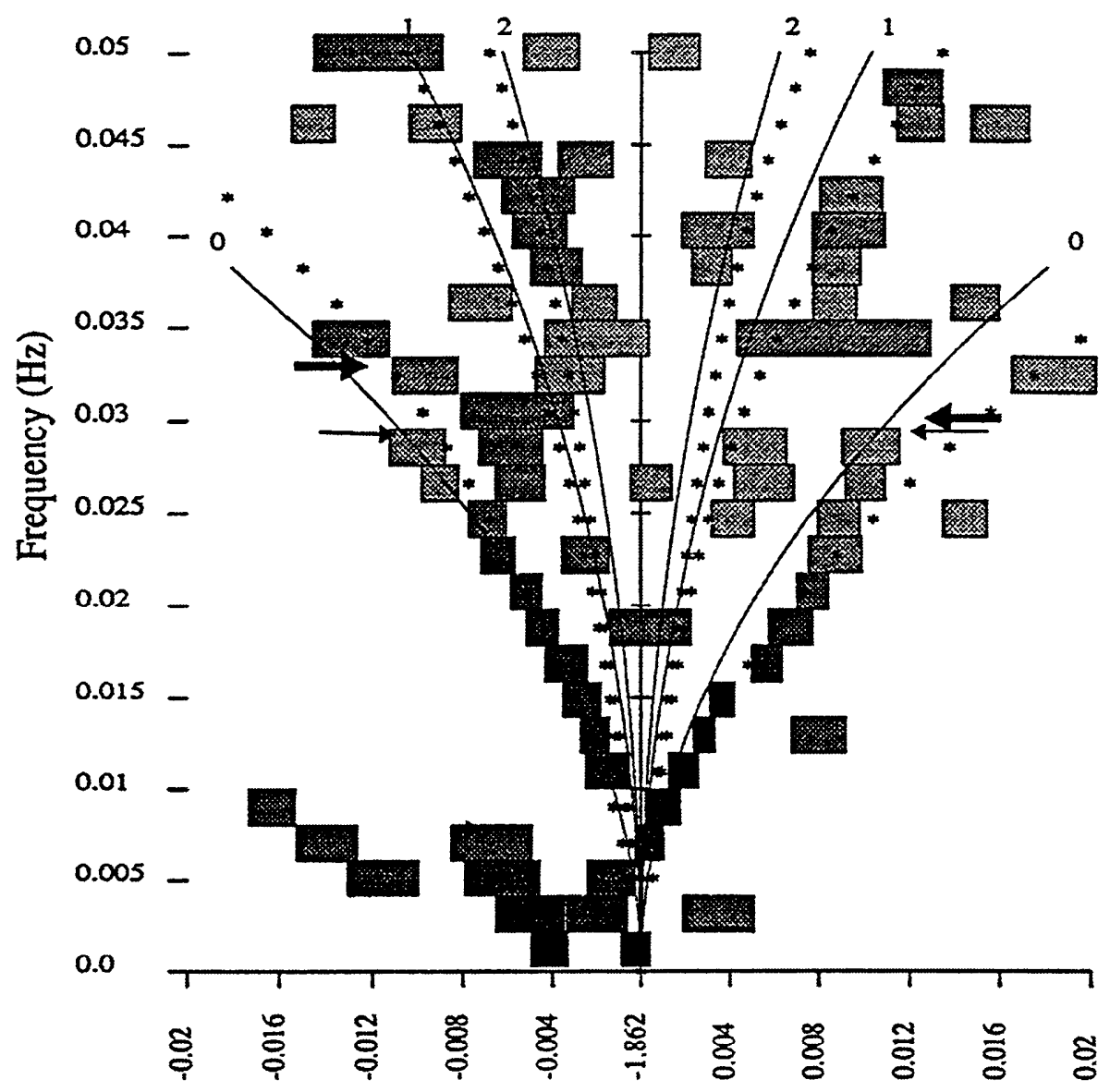

Cyclic Alongshore Wavenumber $\left(\mathrm{m}^{-1}\right)$

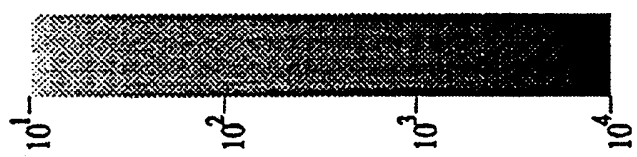

Log Variance Density $(\mathrm{cm} / \mathrm{sec}) * * 2 / \mathrm{Hz}$

Figure 10. Edge waves in the presence of a longshore current exhibit asymmetry in the upstream and downstream $k-f$ modal dispersion curves. Mode 0,1 , and 2 numerical (measured cross-shore current profile, asterisks) and analytical (no current, solid) dispersion solutions are plotted (from Oltman-Shay and Howd 1993) 


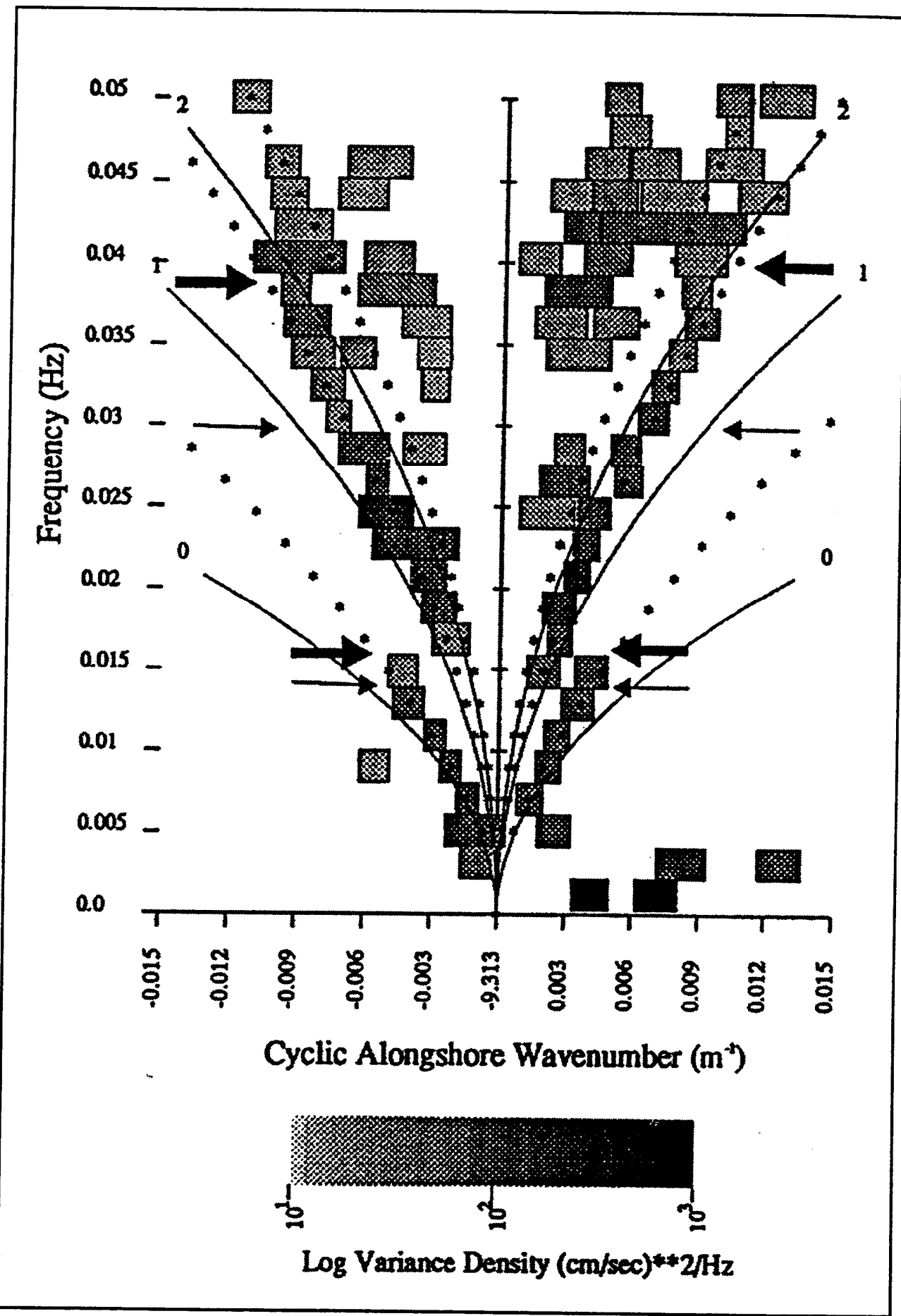

Figure 11. Edge wave $k-f$ spectra solutions showing a steepening of modal dispersion lines from plane beach solution. Mode 0,1 , and 2 numerical (measured depth profile, asterisks) and analytical (planar depth profile, solid) dispersion solutions are plotted (from Oltman-Shay and Howd 1993) 


\begin{tabular}{|c|c|c|c|c|c|c|c|c|}
\hline \multicolumn{9}{|c|}{$\begin{array}{l}\text { Table } 1 \\
\text { Comparison of Numerical and Analytical Solutions of Edge Wave and } \\
\text { Shoreline Elevation Variance from NSTS Torry Pines Beach Site }\end{array}$} \\
\hline \multirow{2}{*}{$\begin{array}{l}\text { Date } \\
\text { November } \\
1978\end{array}$} & \multicolumn{4}{|c|}{ Numerical } & \multicolumn{4}{|c|}{ Analytical } \\
\hline & $n^{2} \cdot k$ & $n_{-k}^{2}$ & $E_{+\kappa}$ & $E_{-\kappa}$ & $\eta^{2} \cdot k$ & $n_{-\kappa}^{2}$ & $E_{* \kappa}$ & $E_{-k}$ \\
\hline \multicolumn{9}{|c|}{ Mode 0, 0.007-0.011 Hz } \\
\hline 04 & 1.2 & 1.2 & 31 & 32 & 2.1 & 2.0 & 39 & 40 \\
\hline 10 & 9.5 & 5.8 & 184 & 92 & 8.4 & 6.5 & 170 & 136 \\
\hline $14 a$ & 1.5 & 1.5 & 40 & 45 & 2.7 & 3.1 & 54 & 73 \\
\hline $14 b$ & 1.6 & 2.0 & 34 & 50 & 2.7 & 3.1 & 54 & 73 \\
\hline 18 & 1.7 & 1.6 & 47 & 41 & 2.8 & 2.7 & 59 & 46 \\
\hline 19 & 1.3 & 1.3 & 28 & 31 & 1.5 & 1.6 & 30 & 34 \\
\hline 20 & 5.1 & 9.5 & 139 & 268 & 6.3 & 14.5 & 167 & 355 \\
\hline \multicolumn{9}{|c|}{ Mode $1,0.017-0.021 \mathrm{~Hz}$} \\
\hline 04 & 3.9 & 2.9 & 105 & 78 & 5.9 & 4.4 & 84 & 59 \\
\hline 10 & 9.8 & 3.5 & 124 & 45 & 10.8 & 3.8 & 125 & 49 \\
\hline $14 a$ & 2.1 & 1.8 & 68 & 60 & 3.9 & 5.8 & 55 & 94 \\
\hline $14 b$ & 2.4 & 2.5 & 48 & 52 & 3.9 & 5.8 & 55 & 94 \\
\hline 18 & 5.2 & 3.0 & 141 & 78 & 6.7 & 3.5 & 94 & 40 \\
\hline 19 & 2.0 & 2.6 & 42 & 54 & 3.0 & 4.5 & 42 & 62 \\
\hline 20 & 2.6 & 4.9 & 54 & 106 & 5.0 & 5.9 & 76 & 80 \\
\hline \multicolumn{9}{|c|}{ Mode $1,0.023-0.027 \mathrm{~Hz}$} \\
\hline 04 & 1.7 & 1.2 & 31 & 21 & 4.7 & 3.6 & 38 & 28 \\
\hline 10 & 0.8 & 1.5 & 7 & 13 & 1.3 & 2.1 & 9 & 15 \\
\hline $14 a$ & 0.8 & 1.1 & 17 & 24 & 3.9 & 5.2 & 32 & 48 \\
\hline $14 b$ & 1.0 & 2.5 & 12 & 31 & 3.9 & 5.2 & 32 & 48 \\
\hline 18 & 2.5 & 1.5 & 44 & 26 & 6.6 & 4.4 & 53 & 30 \\
\hline 19 & 1.2 & 1.1 & 17 & 15 & 2.6 & 2.3 & 19 & 17 \\
\hline 20 & 0.5 & 1.1 & 8 & 14 & 1.4 & 2.6 & 11 & 18 \\
\hline \multicolumn{9}{|c|}{ Units: $\eta^{2}$ are $\mathrm{cm}^{2}, \mathrm{E}$ are $\mathrm{J} / \mathrm{m}$} \\
\hline
\end{tabular}




\section{Infragravity Waves, Nearshore Morphology, and Sediment Transport}

Nearshore bars are a common feature on natural beaches and one of the most dynamic morphologic features, migrating offshore during storms and onshore during low-energy periods. They assume a wide variety of forms, with single or multiple bars, and different shape combinations of linear longshore (twodimensional), oblique, and periodic or nonperiodic crescentic (threedimensional) crests. As mentioned earlier, a number of authors have attributed the formation of linear bars to the location of nodes and antinodes of cross-shore standing waves from reflected incident waves (Carter, Liu, and Mei 1973; Lau and Travis 1973) and from reflected low-frequency waves (Short 1975, Bowen 1980 , Symonds and Bowen 1984). Bar spacings predicted from reflected free infragravity waves are generally more consistent with field observations than spacings predicted from reflected incident wave models.

Other models of bar formation have considered cross-shore flow mechanisms induced by the incident wave field, based primarily on sediment suspension from breaker-induced turbulence and momentum decay-induced undertow (mean offshore directed current). Dally (1987) performed a study in a wave flume specifically designed to test bar formation from surf beat, but he determined that bar generation was primarily produced by breakpoint/undertow mechanisms. A similar laboratory study by Roelvink and Stive (1989) considered an additional flow mechanism, a wave-induced asymmetric oscillatory flow. They determined all flow mechanisms (incident wave turbulence, wave asymmetry, undertow, and wave-group-induced long waves) contributed to the observed total flow moments, to the same order of magnitude, with undertow locally dominant in areas of strong dissipation. These observations support the field observations of linear bar formation during storm events. However, as noted by Roelvink and Stive (1989), an improved understanding of bar formation will need to address the role of infragravity waves, specifically the interactions with incident waves and the longshore variations in water motions and morphology. 
Lippmann and Holman (1990) presented a classification scheme for defining bar types that includes morphologies for highly reflective beaches to fully dissipative beaches (see Figure 12). Bar types are classified into eight possible states such that scaling and alongshore variability define the morphology as either resulting from infragravity or incident wave processes. Based on their classification scheme, a 2-year data set from the FRF revealed that longshorevariable morphology was most frequently observed (68 percent of the cases periodic, 17 percent nonperiodic), and that the more transient linear bars were observed infrequently ( 15 percent of the cases). Infragravity scaled morphology accounted for 91 percent of the observed bar types.

\section{8-BAR TYPE CLASSIFICATION SCHEME}

BAR TYPE H: DISSIPATIVE

(unbarred; infragravity scaled surf zone)

BAR TYPE G: INFRAGRAVITY SCALED 2-D BAR

(no longshore variability; infragravity scaling)

BAR TYPE F: NON-RHYTHMIC, 3-D BAR

(longshore variable; non-rhythmic; continuous trough; infragravity scaling)

BAR TYPE E: OFFSHORE RHYTHMIC BAR

(longshore rhythmicity; continuous trough; infragravity scaling)

BAR TYPE D: ATTACHED RHYTHMIC BAR

(longshore rhythmicity; discontinuous trough; infragravity scaling)

BAR TYPE C: NON-RHYTHMIC, ATTACHED BAR

(no coherent longshore rhythmicity; discontinuous trough;

infragravity scaling)

BAR TYPE B: INCIDENT SCALED BAR

(little or no longshore variability; may be attached; incident scaling)

BAR TYPE A: REFLECTIVE

(unbarred; incident scaled surf zone)

Figure 12. Classification scheme defining bar morphology (after Lippmann and Holman (1990)) 
Critical to many theories of bar formation and migration attributed to infragravity waves is that these waves are standing in the cross-shore (Short 1975, Wright et al. 1986, Sallenger and Holman 1987, Aagaard 1990, among others). Symonds and Bowen (1984) modeled the resonant amplification of lowfrequency waves on a linear bar trough beach. A half wave resonance was predicted with a surface elevation antinode (horizontal current node) at the bar crest. Sallenger and Holman (1987) measured cross-shore flows across the surf zone during a storm while the nearshore bar became better developed and migrated offshore. Early in the storm they observed a dominant low-frequency node in velocity that was clearly related to bar position, consistent with the Symonds and Bowen (1984) model. This mechanism is expected to be more significant when infragravity wave forcing occurs at discrete frequencies near the resonant mode, with a velocity node at the bar crest.

Other studies (e.g., Wright et al. 1986, Aagaard 1988, 1990) have also observed preferential selection of infragravity modes that matched resonant conditions on a beach with bar-trough topography. Wright et al. (1986) concluded that frequencies of standing wave modes prevailed which had amplitude nodes in the trough and antinodes on bar crest. Incident waves were believed to have dominated in the surf zone and caused most of the sediment suspension. However, infragravity waves, although secondary in energy, would be fundamental at influencing surf zone morphology by altering the net drift currents, thus controlling the net drift patterns of sediment. In contrast, many studies have shown a near white infragravity spectrum during storms (e.g., Holman 1981, Oltman-Shay and Guza 1987) which opposes the idea of selective wave modes interacting to reshape the nearshore morphology. When no dominant frequencies or modes occur, then the surf zone will have nodes and antinodes throughout, and bar formation or sediment movement by infragravity motions would not likely occur.

In a field study on an extremely dissipative beach, Beach and Sternberg (1988) observed suspended sediment concentrations associated with lowfrequency motions. These infragravity induced suspensions had mean loads approximately three to four times greater than suspensions from incident waves. Suspension events occurring at infragravity frequencies lasted 30-45 sec, and only a few seconds when incident waves were dominant. Hanes (1991) analysis of a limited data set $(6 \mathrm{hr})$ observed sediment suspension at both incident and wave group frequencies, and that concentrations were enhanced at the group frequencies. Since most sediment transport models omit infragravity motions, and these motions can be comparable or dominate over incident wave energy, that could account for some of the difficulties in modeling sediment transport.

Infragravity waves have also been associated with abrupt berm erosion (Katoh and Yanagishima 1993). Their observations indicated that infragravity waves were the dominant force in berm erosion during storms, and that low 
energy wind waves were responsible for berm building. This is not surprising since, as previously mentioned, these waves are largest during storms and have their greatest amplitudes at the shoreline. The infragravity component of runup was found to accelerate berm erosion two ways. When runup occurs at a low frequency it remains longer on the beach and increases groundwater saturation, causing a rise in the water table. This results in a seepage out of the beach face below the berm that enhances sediment suspension and berm erosion. Erosion will be more severe if the runup goes beyond the berm crest where the lower beach slope slows the rundown and increases saturation. A second effect is a local deepening of water at the shoreline with the infragravity wave crest, allowing incident waves to progress further shoreward, dissipating their energy higher up the beach face.

Present quantitative modeling capabilities are not able to predict beach morphology evolution with confidence. Different models are capable of explaining particular aspects of morphology changes and sediment transport under different conditions. A major problem is that our limited understanding of nearshore sediment transport dynamics often requires models to include simplifying assumptions of littoral processes, whereas actual hydrodynamics are often complex, three-dimensional, and unsteady. Storm processes appear as highly dynamic transient processes which produce large-scale morphology changes at times when it is most difficult to measure. Furthermore, the complex nature of the incident and infragravity wave fields and their interactions with each other, as well as with morphology and currents, are extremely difficult to measure in the field. Additional field measurements are required for better characterization of the hydrodynamics and for improvement of quantitative predictions of nearshore morphology changes. 


\section{Field Observations}

Huntley, Guza, and Thornton (1981) was the first to definitely show the existence of low-mode $(n<2)$ edge waves using a longshore-aligned array of current meters. Subsequent studies have produced abundant field observations of both free and forced infragravity motions (e.g., Oltman-Shay and Guza 1987, Elgar et al. 1992; Herbers, Elgar, and Guza 1995; Herbers et al. 1995). Few studies have been done in laboratory wave tanks owing to the complexity of infragravity motions and the problems associated with seiche actions in the tanks. Laboratory studies are typically designed to examine a particular aspect of infragravity wave generation, such as bound and leaky waves from normally incident wave groups in two-dimensional wave tanks (e.g., Kostense 1984, Dally 1987) or edge waves from obliquely incident wave groups in three-dimensional wave basins (Bowen and Guza 1978). However, the bulk of measurements come from field observations with bound, leaky, edge, and shear waves possibly occurring simultaneously, and where interactions with themselves and the incident waves further complicate data interpretations.

Over the past two decades the most definitive observations of infragravity waves have been made with longshore arrays of current meters. Much of these data were obtained from the two southern California NSTS field sites, Torrey Pines and Leadbetter Beaches, and from the SUPERDUCK, and DELILAH experiments at the FRF (Figure 13). Instrument arrays in these experiments were designed specifically for measuring infragravity waves. The shear wave discovery was made with the SUPERDUCK data. The arrays for the subsequent DELILAH experiment were designed with one cross-shore and two imbedded longshore arrays to measure both infragravity and shear waves. Array spacing was planned as a compromise for measuring both of these wave types, shear waves having longshore wave numbers larger than free infragravity waves (same frequency), thereby requiring shorter longshore gauge spacing in order to be adequately resolved.

An alternate method for measuring infragravity waves uses video image processing to obtain swash spectra. The next section presents the methodology for video analysis of runup, and a description of the photogrammetric methods is presented in Appendix B. Strengths and weaknesses of the system are discussed, along with suggestions for future improvements, some of which are being 


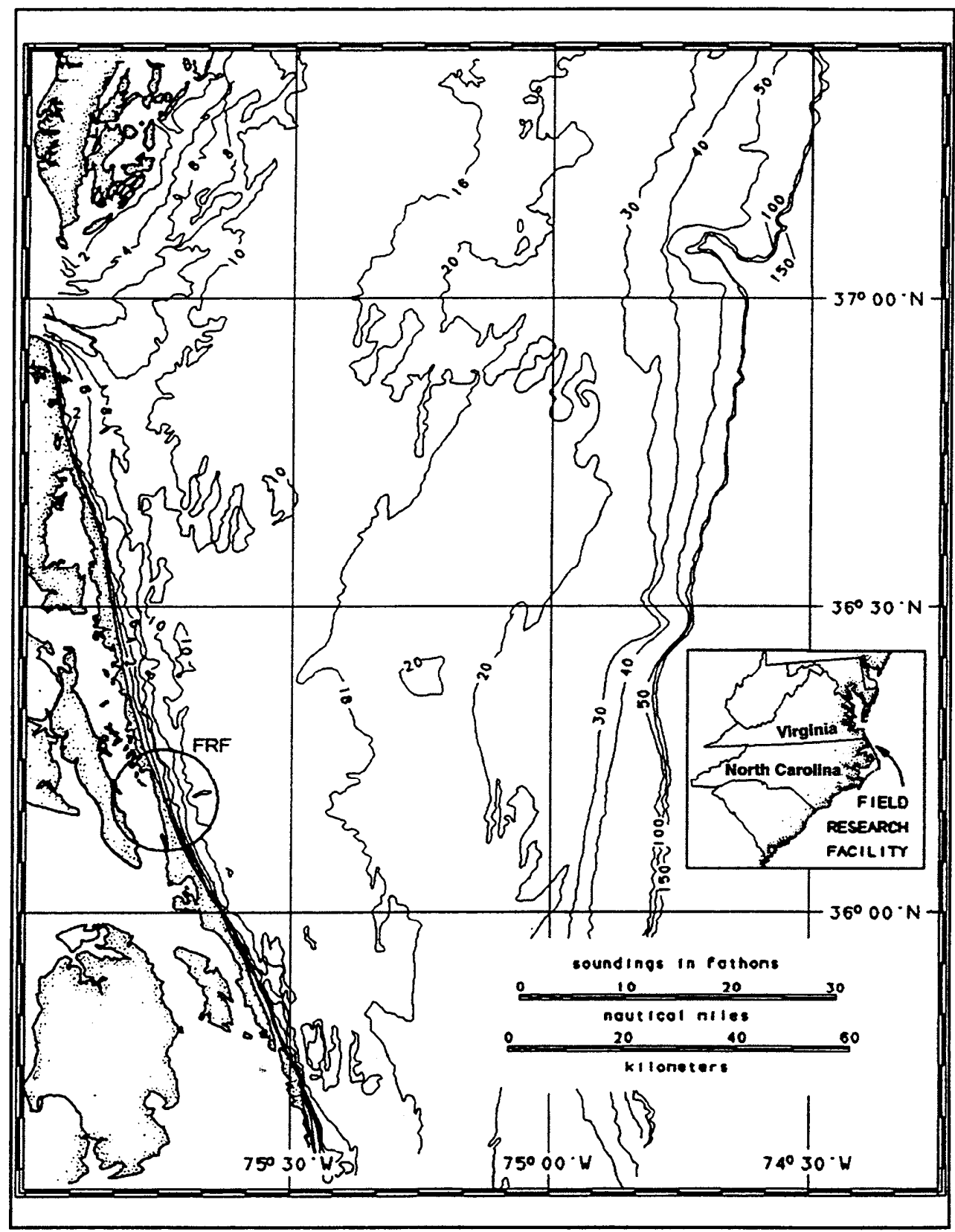

Figure 13. Location of CHL's Field Research Facility (FRF)

developed at the time of this writing. The following section presents field data of infragravity wave observations at the FRF, primarily from the DELILAH experiment, and a summary of statistics characterizing the infragravity wave climate at this site. 


\section{Video Analysis of Runup}

Photographic techniques have been applied to the measurement of nearshore waves and runup by a number of authors (Katoh 1981, Holman and Guza 1984, Holman and Bowen 1984, and others). These techniques have the advantage of being low-cost and logistically simple, and provide measurements over a large longshore distance. The initial method of using photographic films was a timeconsuming process requiring manual digitization, which in turn had questionable precision since it required subjective judgment of the operator. This is especially true in the determination of rundown position, when percolation into the beach and residual foam makes it difficult to determine an obvious swash edge.

An improved method for runup measurements was developed using a video image processor to automate the digitization of runup, which reduced the processing time (U.S. Army Engineer Waterways Experiment Station (1990)). This method measures the cross-shore position of the swash at several longshore locations simultaneously. For each camera view a solution for converting twodimensional image coordinates to three-dimensional ground position is computed using known geometrical transformations (Lippmann and Holman (1989), summarized in the following section). Thus, swash positions digitized on known beach profiles are transformed from image coordinates to a vertical swash elevation. Since this technique relies on a change in image contrast between beach and swash, it has difficulty in detecting swash positions when anomalous features enter the viewing field (e.g., birds, persistent sea foam, or people).

An analysis modification was made based on the "timestack" method described by Aagaard and Holm (1989). The image processor digitizes picture element (pixel) intensities along screen coordinates corresponding to a cross-shore transect of the beach profile. Each sample of these intensities is then "stacked" in a matrix and stored on disk. One dimension of the stack is cross-shore distance and the other is time. Digitization can be done in real time (directly from a video camera), or more typically post-processed from video tape. Subsequently, the data can be retrieved, displayed on a monitor, and analyzed for a runup time series. The timestack provides a two-dimensional image for which swash edge detection is substantially improved over the multiple profile method. In addition, with the timestack method, the image can be edited manually for checking and correcting the edge detection before transforming to runup elevations. Although the timestack method is presently limited to only a single profile, the results are believed more reliable than the multiprofile method. This system uses an Imaging Technologies video image processor (model ITI-151) interfaced to a Sun-4 host computer.

In a typical timestack (Figure 14) the swash is clearly visible as a sharp change in intensity, from the darker beach (left) to the whiter foam of the swash (right). Runup position is found using computer edge detection algorithms combined with 


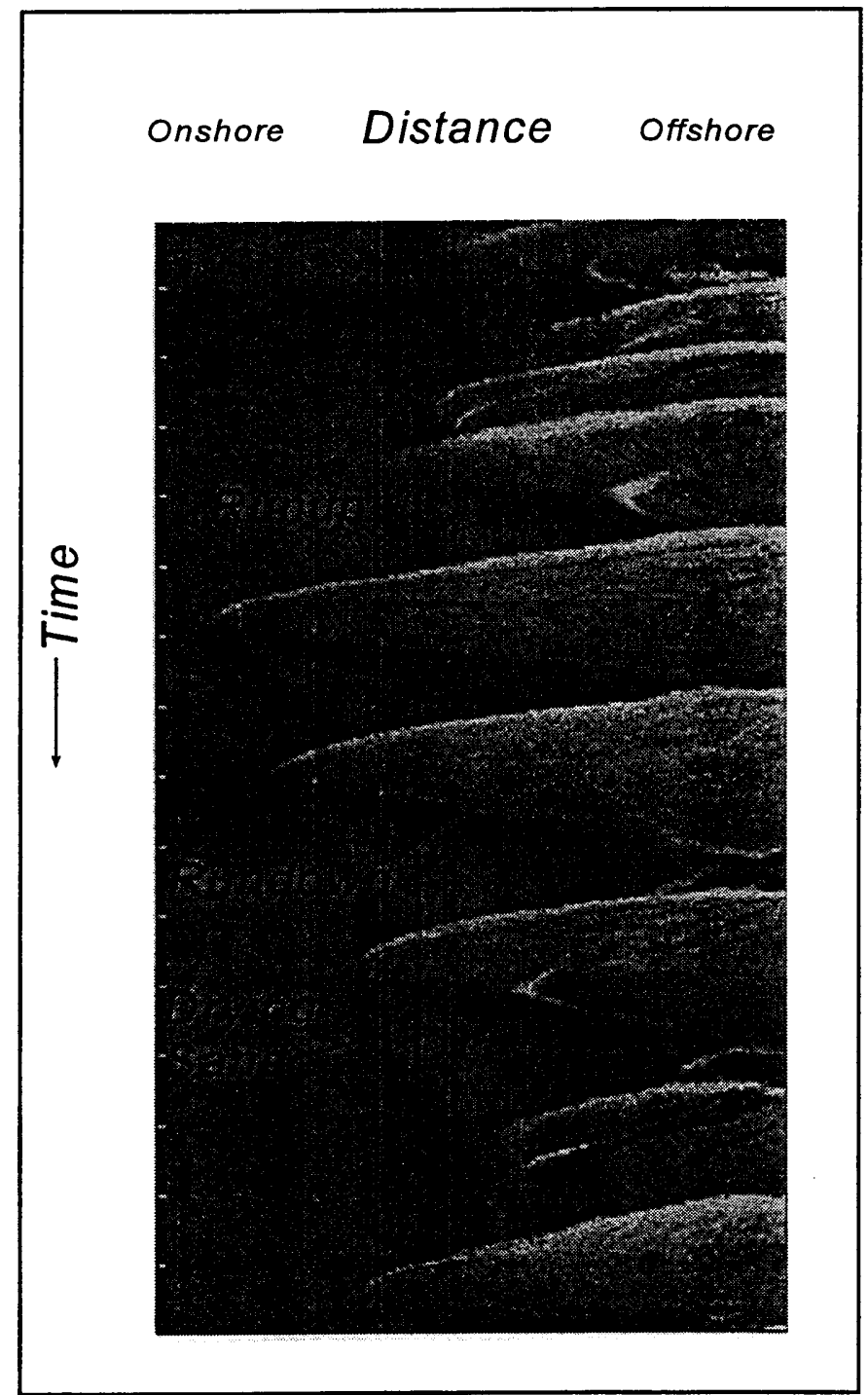

Figure 14. Video timestack of swash

manual refinements. Horizontal swash positions are converted to vertical runup elevation using profile measurements, camera geometry, and photogrammetric transformations. Fundamental to the accuracy of this system is an accurate measure of the beach profile and a precise determination of the camera position and view angles. Errors in profile slope or camera geometry directly affect estimates of runup variance. However, small errors in beach profile measurements have little effect on the shape of the runup spectra (i.e., the proportion of infragravity to incident energy is relatively unaffected). Errors in runup estimates associated with camera geometry can be significant if poor photogrammetry solutions are obtained. Geometry errors are minimized with careful photogrammetric techniques (Appendix B), and generally are not as important as profile errors. 


\section{Observations of Infragravity Waves During SAMSON and DELILAH}

The SAMSON and DELILAH experiments were held at the FRF in fall 1990. The objectives of DELILAH were to measure wave and wind forced threedimensional nearshore dynamics while monitoring the bathymetric response. Particular emphasis was placed on measuring infragravity waves, shear waves, mean circulation, runup, and setup. DELILAH was conceived as an experiment of opportunity for nearshore measurements, taking advantage of the simultaneous directional wave measurements from the FRF 8-m array and from an array at 13-m depth installed for the SAMSON experiment (Figure 15). The SAMSON experiment began 1 Sep 1990 and parts of the experiment $(8 \mathrm{~m}$ and $13 \mathrm{~m}$ array data) continued to be active through April 1991. The DELILAH experiment was a short, 3 week intensive effort between 1 and 21 Oct 1990.

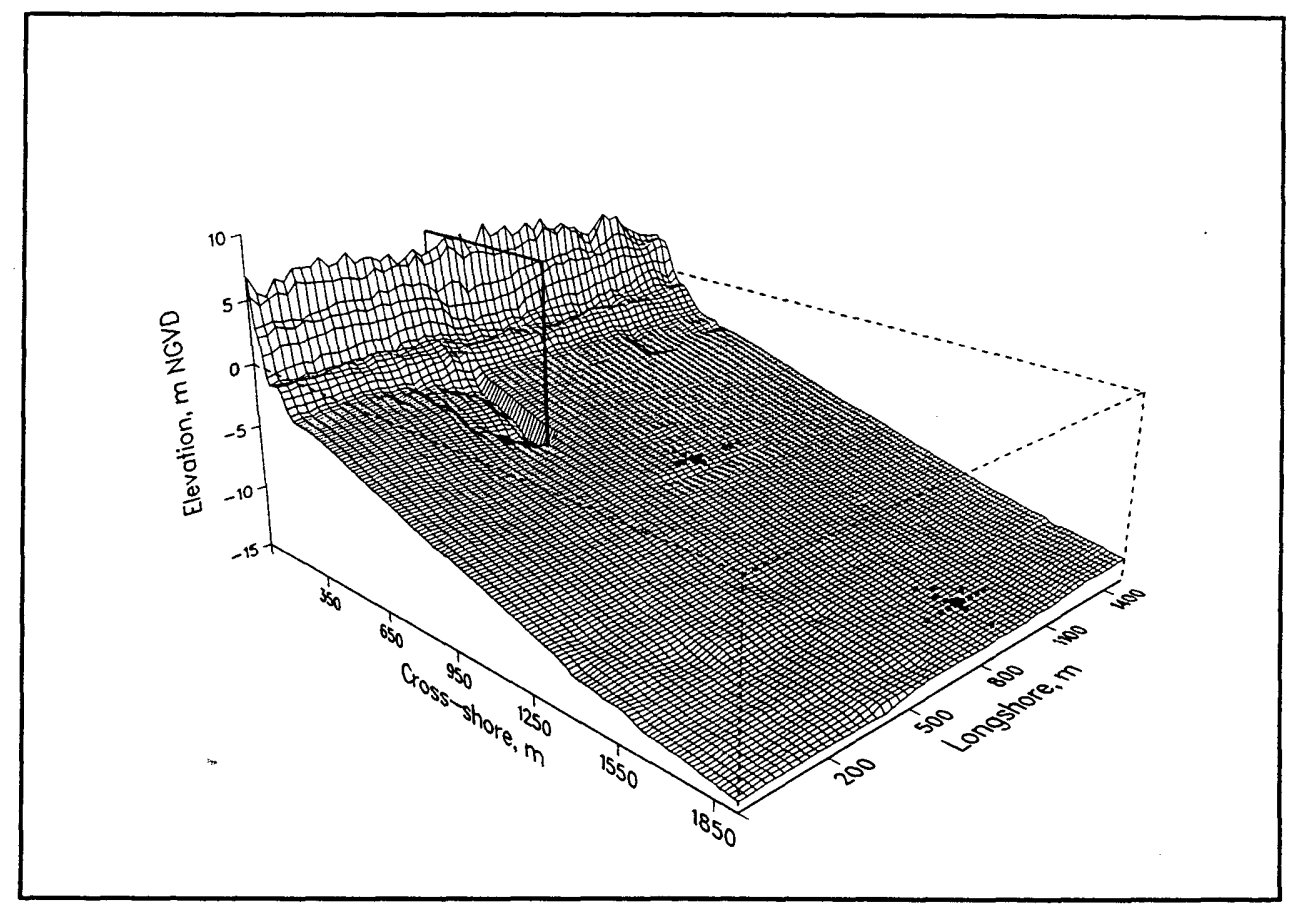

Figure 15. Bathymetric plot with locations of the FRF, SAMSON, and DELILAH arrays in October 1990

The DELILAH surf-zone array was designed to measure infragravity and shear waves using a primary cross-shore array with two imbedded longshore arrays (Figure 16). The cross-shore array consisted of nine instrument packages, each having a Marsh McBirney electromagnetic current meter (EMCM) and two pressure sensors (one ParosScientific and one Setra Sensors). Nine other 
EMCM's were aligned to form a six-element longshore array in the trough and a five-element longshore array seaward of the bar. An additional current meter placed on the bar between the longshore arrays formed a secondary cross-shore array with three gauges. Data were collected continuously at an 8- $\mathrm{Hz}$ sampling rate, pausing for about $10 \mathrm{~min}$ approximately every $8 \mathrm{hr}$ to change data tapes. A detailed description of the DELILAH experiment was provided by Birkemeier et al. (1997).

\section{Infragravity shoreline variance}

As part of the effort of the Infragravity Waves in the Nearshore Zone Work Unit 32430, infragravity variances measured at 8-m depth and at the shoreline were compared with incident swell variance. This analysis examined data from the SAMSON and DELILAH experiments, 4 through 20 Oct 1990, which offered a wide variety of conditions (Figure 17). Incident waves were low to moderate, ranging from $0.5 \mathrm{~m}$ to over $2 \mathrm{~m} \mathrm{H}_{\mathrm{mo}}$. Waves were typically out of the southeast, generating a northward-directed longshore current (Table 2). Three events of waves from the northeast occurred on 5, 16, and 19 October. The second two were of sufficient duration to reverse the direction of the longshore current. Also, on 12 October, swell waves arrived from the passage of Hurricane Lily far offshore, that were moderately high in energy and narrow banded.

The infragravity variance in the $0.02-$ to $0.04-\mathrm{Hz}$ band was found to be significantly correlated with incident swell variance in the 0.05 - to $0.15-\mathrm{Hz}$ band. The frequency limits for the infragravity waves were set to isolate edge wave variance from other infragravity variance (bound or leaky waves) and from swell. The upper limit of $0.04 \mathrm{~Hz}$ avoids including lowfrequency swell variance. The lower limit of $0.02 \mathrm{~Hz}$ is the point at which edge and leaky waves become unresolvable below this

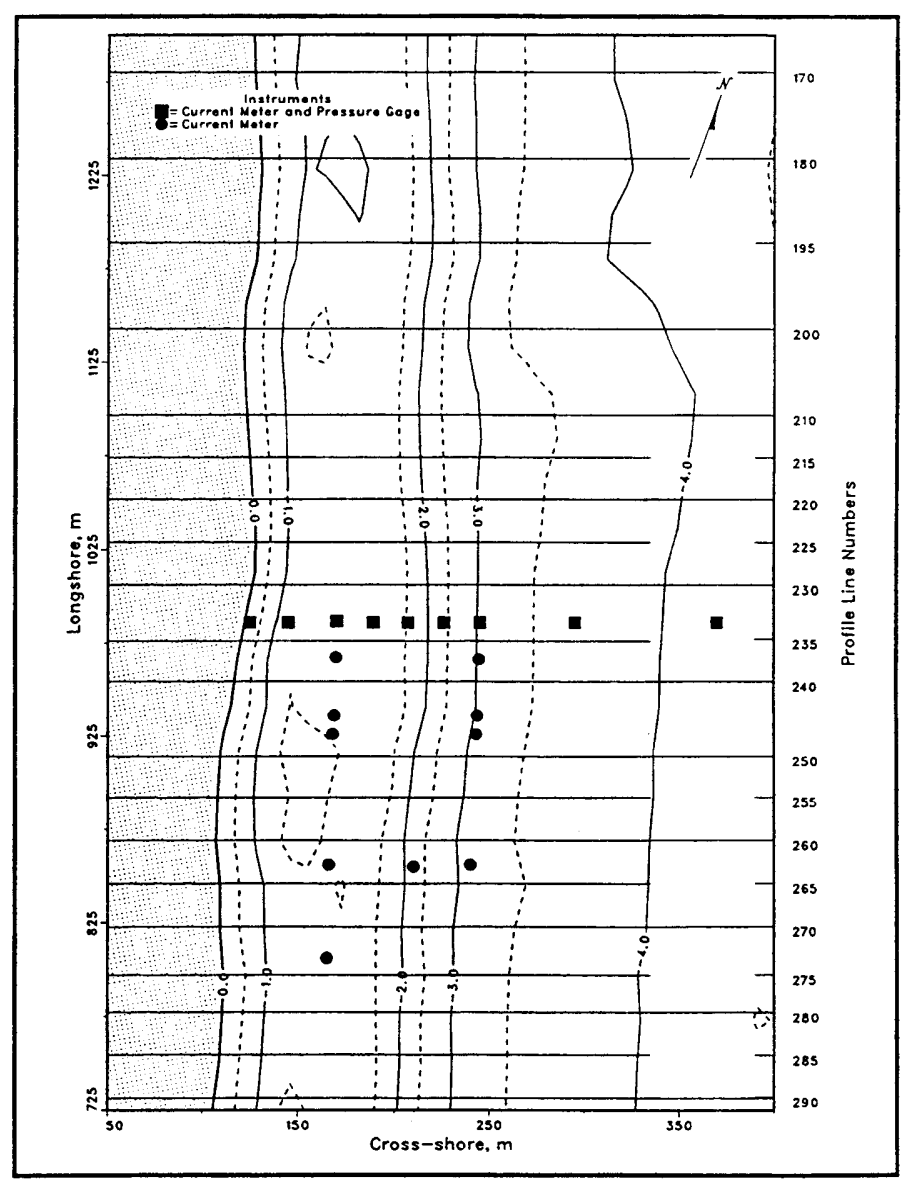

Figure 16. DELILAH surf-zone array 
frequency and for this 8-m depth. For incident wave variance, only swell waves were considered in this analysis, and not sea waves, based on results (e.g., Elgar et al. 1992; and the work herein) from previous work that found significantly higher correlations between swell and infragravity variance than with sea and infragravity variance. Those results are included in the following section. As shown in Figure 18, infragravity variances measured in the runup and at 8-m depth are strongly correlated with incident swell variance. Also, the magnitude of the runup variance at the shoreline was approximately 30 times that measured at 8-m depth.

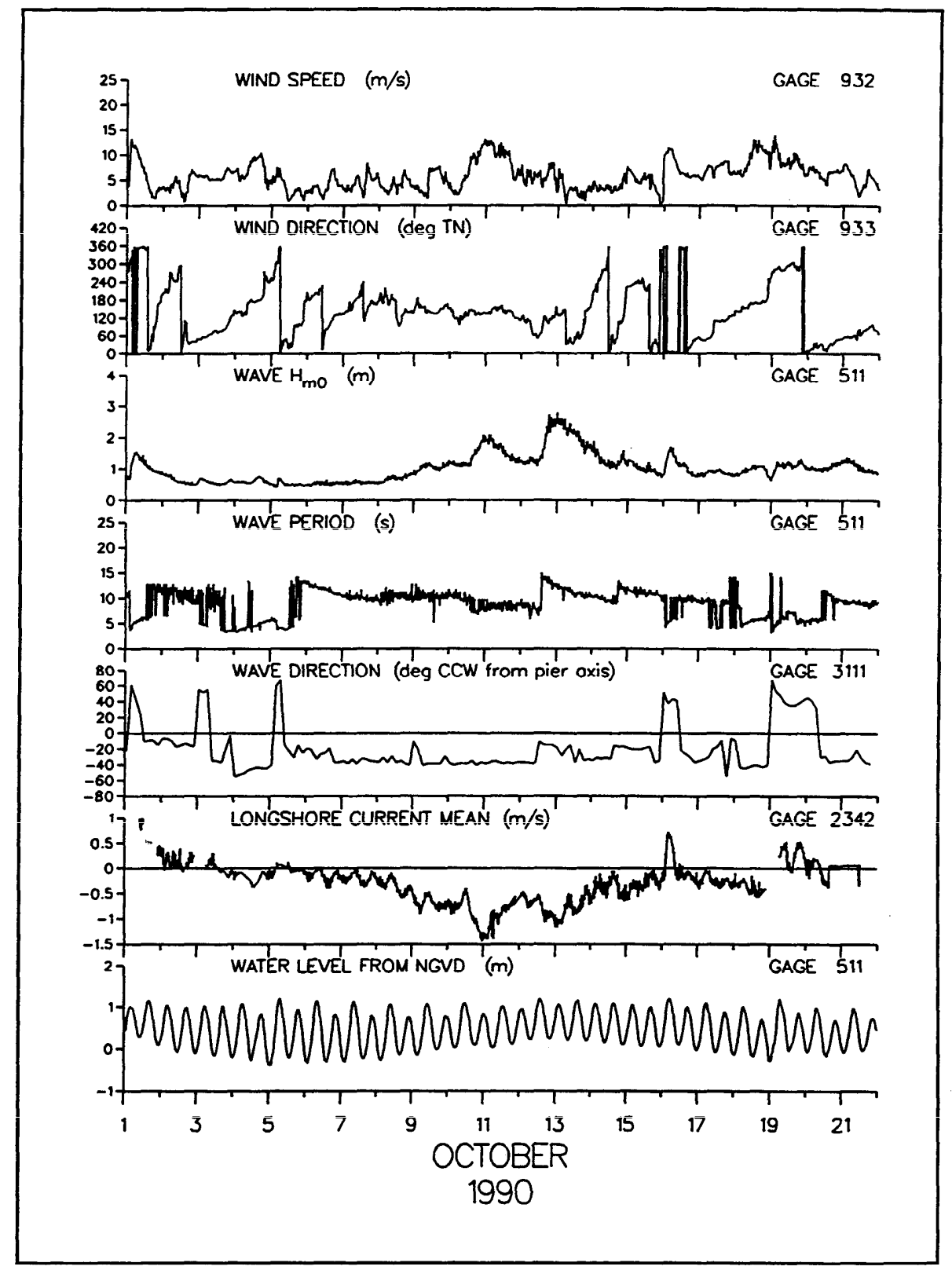

Figure 17. Conditions during the DELILAH experiment 


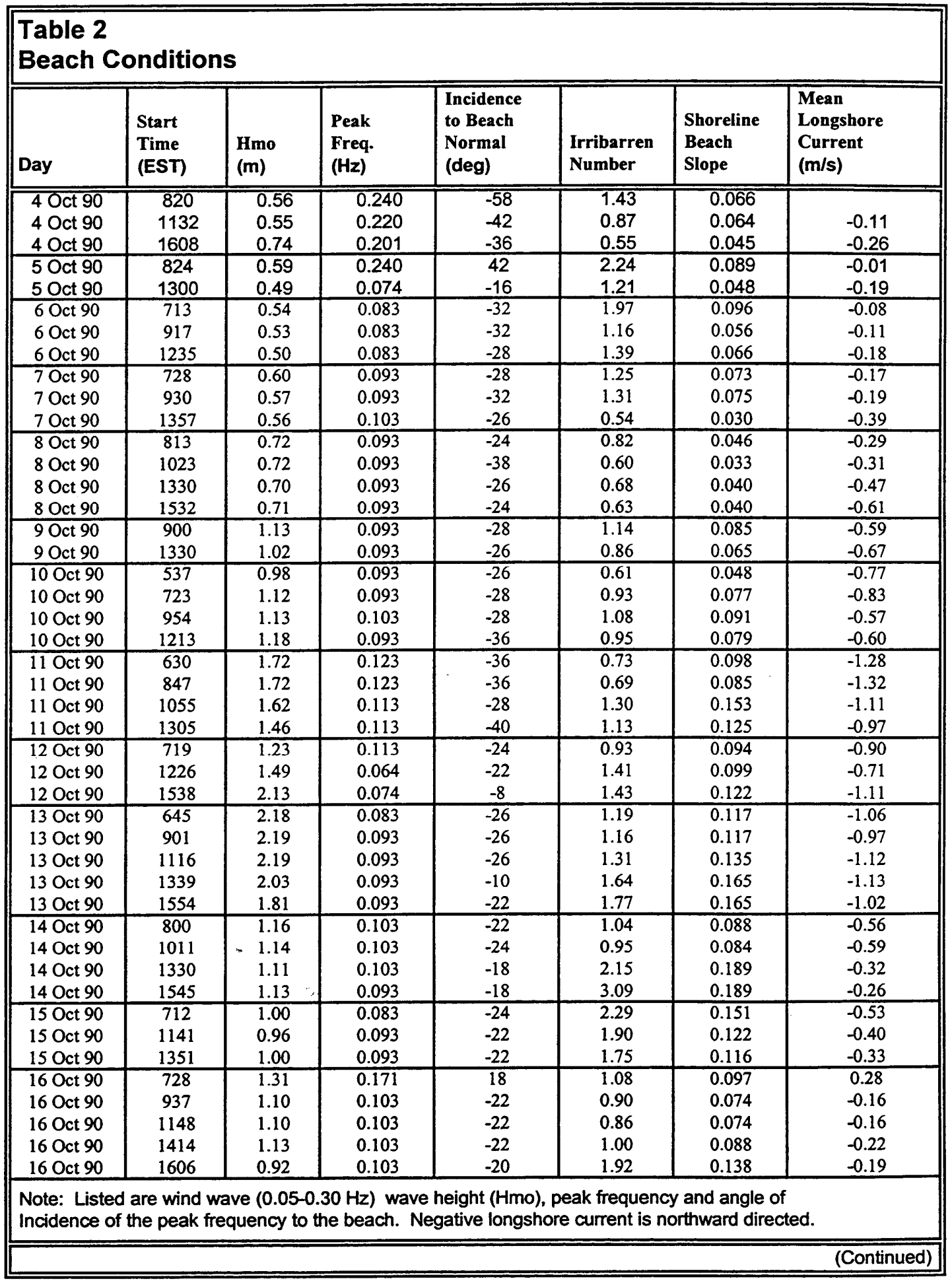




\begin{tabular}{|c|c|c|c|c|c|c|c|}
\hline \multicolumn{8}{|c|}{ Table 2 (Concluded) } \\
\hline Day & $\begin{array}{l}\text { Start } \\
\text { Time } \\
\text { (EST) }\end{array}$ & $\begin{array}{l}\text { Hmo } \\
(\mathrm{m})\end{array}$ & $\begin{array}{l}\text { Peak } \\
\text { Freq. } \\
(\mathrm{Hz})\end{array}$ & $\begin{array}{l}\text { Incidence } \\
\text { to Beach } \\
\text { Normal } \\
\text { (deg) }\end{array}$ & $\begin{array}{l}\text { Irribarren } \\
\text { Number }\end{array}$ & $\begin{array}{l}\text { Shoreline } \\
\text { Beach } \\
\text { Slope }\end{array}$ & $\begin{array}{l}\text { Mean } \\
\text { Longshore } \\
\text { Current } \\
(\mathrm{m} / \mathrm{s})\end{array}$ \\
\hline 17 Oct 90 & $\overline{710}$ & 0.92 & 0.113 & -22 & $\overline{\overline{1.41}}$ & $\overline{0.113}$ & -0.20 \\
\hline 17 Oct 90 & 919 & 0.88 & 0.103 & -18 & 1.23 & 0.099 & -0.35 \\
\hline 17 Oct 90 & 1129 & 0.88 & 0.103 & -18 & 0.87 & 0.074 & -0.35 \\
\hline 17 Oct 90 & 1338 & 0.90 & 0.103 & -20 & 1.12 & 0.097 & -0.44 \\
\hline 17 Oct 90 & 1550 & 0.87 & 0.103 & -22 & 1.30 & 0.101 & -0.35 \\
\hline 18 Oct 90 & 700 & 0.97 & 0.191 & -32 & 1.83 & 0.094 & -0.33 \\
\hline 18 Oct 90 & 1116 & 0.99 & 0.181 & -48 & 1.96 & 0.102 & -0.63 \\
\hline 18 Oct 90 & 1311 & 1.04 & 0.171 & -18 & 1.69 & 0.097 & -0.65 \\
\hline 19 Oct 90 & 710 & 1.15 & 0.152 & 34 & 1.76 & 0.098 & 0.29 \\
\hline 19 Oct 90 & 919 & 1.19 & 0.132 & 6 & 0.75 & 0.085 & 0.30 \\
\hline 19 Oct 90 & 1213 & 1.10 & 0.142 & 10 & 0.71 & 0.085 & 0.10 \\
\hline 190 ct 90 & 1423 & 1.10 & 0.142 & 10 & 0.76 & 0.090 & 0.17 \\
\hline
\end{tabular}

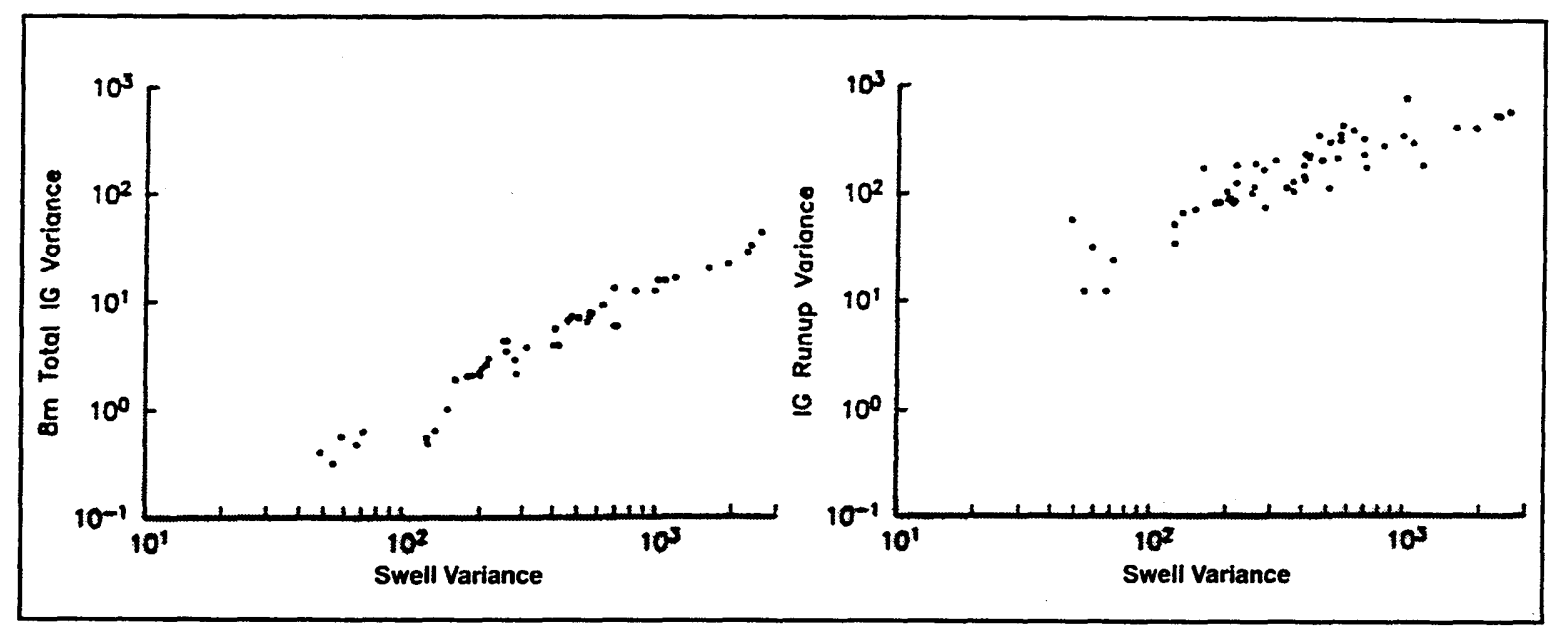

Figure 18. Correlation between incident swell variance and infragravity variance at $8-m$ depth (left) and in the runup (right). Variance units are in $\mathrm{cm}^{2}$

Analysis of $k-f$ spectra in infragravity energy measured at 8-m water depth during this time fount the infragravity band $(0.02-0.04 \mathrm{~Hz})$ typically dominated by trapped edge waves, comprising approximately 80 percent of the total infragravity energy, with the remaining energy consisting primarily of leaky waves. Bound waves generally contributed about 4 percent of the infragravity variance, but as much as 16 percent has been observed. With a high content of trapped edge waves, which have a maximum amplitude at the shoreline and exponentially decay offshore, an amplification of infragravity variance is expected between 8-m depth and in the runup. The average amplification was 35 and ranged from about 10 to over 100 (Table 3). 
A tenfold increase in infragravity variance is predicted between the 8-m depth and the shoreline for edge wave modes 0 through 8 in the $0.02-$ to $0.04-\mathrm{Hz}$ band. Numerical calculations for this prediction were assuming equal shoreline elevation amplitude for modes 0 through 8 (i.e., a "white" spectrum assumption). The average measured amplification of 35 suggests the assumption of equal shoreline elevation for the trapped modes may not be reasonable. The underprediction of the model indicates that low-mode (e.g., 0-3) edge waves, trapped shoreward of the 8-m array, may have had larger shoreline amplitudes than the higher modes (4-8). Thus, it is conceivable that preferential trapping of the lower modes may have occurred, such that modes matching resonant conditions of the beach and bar-trough topography were selectively amplified.

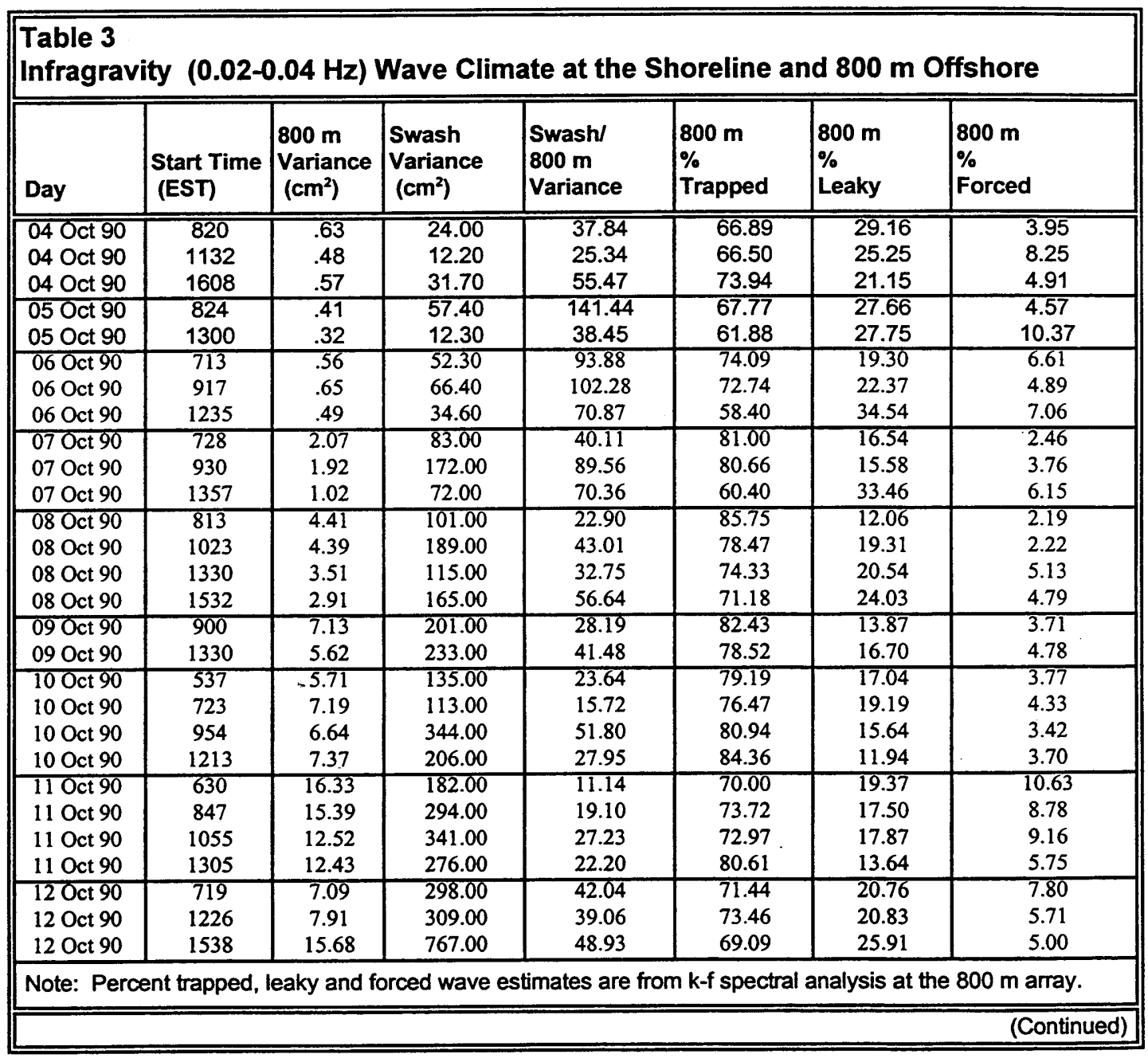




\begin{tabular}{|c|c|c|c|c|c|c|c|}
\hline \multicolumn{8}{|c|}{ Table 3 (Concluded) } \\
\hline Day & $\begin{array}{l}\text { Start Time } \\
\text { (EST) }\end{array}$ & $\begin{array}{l}800 \mathrm{~m} \\
\text { Variance } \\
\left(\mathrm{cm}^{2}\right)\end{array}$ & $\begin{array}{l}\text { Swash } \\
\text { Variance } \\
\left(\mathrm{cm}^{2}\right)\end{array}$ & $\begin{array}{l}\text { Swash / } \\
800 \mathrm{~m} \\
\text { Variance }\end{array}$ & $\begin{array}{l}800 \mathrm{~m} \\
\% \\
\text { Trapped }\end{array}$ & $\begin{array}{l}800 \mathrm{~m} \\
\% \\
\text { Leaky }\end{array}$ & $\begin{array}{l}800 \mathrm{~m} \\
\% \\
\text { Forced }\end{array}$ \\
\hline 13 Oct 90 & $\overline{6645}$ & $\overline{43.14}$ & 583.00 & 13.51 & 61.36 & 29.89 & 8.75 \\
\hline 13 Oct 90 & 901 & 32.53 & 526.00 & 16.17 & 58.03 & 27.97 & 14.00 \\
\hline 13 Oct 90 & 1116 & 28.04 & 539.00 & 19.22 & 45.16 & 38.35 & 16.49 \\
\hline 13 Oct 90 & 1339 & 21.85 & 400.00 & 18.31 & 67.32 & 22.99 & 9.69 \\
\hline 13 Oct 90 & 1554 & 20.05 & 402.00 & 20.05 & 70.76 & 23.64 & 5.60 \\
\hline 14 Oct 90 & 800 & 5.96 & 174.00 & 29.20 & 69.54 & 23.28 & 7.18 \\
\hline 14 Oct 90 & 1011 & 5.94 & 231.00 & 38.91 & 68.82 & 23.01 & 8.17 \\
\hline 14 Oct 90 & 1330 & 9.20 & 383.00 & 41.61 & 76.97 & 17.98 & 5.05 \\
\hline 14 Oct 90 & 1545 & 13.28 & 319.00 & 24.02 & 71.96 & 22.87 & 5.17 \\
\hline 15 Oct 90 & 712 & 7.79 & 421.00 & 54.05 & 75.84 & 18.37 & 5.79 \\
\hline 15 Oct 90 & 1141 & 6.53 & 212.00 & 32.48 & 71.88 & 20.58 & 7.53 \\
\hline 15 Oct 90 & 1351 & 7.24 & 346.00 & 47.80 & 74.23 & 20.08 & 5.69 \\
\hline 16 Oct 90 & 728 & 4.05 & 216.00 & 53.33 & 79.88 & 15.35 & 4.77 \\
\hline 16 Oct 90 & 937 & 4.00 & 183.00 & 45.73 & 75.02 & 19.37 & 5.61 \\
\hline 16 Oct 90 & 1414 & 3.99 & 225.00 & 56.37 & 69.39 & 25.28 & 5.33 \\
\hline 16 Oct 90 & 1606 & 3.84 & 203.00 & 52.84 & 72.63 & 24.16 & 3.21 \\
\hline 17 Oct 90 & 710 & 2.98 & 182.00 & 60.98 & 76.85 & 18.78 & 4.36 \\
\hline 17 Oct 90 & 919 & 2.64 & 86.30 & 32.74 & 72.70 & 21.66 & 5.64 \\
\hline 17 Oct 90 & 1338 & 2.56 & 82.50 & 32.20 & 74.50 & 19.73 & 5.77 \\
\hline 17 Oct 90 & 1550 & 2.42 & 92.20 & 38.15 & 69.16 & 26.07 & 4.78 \\
\hline 18 Oct 90 & 700 & 2.24 & 104.00 & 46.51 & 69.63 & 25.59 & 4.78 \\
\hline 18 Oct 90 & 1116 & 2.11 & 83.80 & 39.77 & 70.68 & 22.41 & 6.91 \\
\hline 18 Oct 90 & 1311 & 2.12 & 90.10 & 42.52 & 62.11 & 29.06 & 8.83 \\
\hline 19 Oct 90 & 710 & 2.18 & 75.50 & 34.68 & 70.80 & 23.15 & 6.05 \\
\hline
\end{tabular}

Another explanation for the observed large shoreline variances is that nonlinear amplification of the swash could have occurred. A recent study by Holland et. al. (1995) suggested that nonlinear amplification of swash variance happens when the wave field is primarily standing. Using measurements of runup from video and above-bed resistance wires and wave measurements from pressure sensors located at various cross-shore positions, swash variance amplification was found to be as much as four times the variance of the standing wave profile. If this type of amplification occurred at the FRF site, it could account for the unexpected large runup variance. Thus, the assumption of equal shoreline amplitudes for each edge wave mode may be valid. Additional work is required to resolve the relative contributions from nonlinear amplinication effects and selective trapping of modes with a bar/trough morphology. 


\section{Correlation between infragravity waves, sea, and swell in 8-m depth}

This section presents results from an analysis (Oltman-Shay et al. 1992) of the 8-month SAMSON data set from the FRF 8-m depth array. The analysis separates the wave variance into three frequency bands for infragravity $(0.02-$ $0.04 \mathrm{~Hz})$, swell $(0.05-0.15 \mathrm{~Hz})$, and sea $(0.15-0.3 \mathrm{~Hz})$. The infragravity wave frequency limits were selected, as mentioned above, for isolating edge wave variance from swell and leaky/bound wave variance. Wave variance in this infragravity band is further partitioned, to separate edge and bound wave variance, by summing edge wave variance that lies on edge wave dispersion lines in $k$ - $f$ spectra. In this 8-month data set, 50 percent of the total infragravity variance was from edge waves with as much as 80 percent at times (Figure 19).

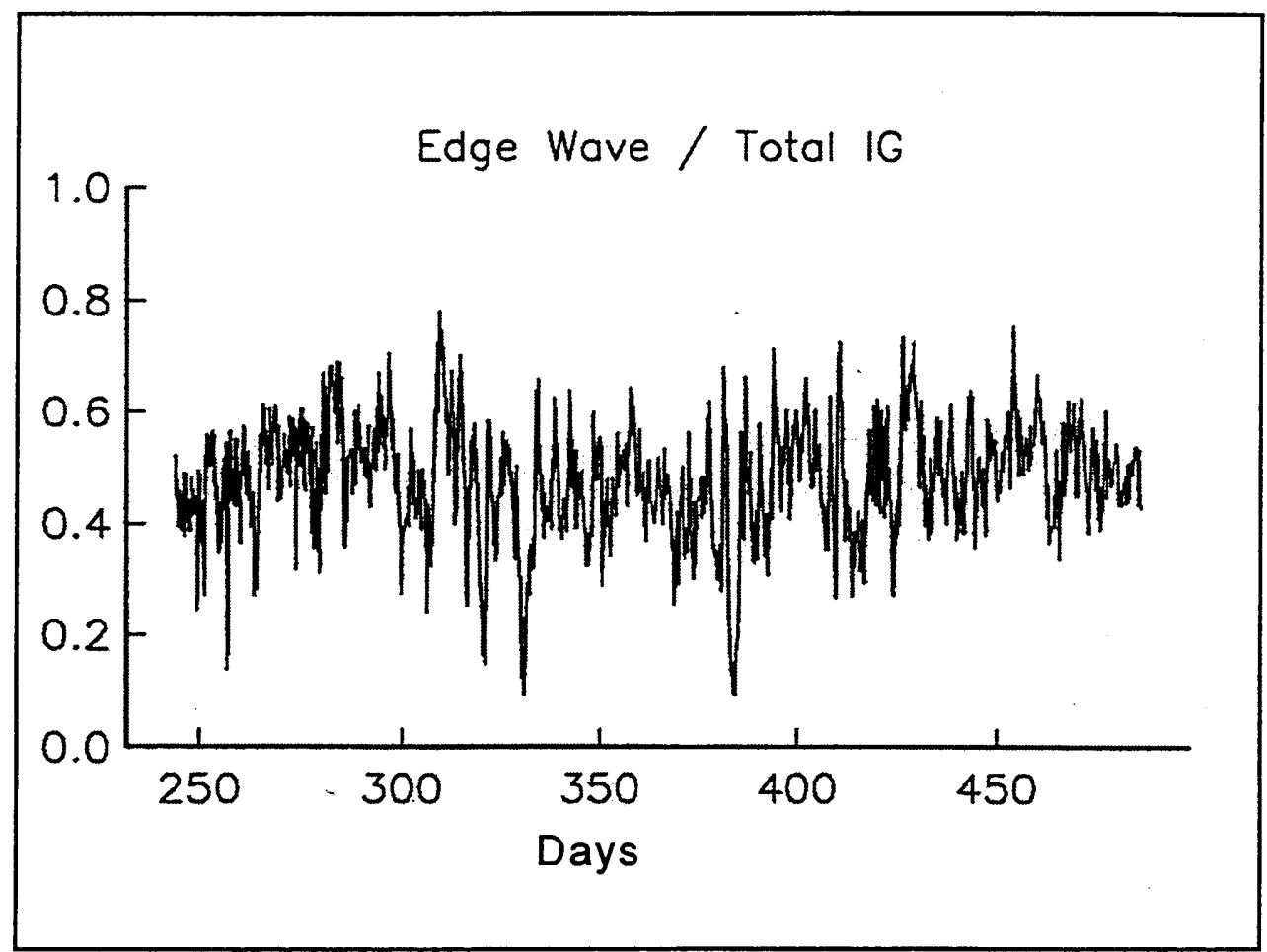

Figure 19. Ratio of edge wave to total infragravity wave variance observed from 1 Sep 1990 to 31 Apr 1991 (OtIman-Shay 1991; OtImanShay et al. 1992)

Infragravity wave variance was shown to have a higher correlation with swell variance than with sea variance (Figures $20 \mathrm{a}$ and $20 \mathrm{~b}$ ). Similar correlations are observed for the edge wave variance portion of the infragravity band (Figures $20 \mathrm{c}$ and 20d). This is consistent with observations by Elgar et al. (1992) that showed similar correlations at this site and other sites. Their analysis 


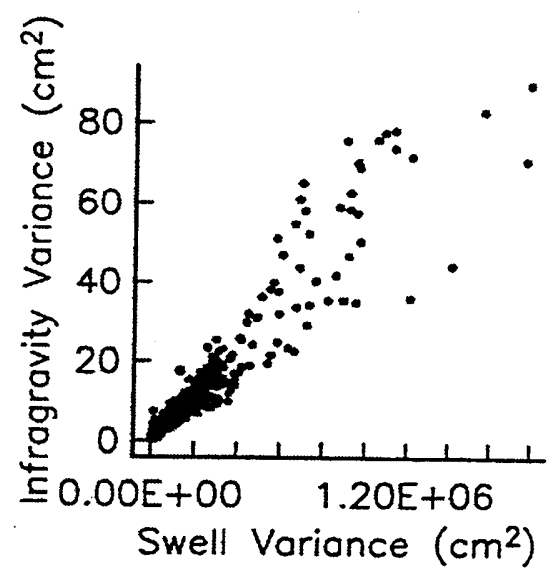

(a)

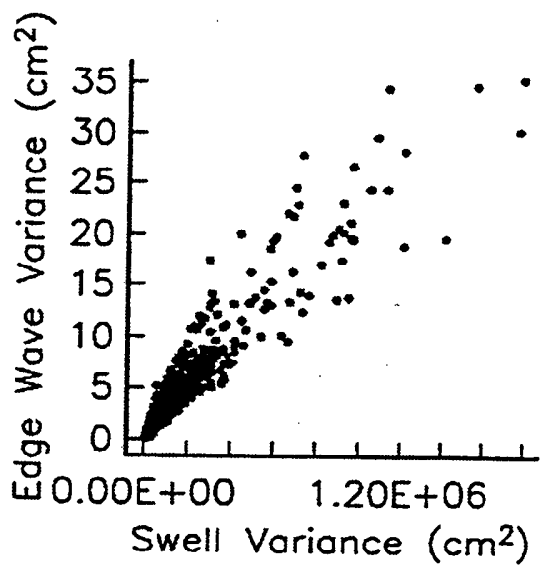

(c)

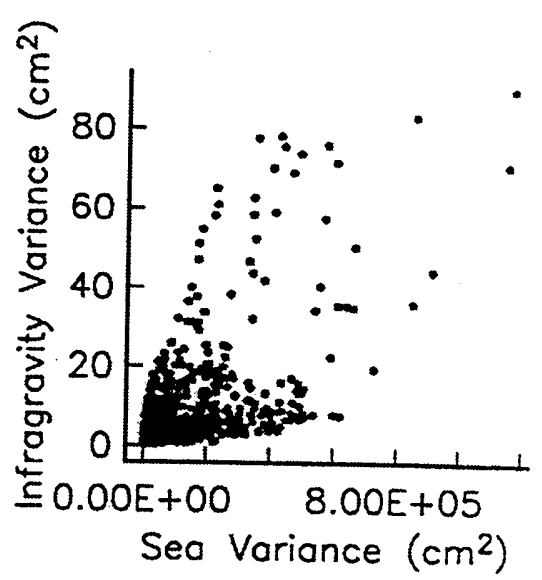

(b)

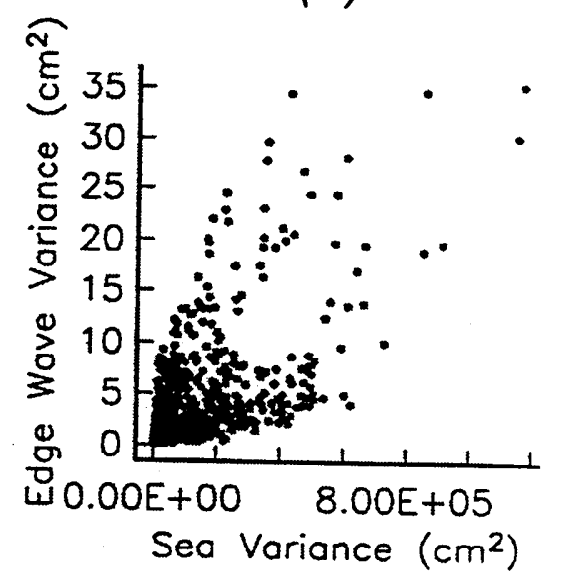

(d)

Figure 20. Scatterplot of infragravity variance against swell (a) and sea (b) variance, and edge wave variance against swell (c) and sea (d) variance (OtIman-Shay 1991)

determined that at the FRF site, the relationship between infragravity band energy and incident swell energy was linear, suggesting that infragravity energy was predominately from free waves. If the infragravity energy was from bound waves, then the relationship would have been nonlinear, with infragravity energy being proportional to the square of the swell energy.

The relationship between propagation directions of edge waves and incident swell was also examined in this 8 month data set. $k_{y}-f$ analysis was used to separate up-coast and downcoast propagating edge waves, symmetric about the $k_{y}=0$ line, with $+k_{y}$ defining edge waves traveling south, and $-k_{y}$ traveling northward (Figure 21). Incident waves at this time were from a relatively narrow band swell, approaching from approximately $30 \mathrm{deg}$ south of shore normal 


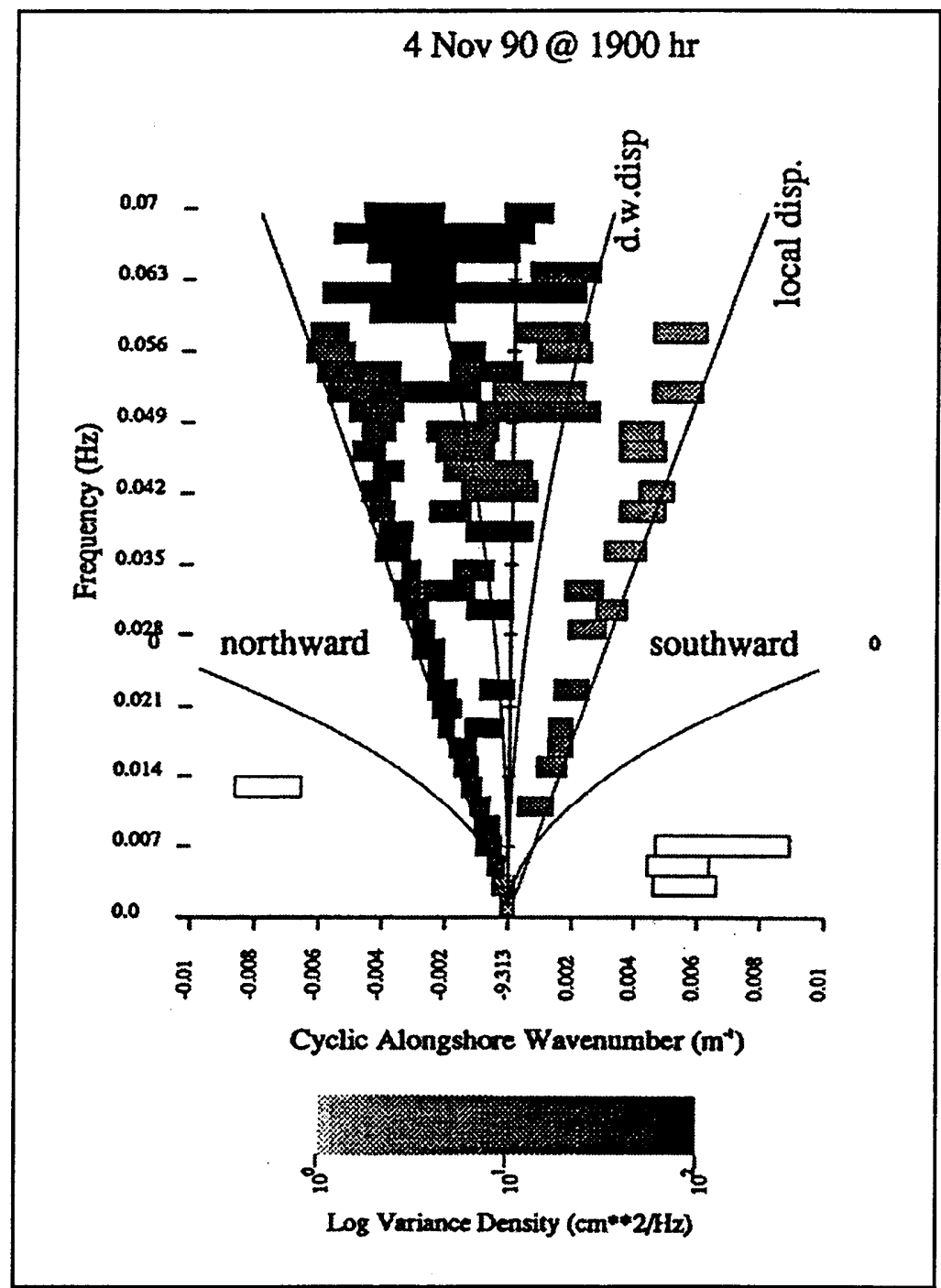

Figure 21. $k_{y}-f$ spectrum from 4 Nov 1990 in 8-m depth. The rectangular boxes mark variance peaks, with shading indicating the log variance density within the half-power bandwidth, shown as the box width (Oltman-Shay 1991; Oltman-Shay et al. 1992)

(Figure 22). Correlation analysis of the entire data set clearly showed that upcoast and downcoast progressive edge wave variance was dependent on the propagation direction of the incident swell. Incident waves from south of shore normal generated progressive edge waves traveling northward (cf. Figures 23a and 23d). Similarly, incident waves from the north produced progressive edge waves moving southward (cf. Figures $23 \mathrm{~b}$ and $23 \mathrm{c}$ ). Swell and edge waves 
propagating from the same directional quadrant are sufficiently correlated, such that linear regression can account for more than 90 percent of the up-coast and downcoast variance (Table 4). The correlation of edge wave variance is much lower with seas (either direction) or with incident swell from the opposite quadrant (Table 4).

The high correlation between edge waves and swell from the same directional quadrant is consistent with a triad interaction description of edge wave forcing (Gallagher 1971). In these triad interactions, two incident waves generate a difference interaction that satisfies an edge wave mode dispersion relationship, thus producing the resonant excitation of that edge wave mode. Theoretical examination of these nonlinear interactions shows that directional swell wave pairs can generate interactions traveling from the same quadrant as the edge wave propagation (Bowen and Guza 1978; Oltman-Shay et al. 1992). It was found unlikely that sea-sea interactions would create a difference interaction capable of exciting an edge wave mode with a preferential direction.

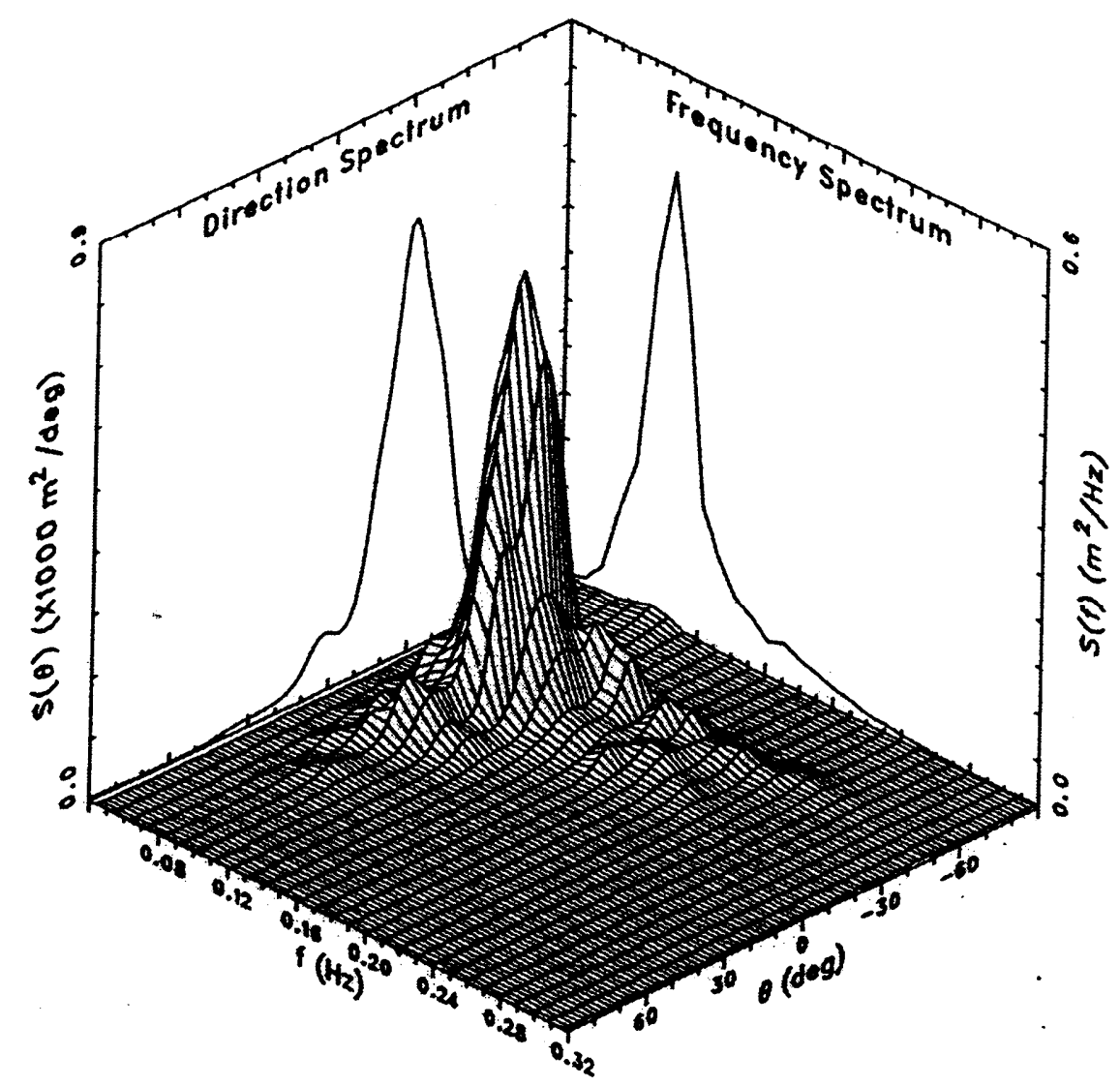

Figure 22. Incident directional wave spectrum on 4 Nov 1990. Peak wave direction is from $32 \mathrm{deg}$ south of shore normal 


\begin{tabular}{|c|c|c|c|c|}
\hline \multicolumn{5}{|c|}{$\begin{array}{l}\text { Table } 4 \\
\text { Linear Regression Analysis of Infragravity, Sea, and Swell } \\
\text { Variance }\end{array}$} \\
\hline Variance Quantities & NE Sea & SE Sea & NE Swell & SE Swell \\
\hline Northward edge waves & $C=0.76$ & $C=0.40$ & $C=0.96$ & $C=0.54$ \\
\hline Southward edge waves & $C=0.50$ & $c=0.76$ & $C=0.38$ & $C=0.95$ \\
\hline
\end{tabular}

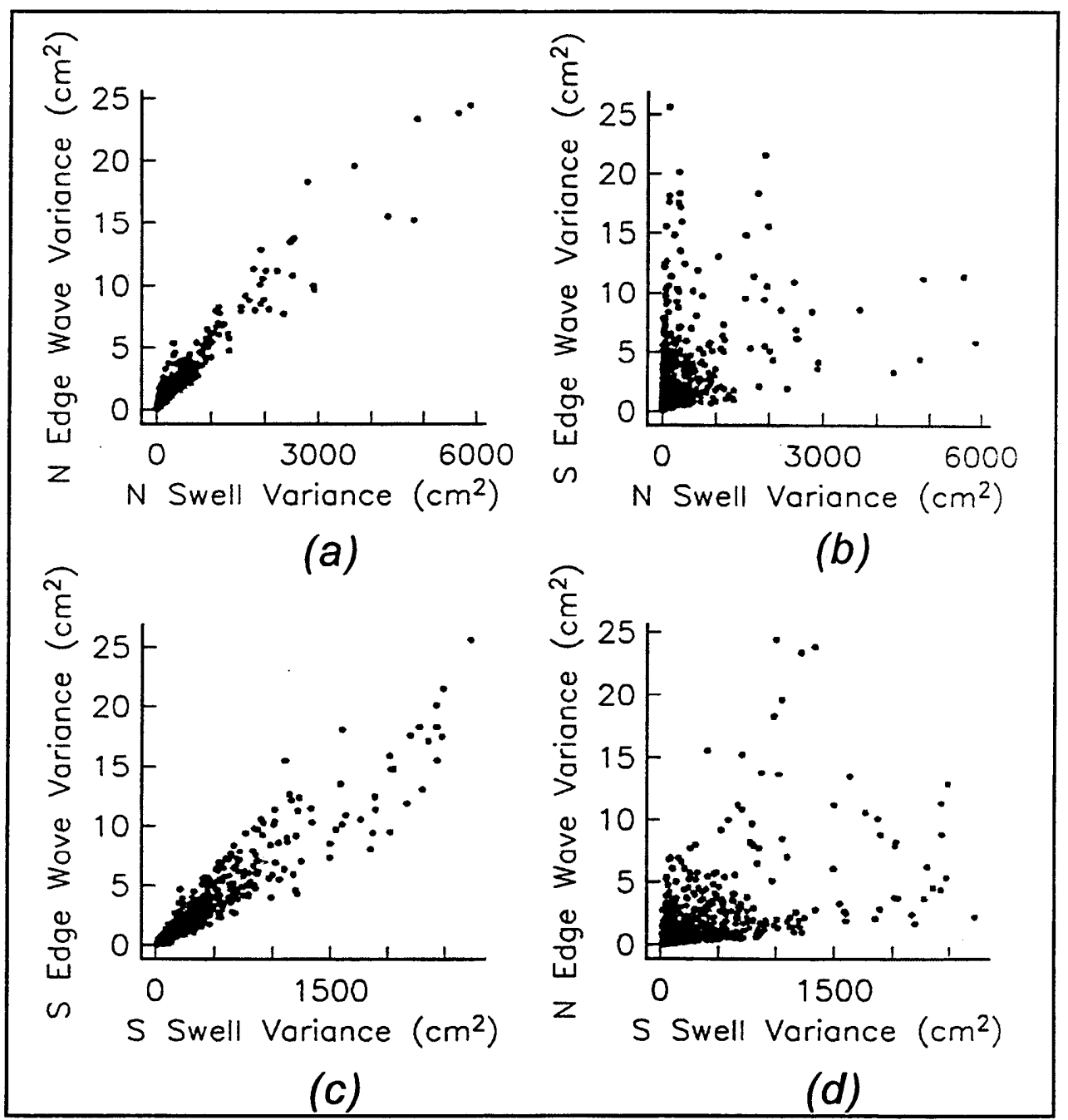

Figure 23. Scatterplot of northward $(a, d)$ and southward $(b, c)$ propagating edge wave variance against swell directional variance (OltmanShay 1991; Otlman-Shay et al. 1992) 


\section{Summary}

Measurements of nearshore waves and currents have shown that a significant amount of the total energy can be contained in the infragravity band (nominally 0.003 to $0.05 \mathrm{~Hz}$ ). On highly dissipative beaches the infragravity wave variance often dominates over energy in the incident wave band $(0.05$ to $0.3 \mathrm{~Hz})$, particularly inside the surf zone and in the runup. Infragravity waves are surface gravity waves that are classified as either free waves, which are nonlocally forced and freely propagating, or forced waves, which are second-order forced waves generated by wave groups and are bound to the group. These forced waves are also referred to as bound waves since they are bound to the group and travel at the group velocity. There are two types of free waves, edge waves that are refractively trapped to the shoreline and leaky waves that escape out to deep water upon reflection from the shoreline. Edge and leaky waves are free surface gravity waves, free to propagate away from the generating source.

Infragravity waves are generally believed to be produced by the nonlinear interactions of incident wind-generated surface gravity waves in the 0.05 to 0.03 $\mathrm{Hz}$ band. Longuet-Higgins and Stewart (1962) showed theoretically that groupforced waves could be generated by variations in radiation stress (momentum flux tensor). Gallagher (1971) extended the work of Longuet-Higgins and Stewart (1962) from two to three dimensions and described wave triad interactions approaching the shore at oblique angles. Gallagher's model is the only spectral edge wave generation model, and it is consistent with observations of positive correlation between edge wave and incident wave propagation directions. Field investigations of infragravity energy have also verified a positive correlation between incident wave energy and nearshore infragravity wave energy (e.g., Guza and Thornton 1982; Elgar et al. 1992; Oltman-Shay et al. 1992). Another proposed mechanism considers a forcing of low-frequency waves by a group-modulated variation in the breakpoint location (Symonds, Huntley, and Bowen 1982; Schäffer and Svendsen 1988; Schäffer 1990). Based on field observations (e.g., List 1992), it is reasonable to assume that both mechanisms have a role in the production of low-frequency motions in the nearshore region. Clearly, more research is needed to improve our understanding of infragravity wave generation processes. 
An 8-month data set of infragravity variance measured at 8-m depth and at the shoreline (runup) was compared with incident wave variance. Analysis of the 8-m-depth data showed that high mode edge waves account for about 50 percent of the total infragravity variance, and as high as 80 percent at times. Significant edge wave heights greater than $20 \mathrm{~cm}$ were observed at the 8-m depth. Infragravity wave variance was shown to have a higher correlation with swell variance $(C=0.95)$ than with sea variance $(C=0.61)$. Correlations between swell and edge waves were found to be dependent on their propagation direction. Swell and edge waves propagating from the same directional quadrant had a much higher correlation than when propagating from different directional quadrants. The correlation between swell and edge waves, propagating from the same quadrant, is approximately linear, with linear regression accounting for more than 90 percent of the upcoast and downcoast variance. Measurements of swash infragravity variance was shown to be significantly correlated with incident swell, however, the correlation was lower $(C=0.70)$ than that measured at the $8-\mathrm{m}$ depth. Ratios of infragravity variance in the swash relative to the $8-\mathrm{m}$ depth had a mean value of 35 , and ranged from 10 to 100 . This amplification of infragravity energy at the shoreline is expected when the infragravity field is dominated by trapped edge waves.

Many studies have shown the infragravity spectrum is broadbanded (white) during storms (e.g., Holman 1981, Oltman-Shay and Guza 1987), implying it is unlikely that selective edge wave modes are interacting to reshape the nearshore morphology. Other studies (e.g., Wright et al. 1986, Aagaard 1988,1990) observed preferential selection of infragravity modes that matched resonant conditions on a beach with bar-trough topography. A basic concept model presently exists for bar formation. It is suggested that in the surf zone, sediment suspension is dominated by incident waves, and that infragravity waves influence surf zone morphology by altering the net drift currents. Future modeling of nearshore bar morphodynamics will improve as we learn more about the interplay of wind waves, infragravity waves, mean currents, and sediments. 


\section{References}

Aagaard, T. (1988). "A study on nearshore bar dynamics in a lowenergy environment; Northern Zealand, Denmark.," J. Coastal Research 94, 115-218.

Aagaard, T. (1990). "Infragravity waves and nearshore bars in protected storm-dominated coastal environments," Marine Geology 94, 181-203.

Aagaard, T., and Holm, J. (1989). "Digitization of wave run-up using video records," J. Coastal Research 5(3), 547-51.

Ball, F. K. (1967). "Edge waves in an ocean of finite depth," Deep-Sea Research 14, 79-88.

Beach, R. A., and Sternberg, R. W. (1988). "Suspended sediment transport in the surf zone: response to cross-shore infragravity motion," Marine Geology 80, 61-79.

Bendat, J. S., and Piersol, A. G. (1971). Random data: analysis and measurement procedures. John Wiley \& Sons, New York.

Birkemeier, W. A., Donoghue, C., Long, C. E., Hathaway, K. K., and Baron, C. F. (1997). "1990 DELILAH nearshore experiment: Summary report," Technical Report CHL-97-24, U.S. Army Engineer Waterways Experiment Station, Vicksburg, MS.

Bowen, A. J. (1980). "Simple models of nearshore sedimentation, beach profiles and longshore bars." Coastline of Canada, littoral processes and shore morphology. S. B. McCann, ed., Geological Survey of Canada, Paper 80-10, 1-11.

Bowen, A. J., and Guza, R. T. (1978). "Edge waves and surf beat," J. Geophysical Research 83(C4), 1913-20. 
Bowen, A. J., and Holman, R. A. (1989). "Shear instabilities of the mean longshore current," J. Geophysical Research 94(C12), 18,023-30.

Bowen, A. J., and Huntley, D. A. (1984). "Waves, long waves and nearshore morphology," Marine Geology 60, 1-13.

Bowen, A. J., and Inman, D. L. (1971). "Edge waves and crescentic bars," J. Geophysical Research 76(36), 8662-71.

Bryan, K. R., and Bowen, A. J. (1996). "Edge wave trapping and amplification on barred beaches," J. Geophysical Research 101(C3), 6543-52.

Bryan, K. R., Howd, P. A., and Bowen, A. J. (1998). "Field observations of bar-trapped edge waves," J. Geophysical Research 103(C1), 1285305.

Carter, T. G., Liu, P. L., and Mei, C. C. (1973). "Mass transport by waves and offshore sand bedforms," J. Waterways, Ports, Coastal and Ocean Division, American Society of Civil Engineers, ww2, 165-84.

Crowson, R. A., Birkemeier, W. A., Klein, H. M., and Miller, H. C. (1988). "SUPERDUCK nearshore processes experiment: Summary of studies, CERC Field Research Facility," Technical Report CERC-8812, US Army Engineer Waterways Experiment Station, Vicksburg, MS.

Dally, W. R. (1987). "Longshore bar formation - surf beat or undertow?" Proceedings of special conference on coastal sediments. American Society of Civil Engineers, New York.

Eckart, E. (1951). "Waves on water of variable depth," Wave Report 100, University of California, Scripps Institute of Technology, La Jolla, CA:

Elgar, S., and Guza, R. T. (1985). "Shoaling gravity waves: Comparisons between field observations, linear theory, and a nonlinear model," $J$. Fluid Mechanics 158, 47-70.

Elgar, S., Herbers, T. H. C., Okihiro, M., Oltman-Shay, J., and Guza, R. T. (1992). "Observations of infragravity waves," J. Geophysical Research 97(C10), 15,573-77.

Falques, A., and Iranzo, V. (1992). "Edge waves on a longshore shear flow," Physics of Fluids A(10), 2169-90. 
Fowler, R. E., and Dalrymple, R. A. (1991). "Wave group forced nearshore circulation: A generation mechanism for migrating rip currents and low frequency motion," Research Report No. CACR91-03, Center for Applied Coastal Research, University of Delaware, Newark, DE.

Gallagher, B. (1971). "Generation of surf beat by non-linear wave interactions," J. Fluid Mechanics 49(1), 1-20.

Guza, R. T., and Thornton, E. B. (1982). "Swash oscillations on a natural beach," J. Geophysical Research 87(C1), 483-91.

\section{Research 90(C2), 3161-72.}

Hanes, D. M. (1991). "Suspension of sediment due to wave groups," $J$. Geophysical Research 96(C5), 8911-15.

Herbers, T. H. C., Elgar, S., and Guza, R. T. (1994). "Infragravityfrequency $(0.005-0.05 \mathrm{~Hz})$ motions on the shelf; I, Forced waves," J. Physical Oceanography 24, 917-27.

Herbers, T. H. C., Elgar, S., Guza, R. T., and O'Reilly, W. C. (1995). "Infragravity-frequency $(0.005-0.05 \mathrm{~Hz})$ motions on the shelf; II, Free waves," J. Physical Oceanography 25, 1063-79.

Herbers, T. H. C., Elgar, S., and Guza, R. T. (1995). "Generation and propagation of infragravity waves," $J$. Geophysical Research 100(C12), 24,863-72.

Holland, K. T., Holman, R. A., Lippmann, T. C., Stanley, J., and Plant, N. (1997). "Practical use of video imagery in nearshore oceanographic filed studies," IEEE J. Oceanic Engineering 22(1), $8 \Gamma-92$.

Holland, K. T., Raubenheimer, B., Guza, R. T., and Holman, R. A. (1995). "Runup kinematics on a natural beach," J. Geophysical Research 100(C3), 4985-93.

Holman, R. A. (1981). "Infragravity energy in the surf zone," $J$. Geophysical Research 86(C7), 6442-50.

Holman, R. A. (1983). "Edge waves and the configuration of the shoreline." The CRC handbook of coastal processes and erosion. CRC Press, Boca Raton, FL, 21-33. 
Holman, R. A., and Bowen, A. J. (1979). "Edge waves on complex beach profiles," J. Geophysical Research 84(C10), 6339-46.

. (1982). "Bars, bumps, and holes: models for the generation of complex beach topography," J. Geophysical Research 87(C1), 458-68. . (1984). "Longshore structure of infragravity wave motions," J. Geophysical Research 89(C4), 6446-52.

Holman, R. A., and Guza, R. T. (1984). "Measuring run-up on a natural beach," Coastal Engineering 8, 129-40.

Holman, R. A., Lippmann, T. C., O'Neill, P. V., and Hathaway, K. K. (1991). "Video estimation of subaerial beach profiles," Marine Geology 97, 225-31.

Holman, R. A., and Sallenger, A. H. (1985). "Setup and swash on a natural beach," J. Geophysical Research 90(C1), 945-53.

Howd, P. A., Bowen, A. J., and Holman, R. A. (1992). "Edge waves in the presence of strong longshore currents," J. Geophysical Research 97(C7), 11,357-71.

Howd, P. A., Oltman-Shay, J., and Holman, R. A. (1991). "Wave variance partitioning in the trough of a barred beach," J. Geophysical Research 96(C7), 12,781-95.

Huntley, D. A., Guza, R. T., and Thornton, E. B. (1981). "Field observations of surf beat; 1, Progressive edge waves," J. Geophysical Research 86(C7), 6451-66.

Katoh, K. (1981). "Analysis of edge waves by means of empirical eigenfunctions," Report of the Port and Harbour Research Institute, 20(3), 3-51.

Katoh, K., and Yanagishima, S. (1993). "Beach erosion in a storm due to infragravity waves," Report of the Port and Harbour Research Institute 31(5), 73-102.

Kirby, J. T., Dalrymple, R. A., and Liu, P. L.-F. (1981). "Modification of edge waves by barred-beach topography," Coastal Engineering 5, $35-49$.

Kostense, J. K. (1984). "Measurements of surf beat and set-down beneath wave groups." Proceedings of the 19th Coastal Engineering Conference. American Society of Civil Engineers, 724-40. 
Lau, J., and Travis, B. (1973). "Slowly varying Stokes waves and submarine longshore bars," J. Geophysical Research 78, 4489-97.

Lippmann, T. C., and Holman, R. A. (1989). "Quantification of sand bar morphology: A video technique based on wave dissipation," $J$. Geophysical Research 94(C1), 995-1011.

. (1990). "The spatial and temporal variability of sand bar morphology," J. Geophysical Research 95(C7), 11,585-90.

Lippmann, T. C., Holman, R. A., and Bowen, A. J. (1997). "Generation of edge waves in shallow water," J. Geophysical Research 102(C4), 8663-79.

List, J. H. (1992). "A model for the generation of two-dimensional surf beat," J. Geophysical Research 97(C4), 5623-35.

Longuet-Higgins, M. S., and Stewart, R. W. (1962). "Radiation stress and mass transport in gravity waves, with applications to surf-beats," J. Fluid Mechanics 13, 481-504.

Longuet-Higgins, M. S., and Stewart, R. W. (1964). "Radiation stress in water waves; A physical discussion, with applications," Deep Sea Research 11, 529-62.

Munk, W. H. (1949). "Surf beats," Transactions American Geophysical Union 30(6), 849-54.

Okihiro, M., and Guza, R. T. (1996). "Observations of seiche forcing and amplification in three small harbors," J. Geophysical Research 100(C8), 16,143-48:

Okihiro, M., Guza, R. T., and Seymour, R. J. (1992). "Bound infragravity waves," J. Geophysical Research 97(C7), 11,453-69. . (1993). "Excitation of seiche observed in a small harbor," J. Geophysical Research 98(C10), 18,201-11.

Oltman-Shay, J. (1991). "A climatological study of infragravity wave in 8m depth," Abstract 031E3, Trans. American Grophysical Union. 72(44), 253.

Oltman-Shay, J., and Guza, R. T. (1987). "Infragravity edge wave observations on two California beaches," J. Physical Oceanography $17,644-63$. 
Oltman-Shay, J., and Howd, P. A. (1993). "Edge waves on nonplanar bathymetry and alongshore currents: A model and data comparison," Journal of Geophysical Research 98(C2), 2495-507.

Oltman-Shay, J., Howd, P. A., and Birkemeier, W. A. (1989). "Shear instabilities of the mean longshore current; 2, Field observations," J. Geophysical Research 94(C12), 18031-42.

Oltman-Shay, J., Howd, P. A., Holman, R. A., and Guza, R. T. (1992). "Infragravity waves across the nearshore," Abstract 0113-3, Trans. American Geophysical Union. 73(43), 246.

Pawka, S. S. (1982). "Wave directional characteristics on a partially sheltered coast," Ph.D. diss., Scripps Institute of Oceanography, Univ. California San Diego, La Jolla, CA.

. (1983). "Island shadows in wave directional spectra," J. Geophysical Research 88(C4), 2579-91.

Roelvink, J. A., and Stive, M. J. F. (1989). "Bar-generating cross-shore flow mechanisms on a beach," J. Geophysical Research 94(C4), 4785-800.

Ruessink, B. G. (1998). "Bound and free infragravity waves in the nearshore zone under breaking and nonbreaking conditions," $J$. Geophysical Research 103(C6), 12,795-805.

Sallenger, A. H., and Holman, R. A. (1984). "On predicting infragravity energy in the surf zone." Proceedings of the 19th Conference on Coastal Engineering. American Society of Civil Engineers, 1940-51.

. (1987). "Infragravity waves over a natural barred profile," J. Geophysical Research 92(C9), 9531-40.

Sallenger, A H., Holman, R. A., and Birkemeier, W. A. (1985). "Storm Induced Response of a Nearshore Bar System," Marine Geology 64, 237-57.

Sand, S. E. (1982). "Wave grouping described by bounded long waves," Ocean Engineering 9(6), 567-80.

Schäffer, H. A. (1990). "Infragravity water waves induced by shortwave groups," Ph.D. diss., Series paper \#50, Institute of Hydrodynamics and Hydraulic Engineering, Technical University of Denmark. 
Schäffer, H. A., and Jonsson, I. G. (1992). "Edge waves revisited," Coastal Engineering 16, 349-68.

Schäffer, H. A. and Svendsen, I. A. (1988). "Surf Beat Generation on a Mild-Slope Beach," Proceedings of 21th Coastal Engineering Conference. American Society of Civil Engineers, 1058-72.

Short, A. D. (1975). "Multiple offshore bars and standing waves," $J$. Geophysical Research 80(27), 3838-40.

Slinn, D. N., Allen, J. S., Newberger, P. A., and Holman, R. A. (1998). "Nonlinear shear instabilities of alongshore currents over barred beaches," J. Geophysical Research 103(C9), 18,357-79.

Suhayda, J. N. (1974). "Standing waves on beaches," J. Geophysical Research 79(21), 3065-71.

Symonds, G., and Bowen, A. J. (1984). "Interactions of nearshore bars with incoming wave groups," J. Geophysical Research 89(C2), 1953-59.

Symonds, G., Huntley, D. A., and Bowen, A. J. (1982).

"Two-dimensional surf beat: Long wave generation by a time-varying breakpoint," J. Geophysical Research 87(C1), 492-98.

Tang, E., and Dalrymple, R. A. (1989). "Rip currents, nearshore circulation and wave groups," Nearshore sediment transport, R. J. Seymour ed., Plenum, New York.

Tucker, M. J. (1950). "Surf beats: Sea waves of 1 to 5 minute period," Proceedings of the Royal Society, London, Series A, 202, 565-73.

Ursell, F. (1952). "Edge waves on a sloping beach," Proceedings of the Royal Society, London, Series A, 214, 79-97.

U.S. Army Engineer Waterways Experiment Station. (1990). “A remote sensing system for measuring runup," Coastal Engineering Technical Note II-23, Coastal Hydraulics Laboratory, Vicksburg, MS

Wright, L. D., Guza, R. T., and Short, A. D. (1982). "Surf zone dynamics on a high energy dissapative beach," Marine Geology 45, 41-62.

Wright, L. D., Nielsen, P., Shi, N. C., and List, J. H. (1986). "Morphodynamics of a bar-trough surf zone," Marine Geology $70(3 / 4), 251-85$. 
Wright, L. D. and Short, A. D. (1984). "Morphodynamic variability of surf zones and beaches: A synthesis," Marine Geology 56, 93-118. 


\section{Appendix A DELILAH Runup Spectra and Beach Profiles}

The following spectra (Figure A1) were computed from video runup time series measurements made on FRF profile line $995 \mathrm{~m}$. Most runs were of 120-min duration and have spectral estimates have 93 degrees of freedom (dof). Shorter duration runs can be identified with fewer dof, the shortest was 90 minutes with 65 dof. Spectral analysis was done using segment (ensemble) and frequency band averaging (Bendat and Piersol 1971). ${ }^{1}$ The spectra have a resolution of approximately $0.005 \mathrm{~Hz}$. Statistics shown for infragravity $(0.001-$ $0.04 \mathrm{~Hz})$, swell $(0.05-0.15 \mathrm{~Hz})$, and sea $(0.15-0.32 \mathrm{~Hz})$ frequency bands.

Beach profiles (solid thin line) from the DELILAH experiment are show in Figure A2. The range of swash excursion is indicated with a thick line drawn on the profile. The dotted horizontal lines indicate the NGVD vertical datum and mean tide level recorded at 8-m depth (inverted triangle). An estimate of setup can be made from the elevation difference between the average runup (circle) and the mean tide level. The mean runup cross-shore position (X) and elevation $(Z)$ are listed in the tables. The Iribarren number $\left(\xi_{0}\right)$ beach slope, and $\mathrm{H}_{\mathrm{mo}}$ (measured at 8-m depth) are also listed for each run.

\footnotetext{
1 References sited in this appendix are located at the end of the main text.
} 


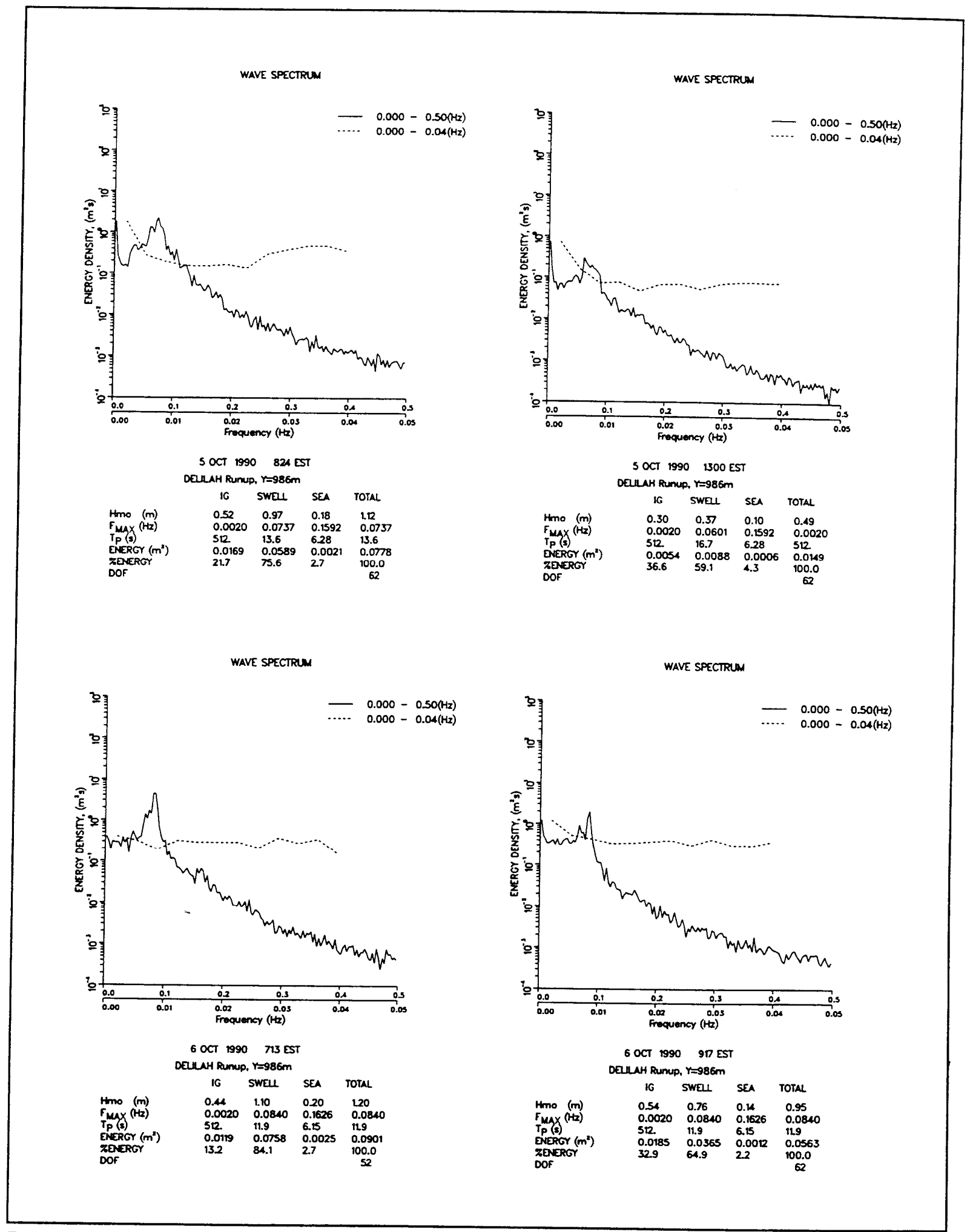

Figure A1. Runup spectra from DELILAH (Sheet 1 of 12) 
WAVE SPECTRUM

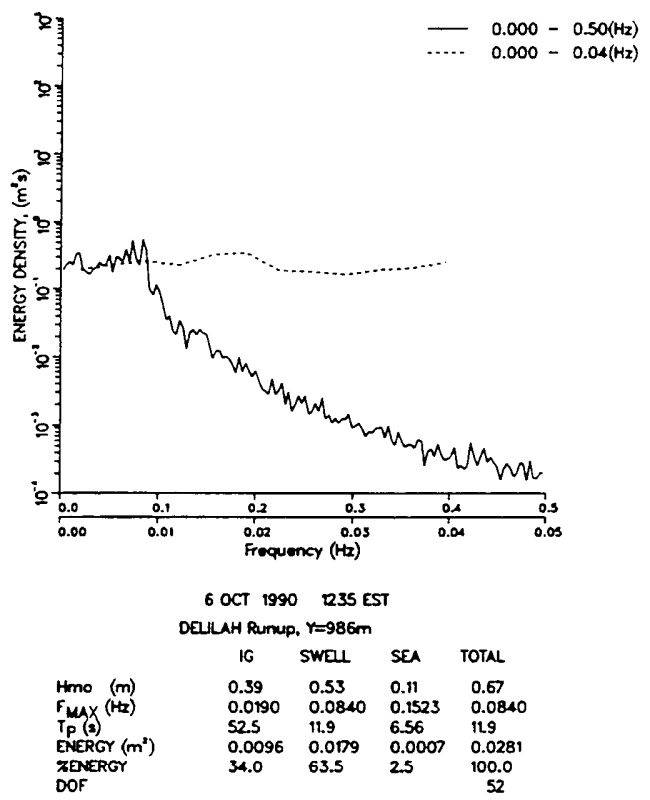

WAVE SPECTRUM

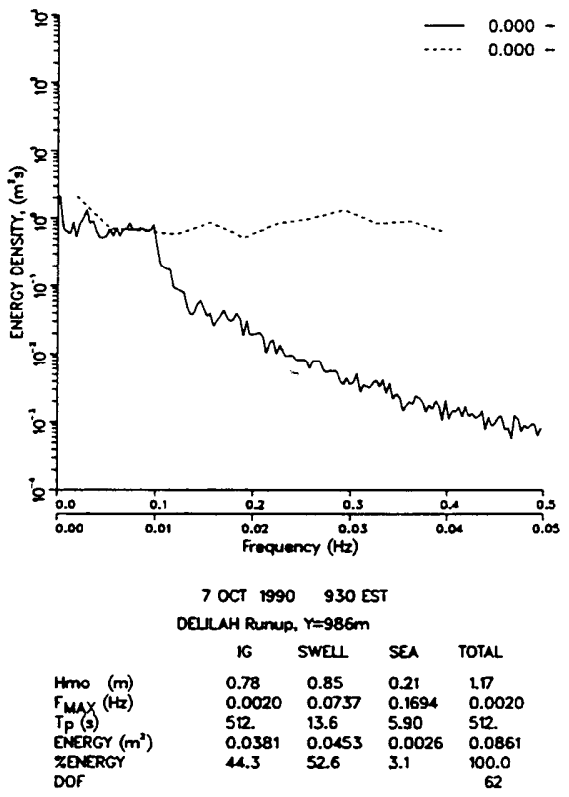

WAVE SPECTRUM

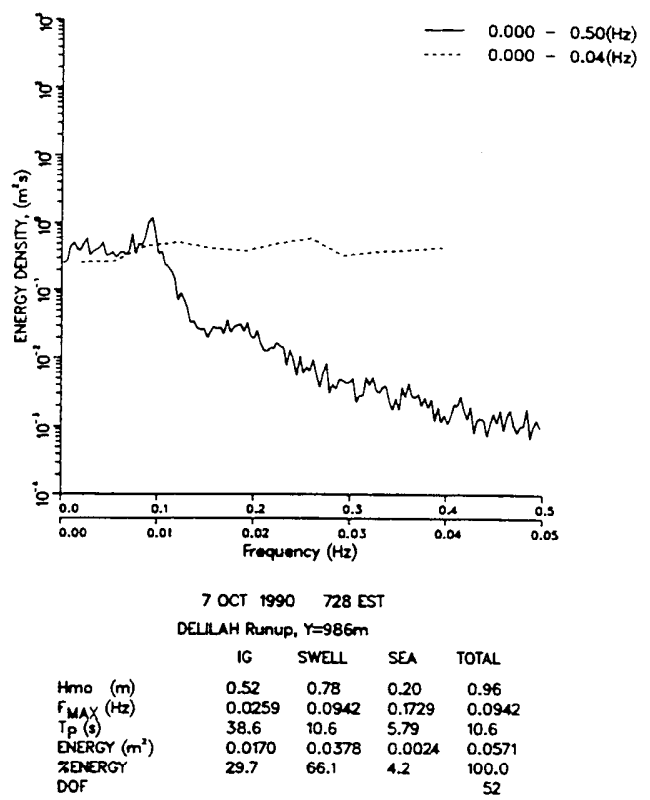

WAVE SPECTRUM

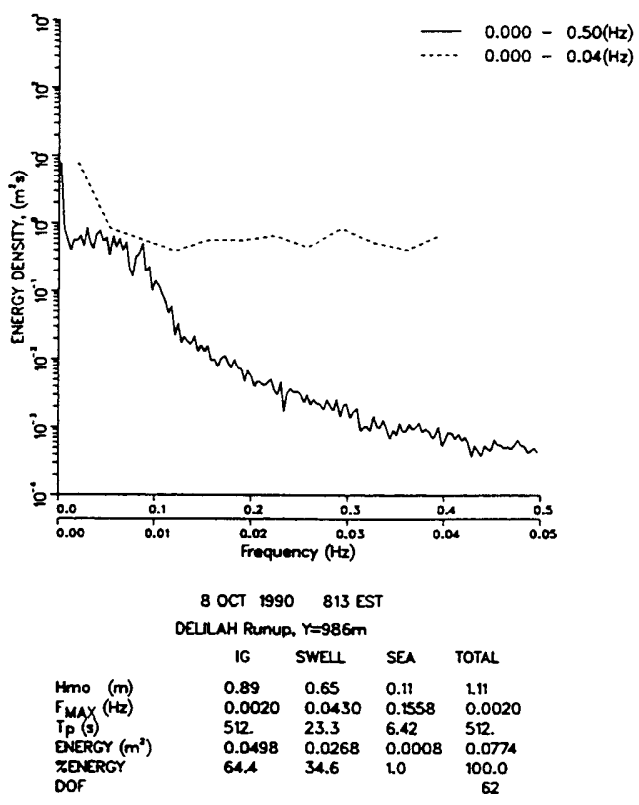

Figure A1. (Sheet 2 of 12 ) 

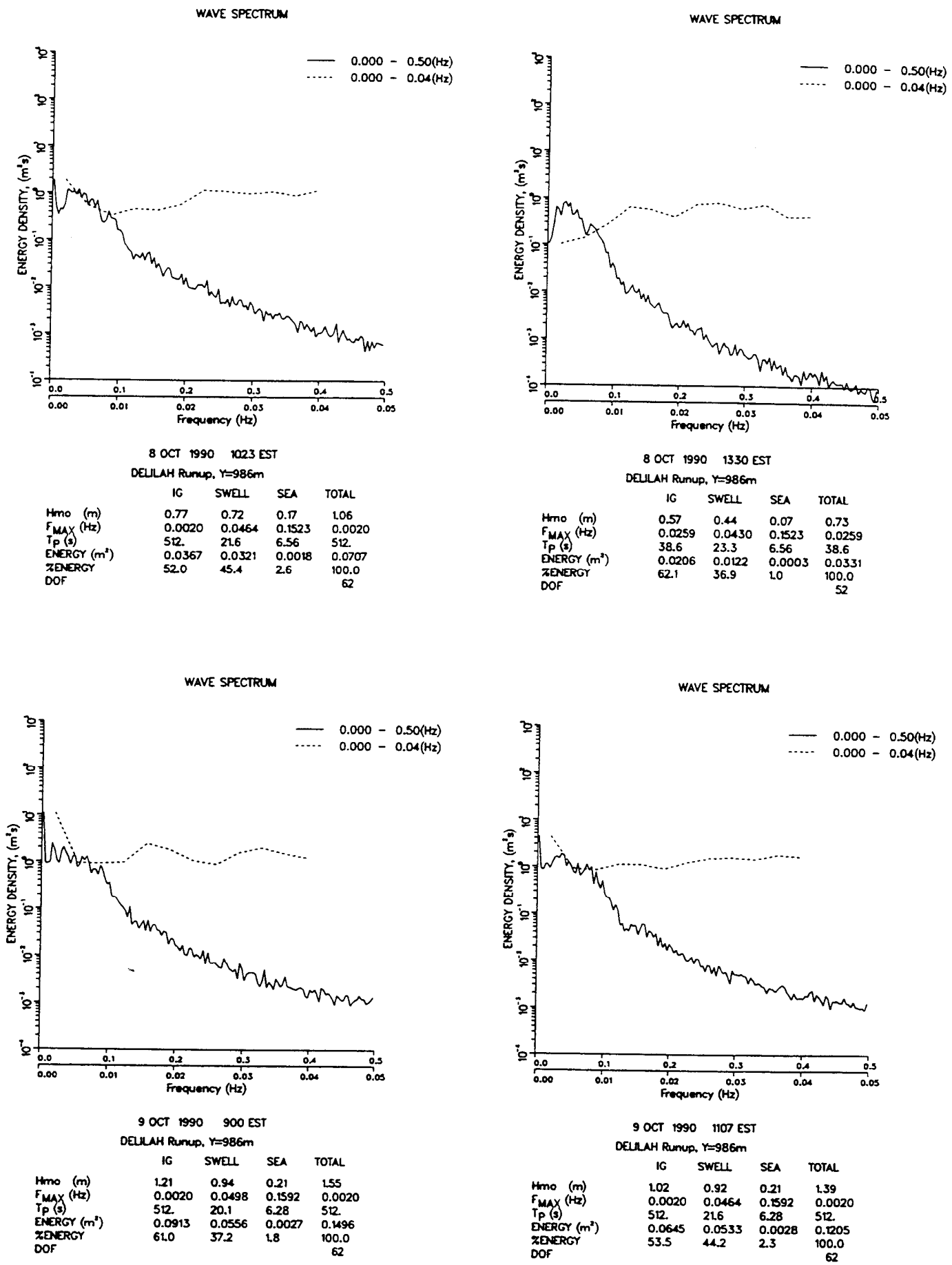

Figure A1. (Sheet 3 of 12) 


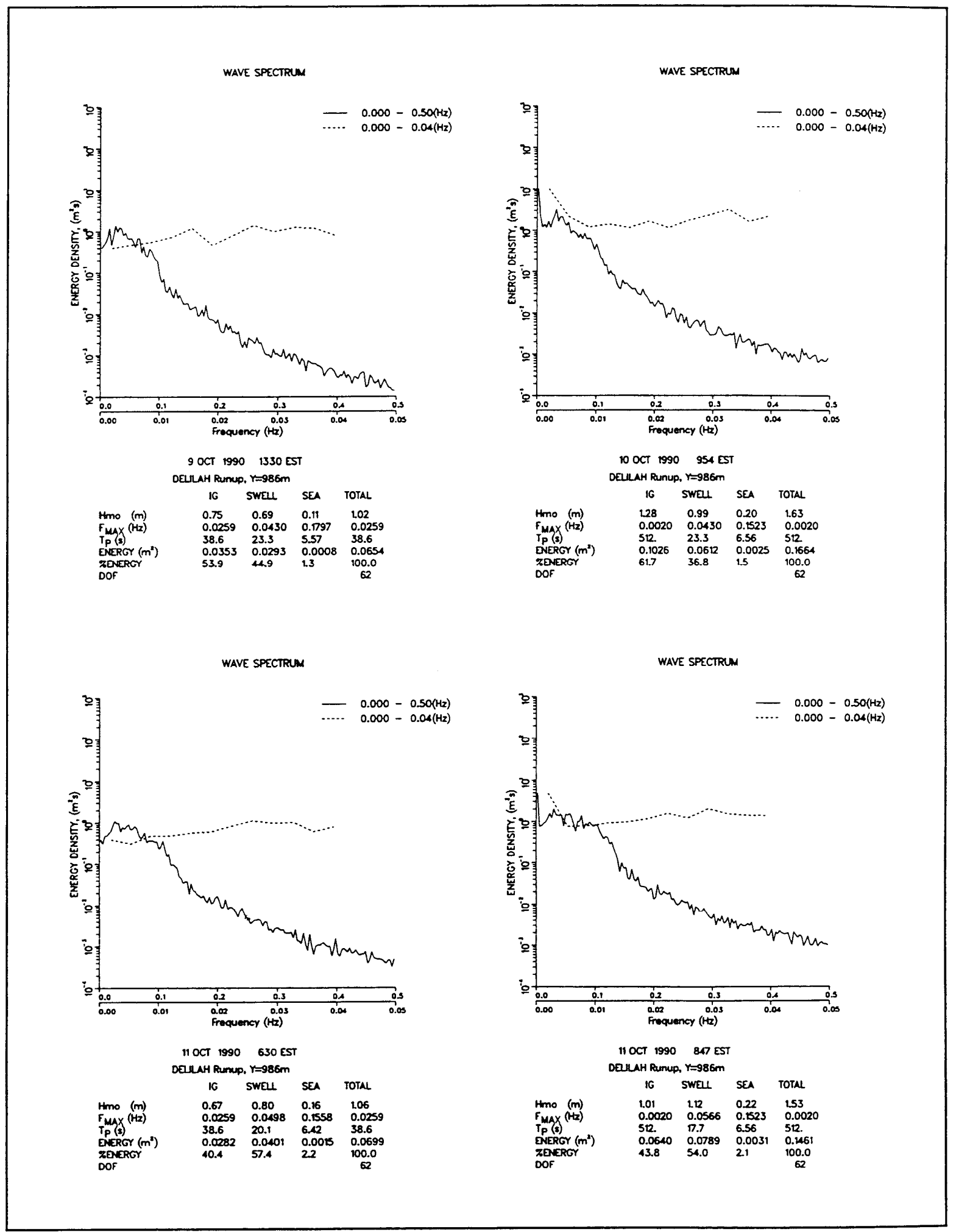

Figure A1. (Sheet 4 of 12) 


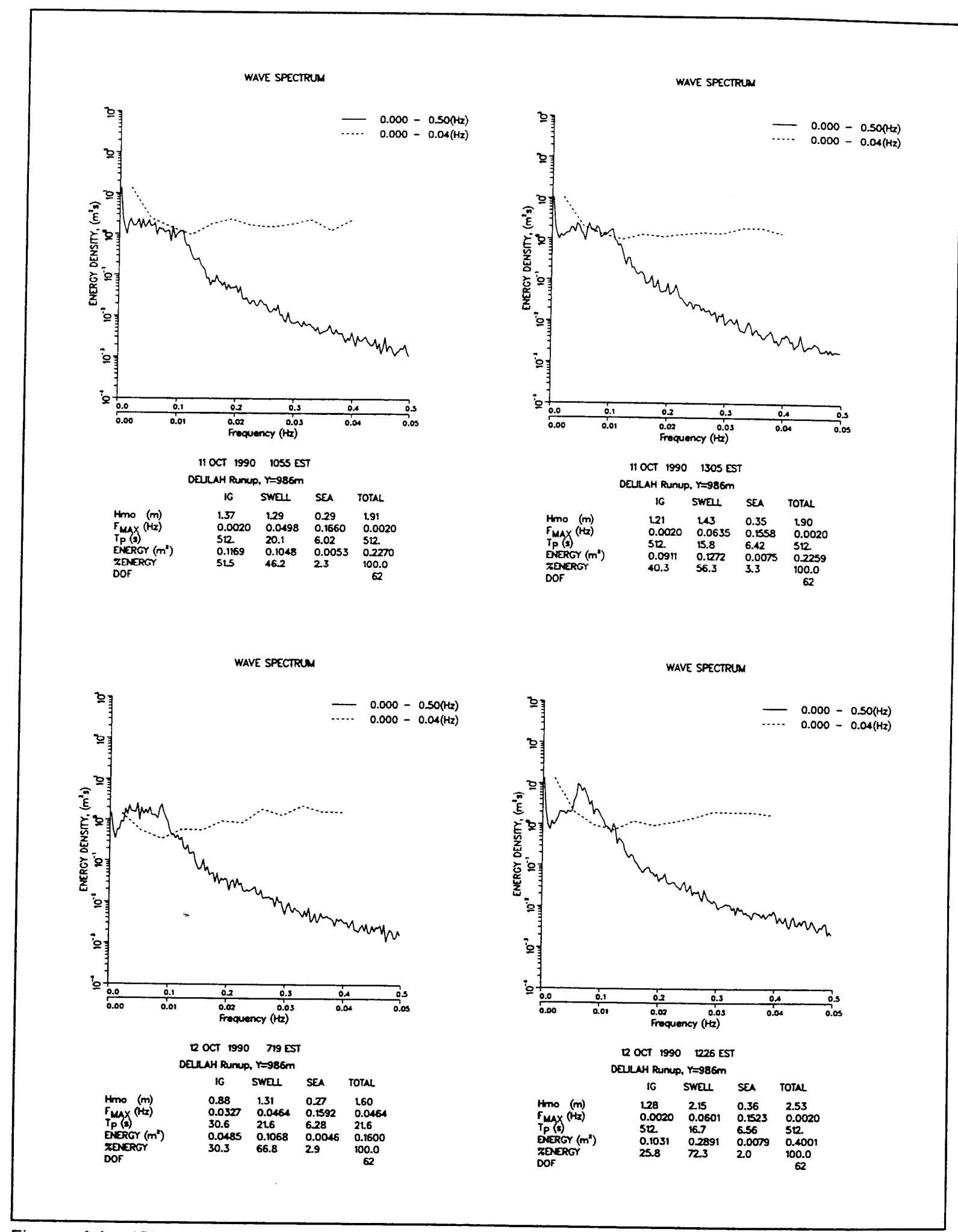

Figure A1. (Sheet 5 of 12) 


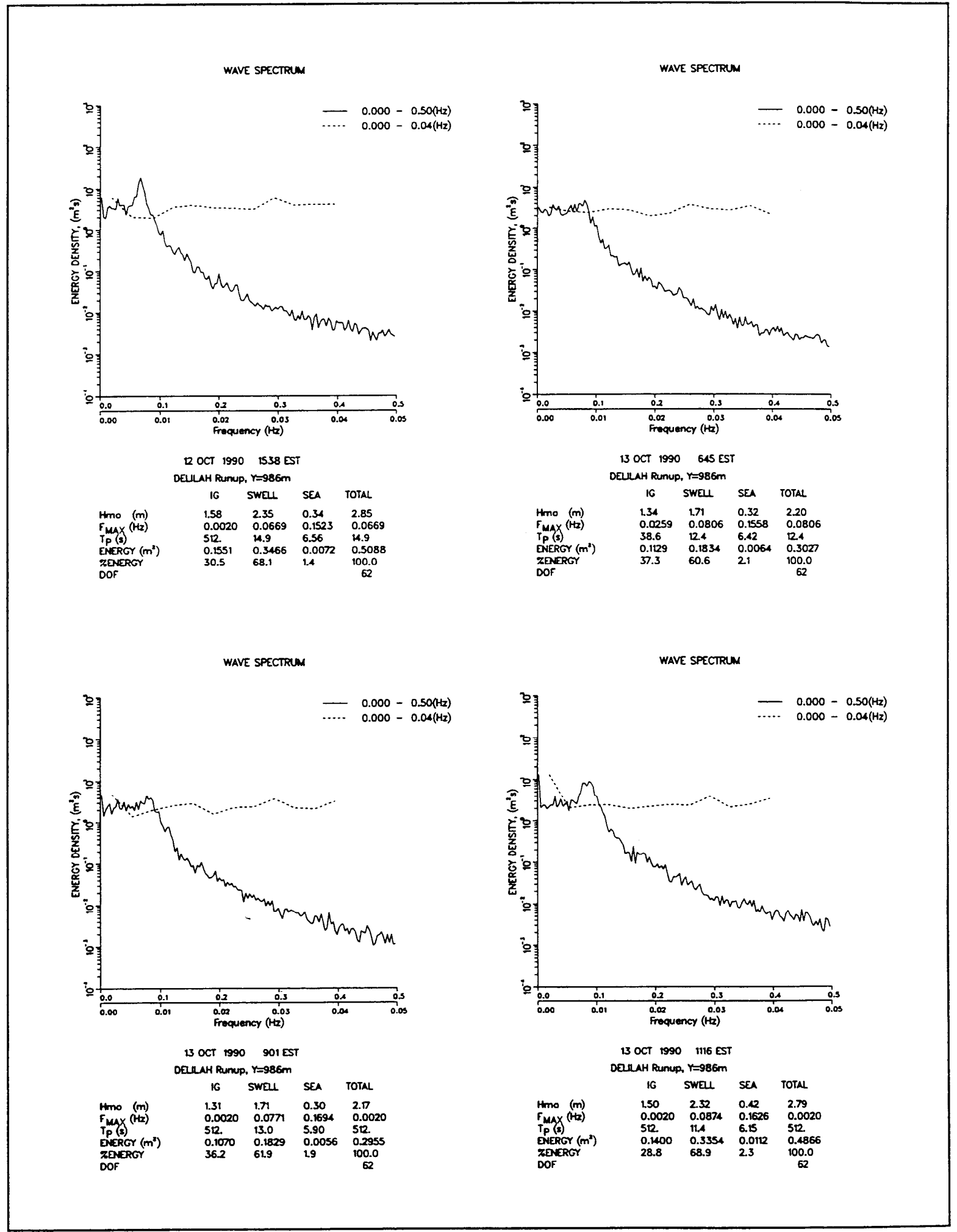

Figure A1. (Sheet 6 of 12) 


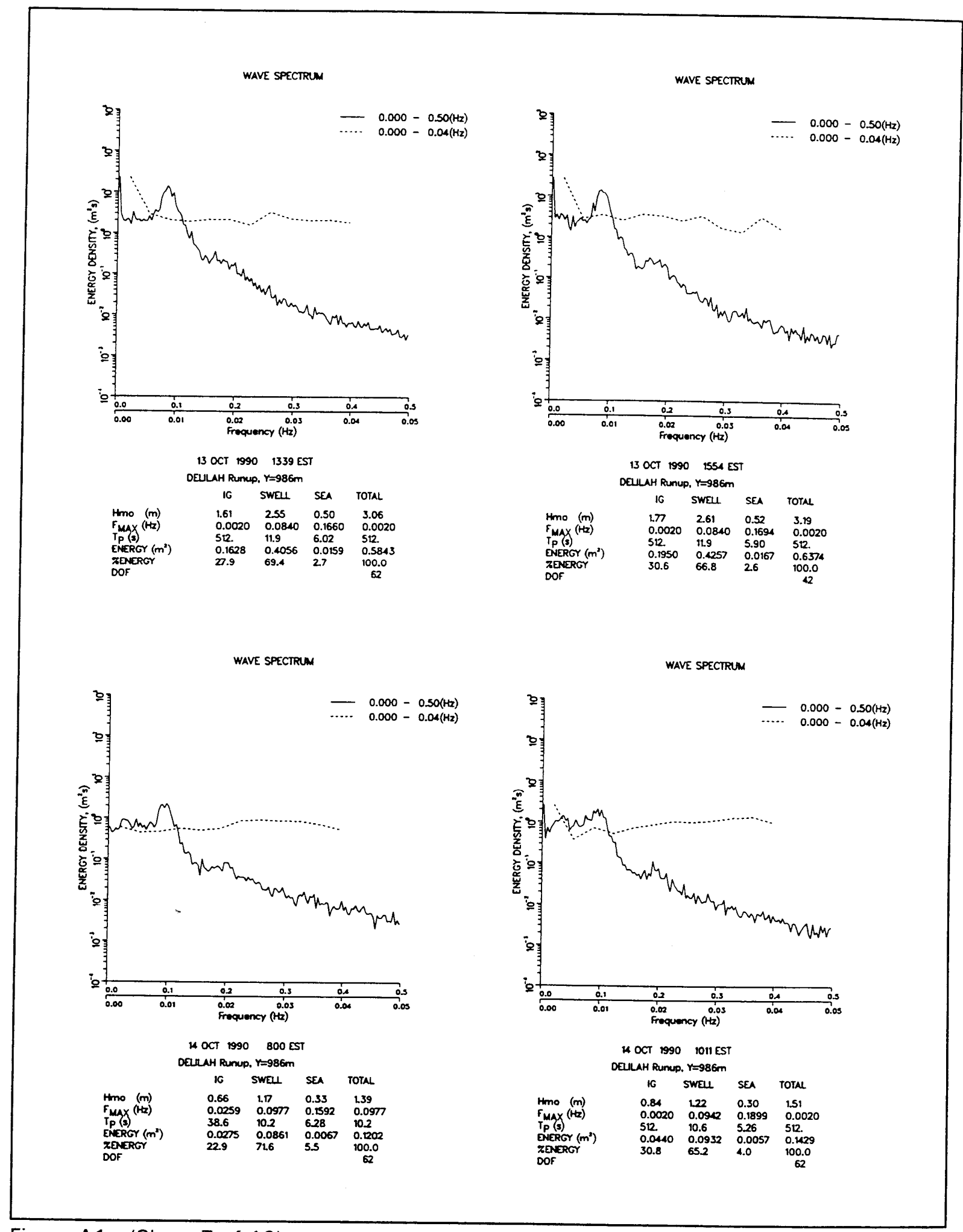

Figure A1. (Sheet 7 of 12) 
WAVE SPECTRUM

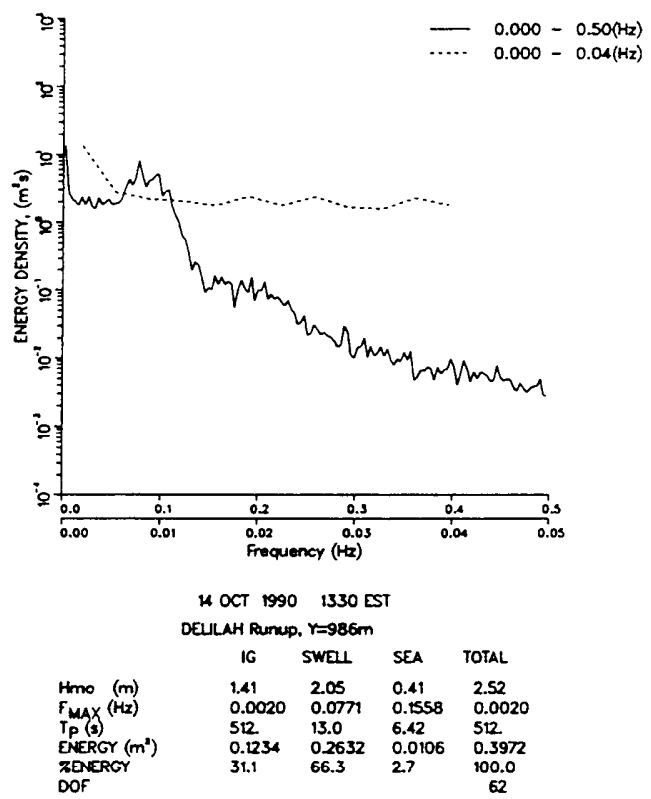

WAVE SPECTRLM

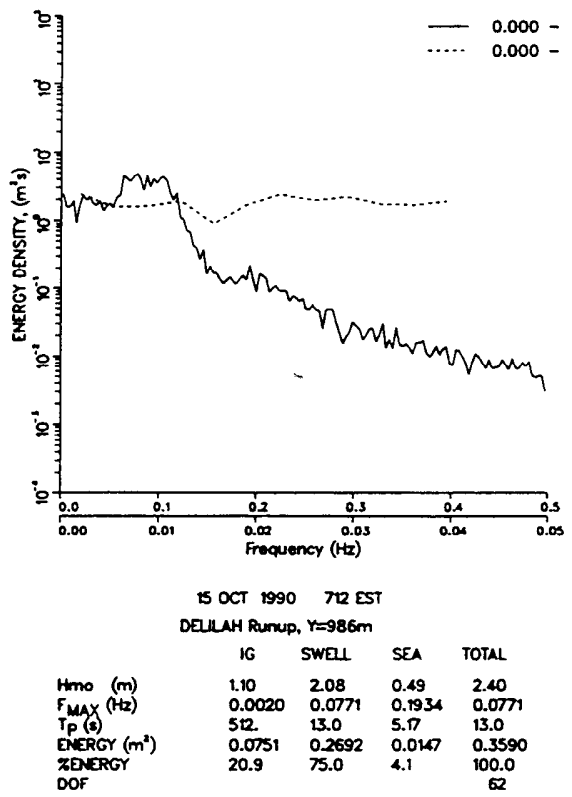

WAVE SPECTRUM

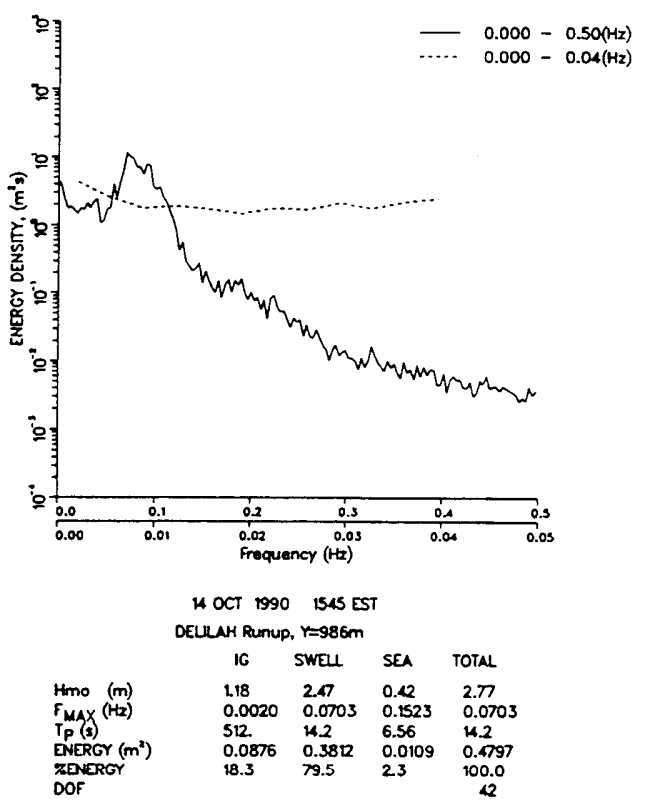

WAVE SPECTRUM

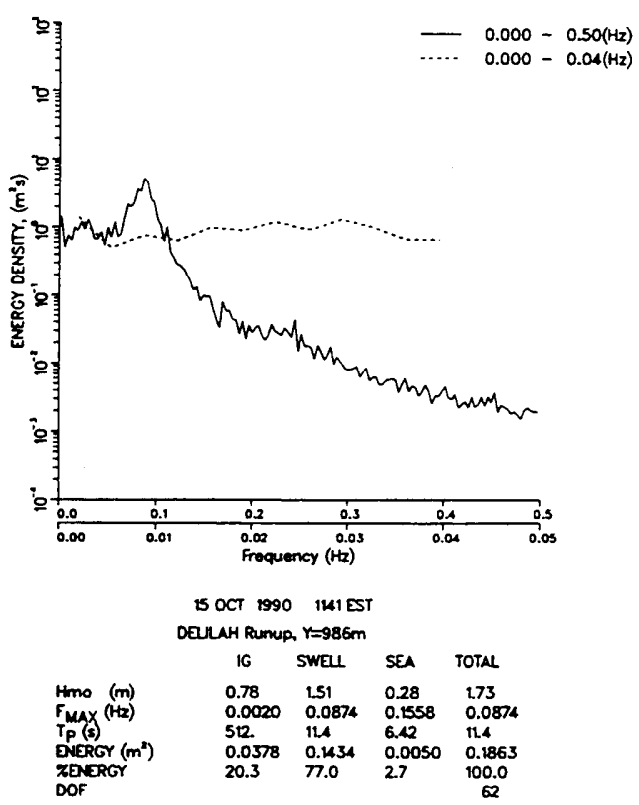

Figure A1. (Sheet 8 of 12) 

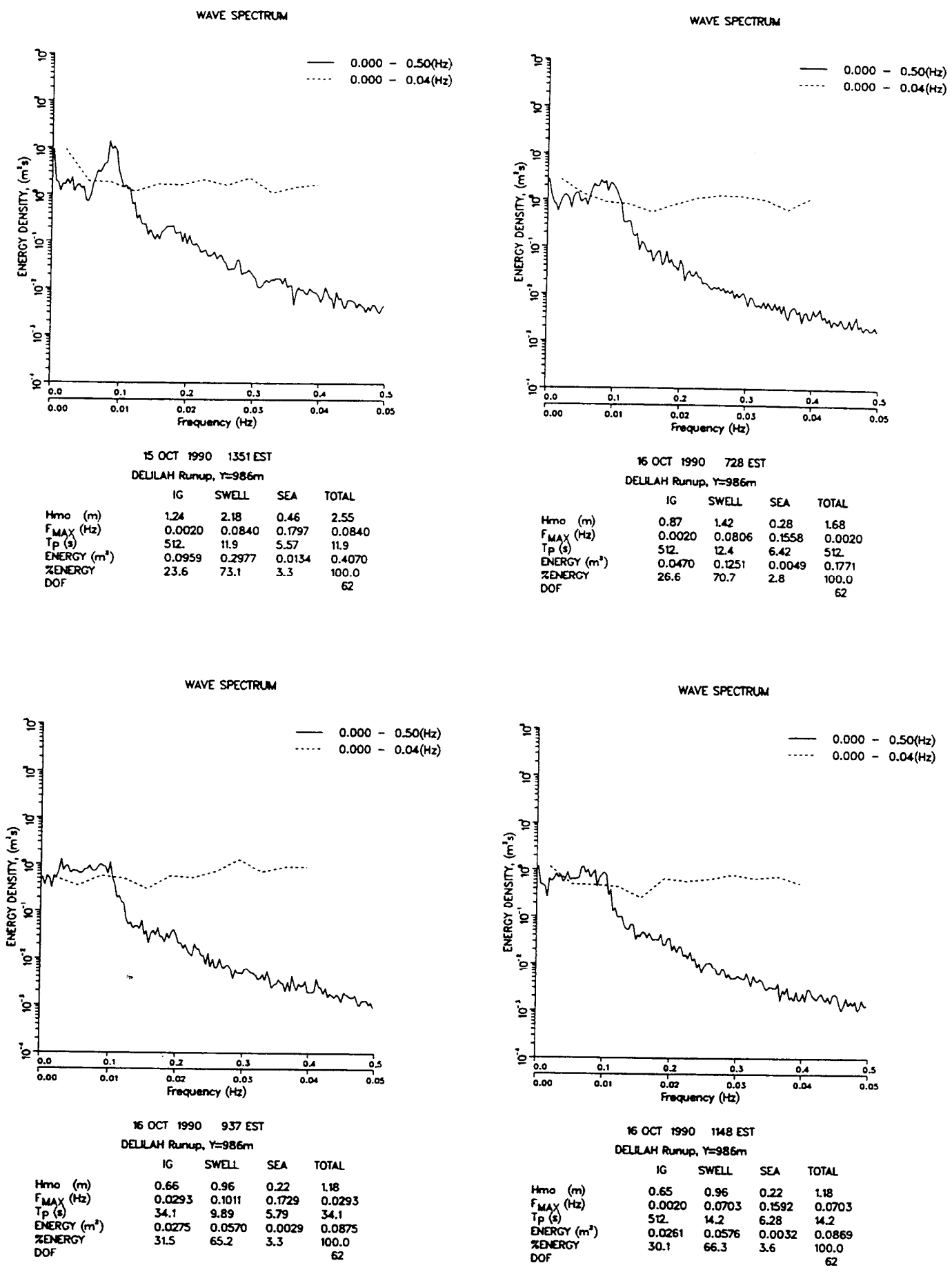

Figure $A 1$. (Sheet 9 of 12) 


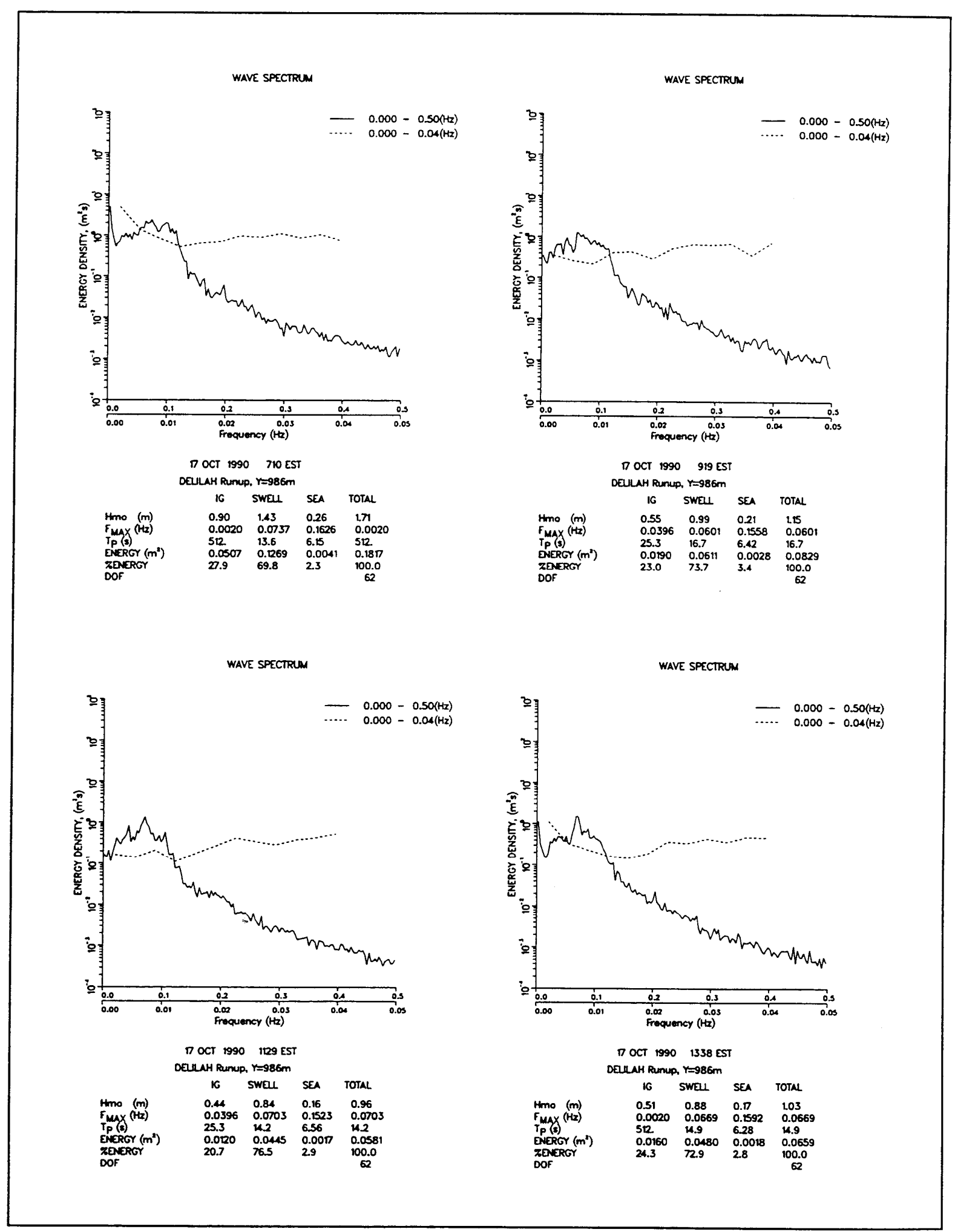

Figure A1. (Sheet 10 of 12) 
WAVE SPECTRUM

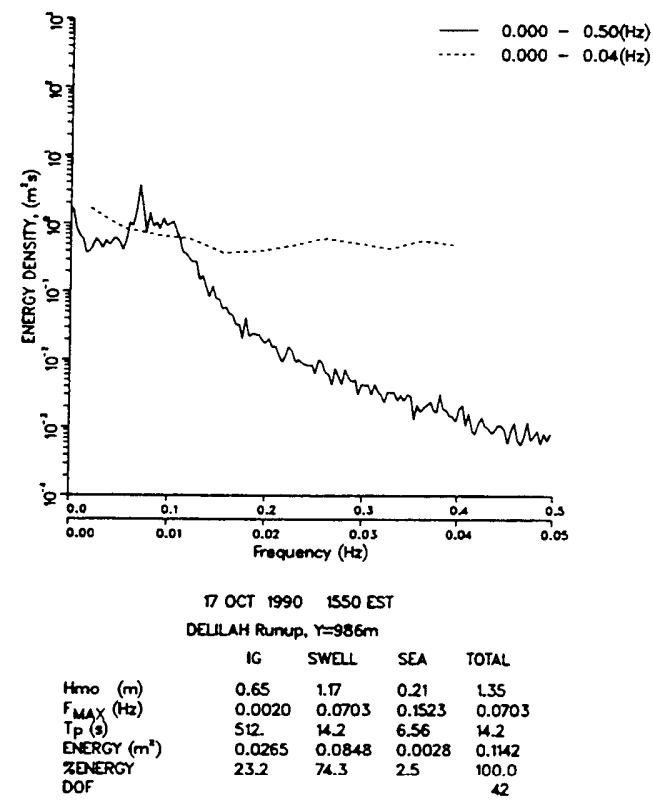

WAVE SPECTRUM

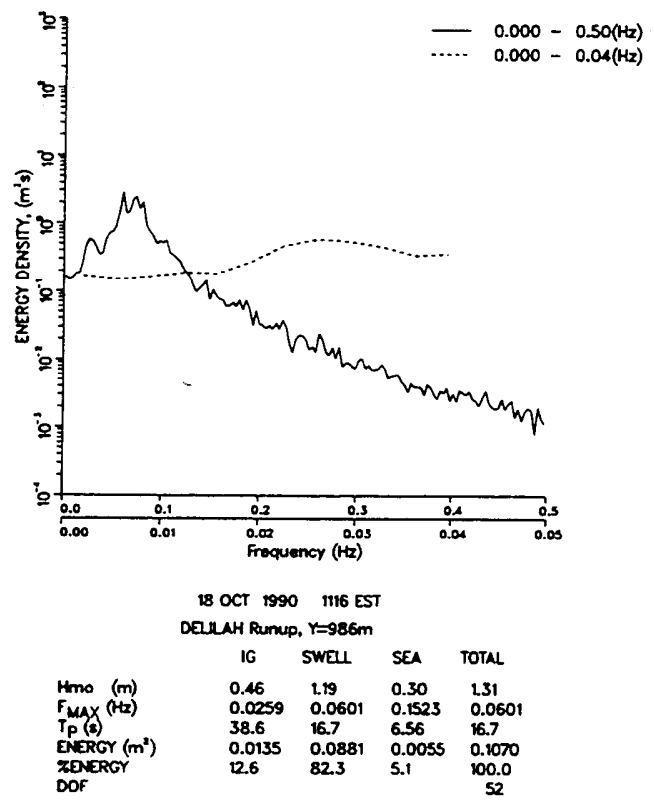

WAVE SPECTRUN

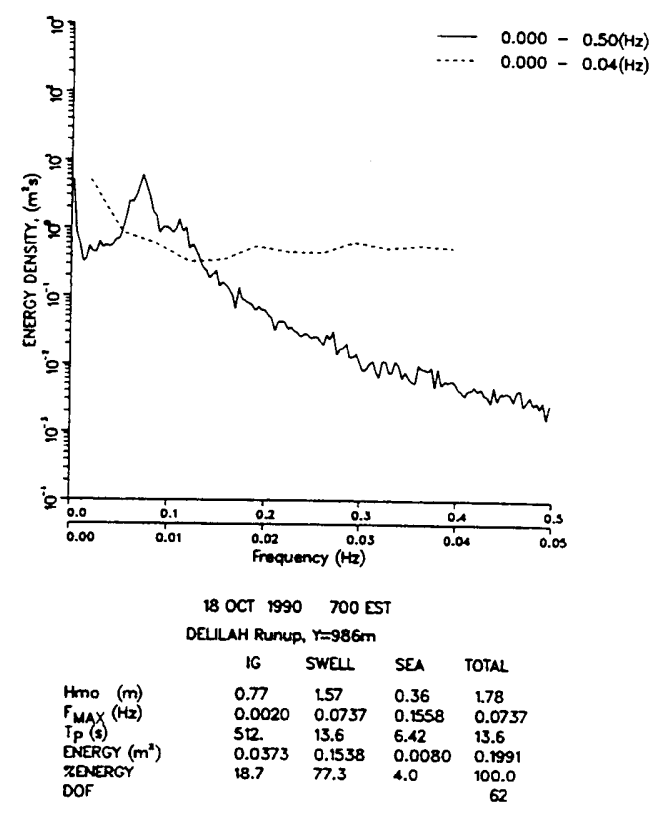

WAVE SPECTRUW

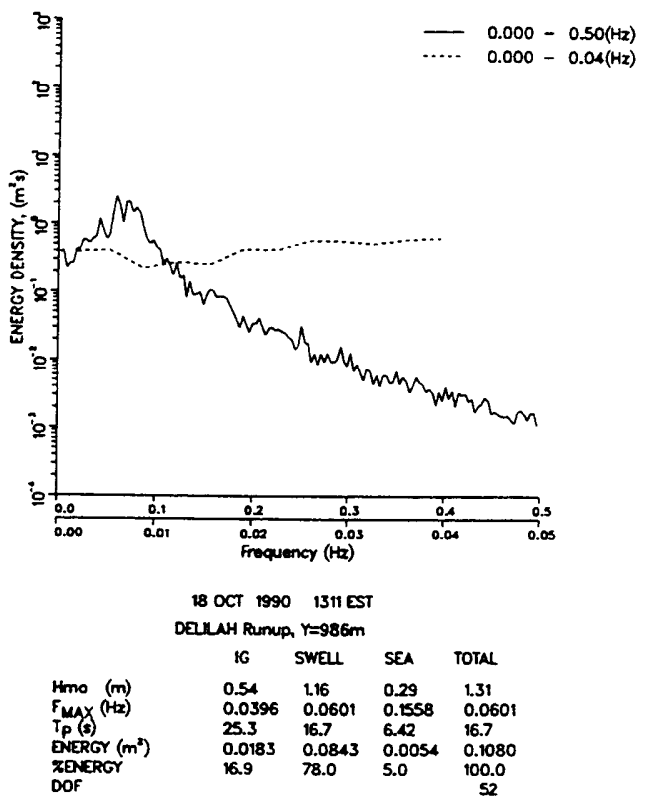

Figure A1. (Sheet 11 of 12) 


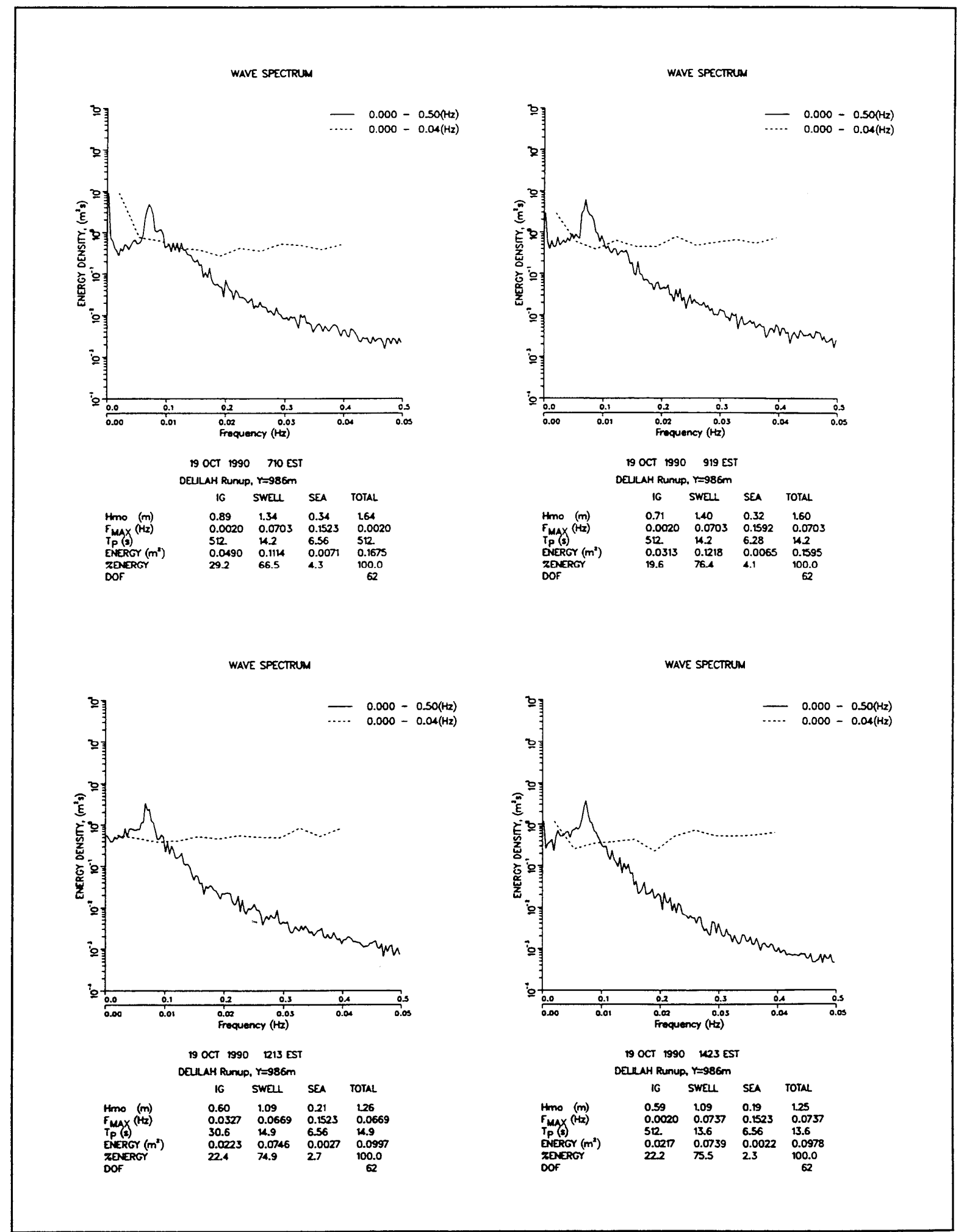

Figure $A 1$. (Sheet 12 of 12) 


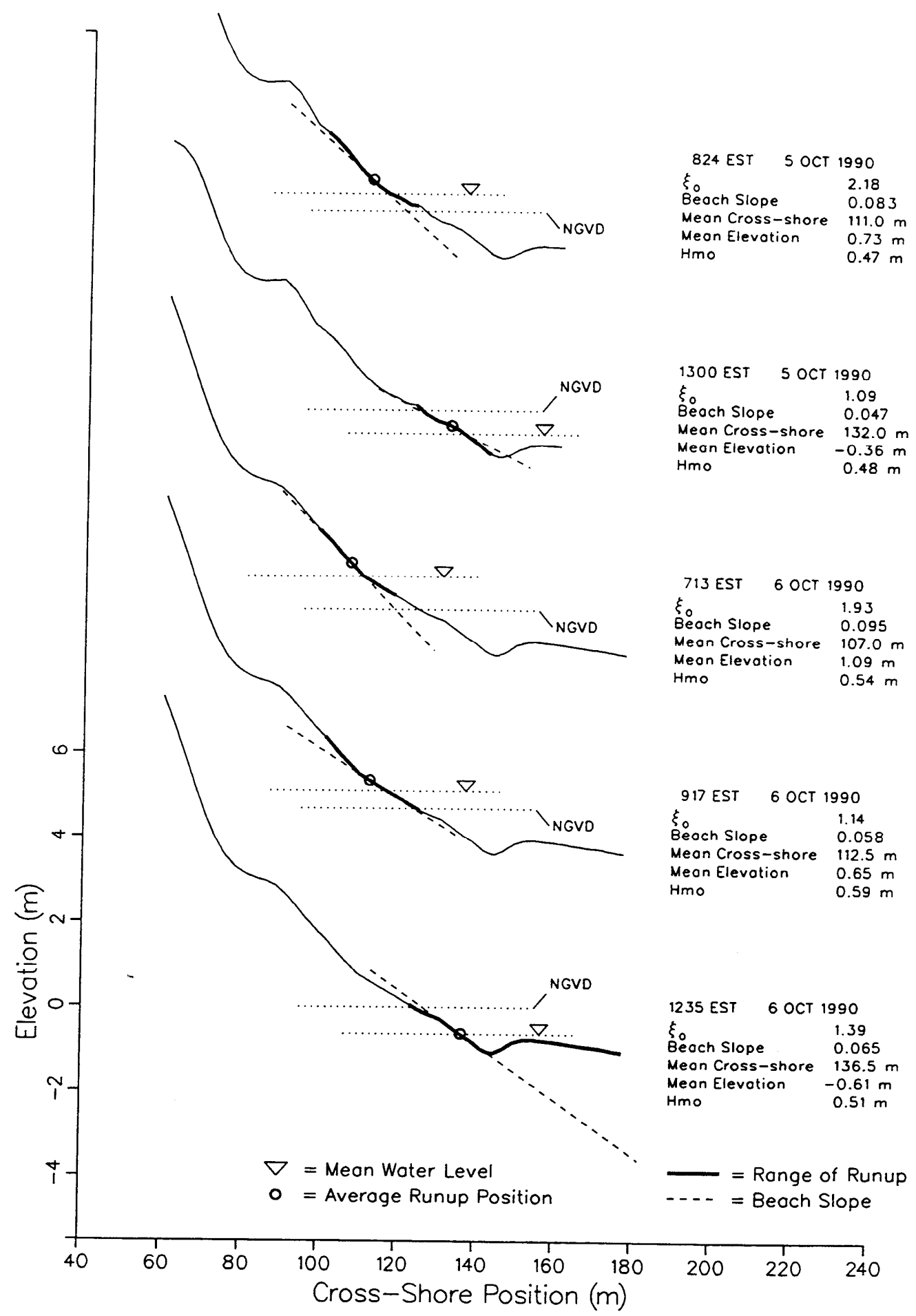

Figure A2. Beach profiles and runup statistics during DELILAH (Sheet 1 of 8 ) 


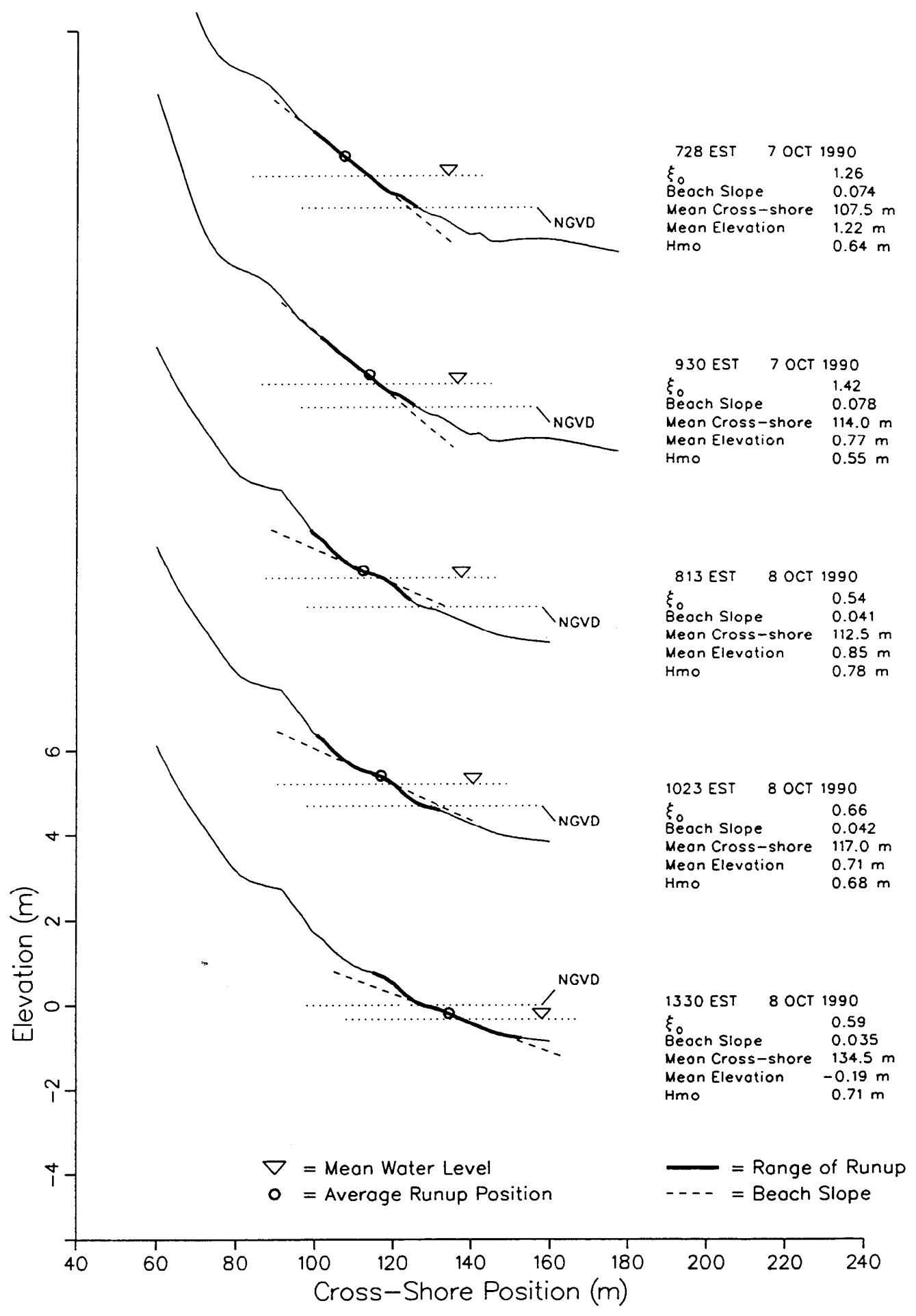

Figure A2. (Sheet 2 of 8 ) 


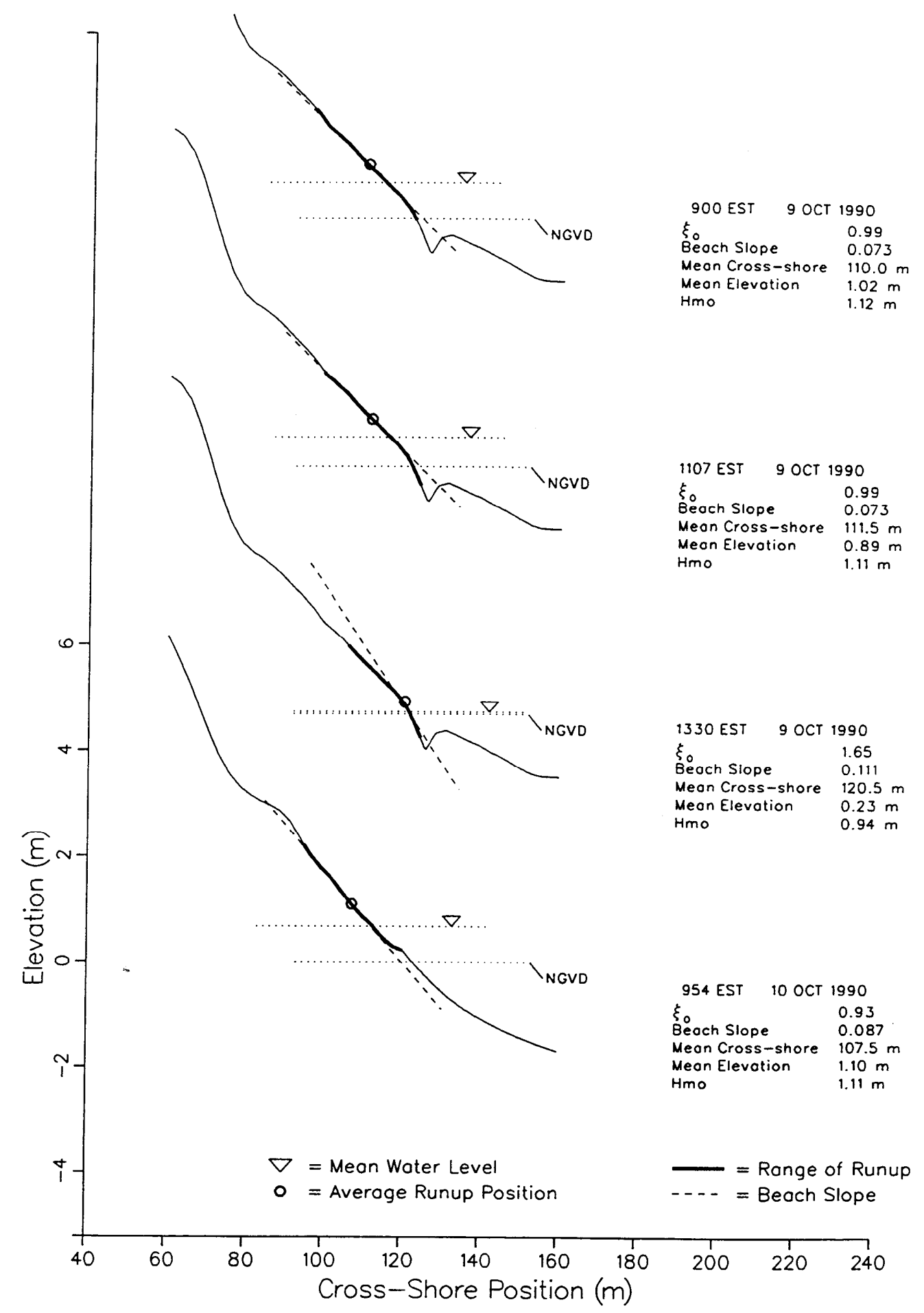

Figure A2. (Sheet 3 of 8 ) 


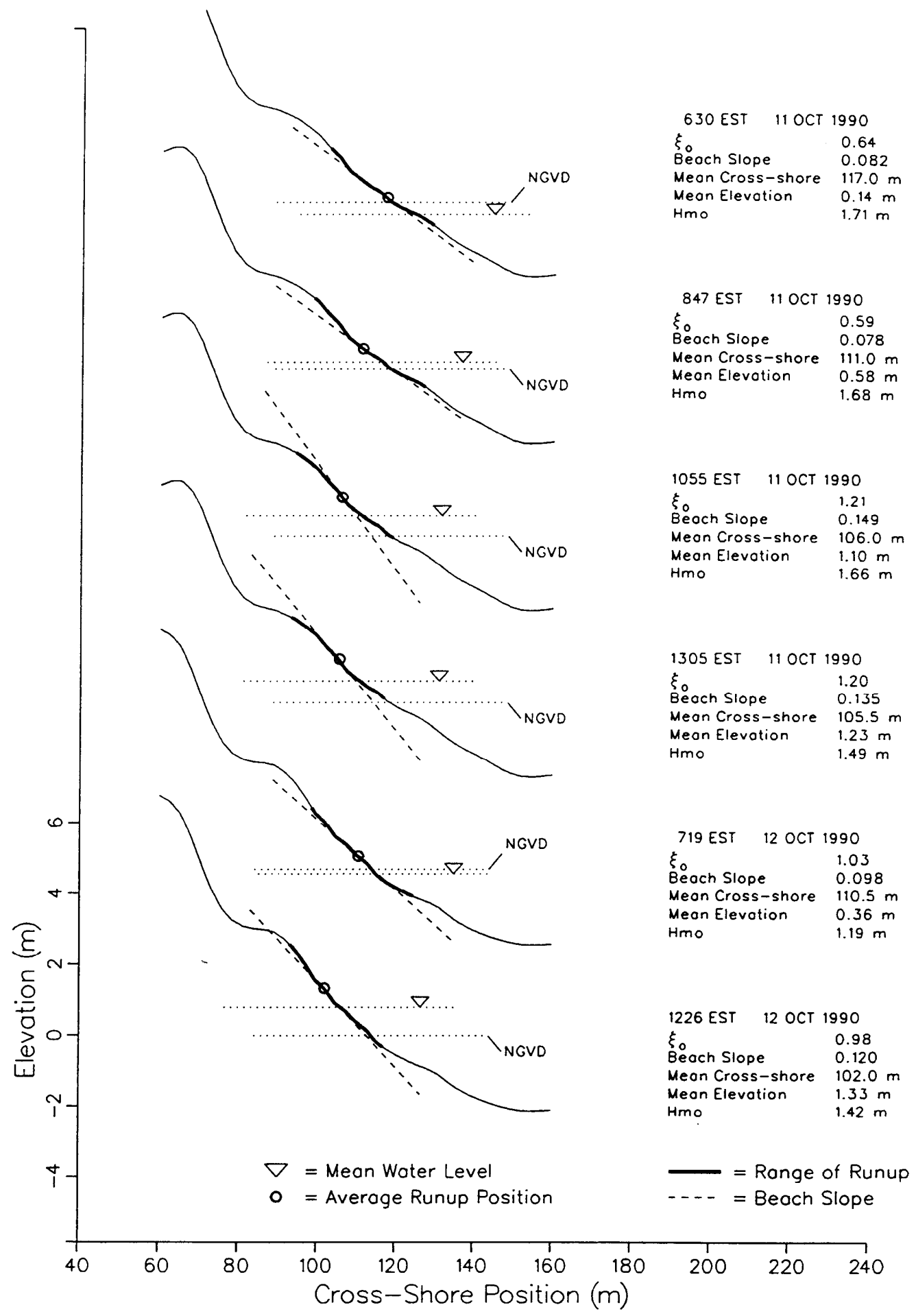

Figure A2. (Sheet 4 of 8 ) 


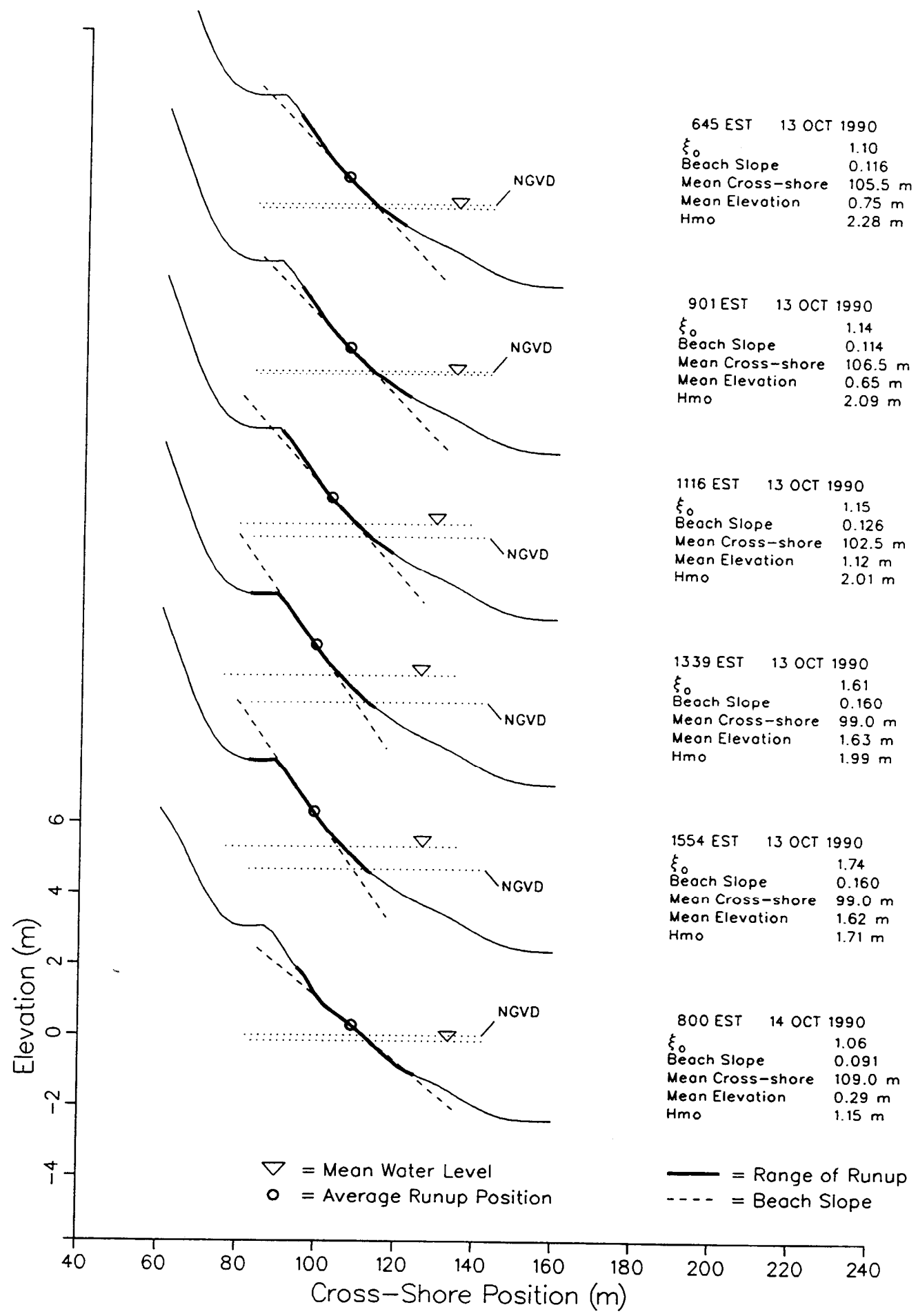

Figure A2. (Sheet 5 of 8 ) 


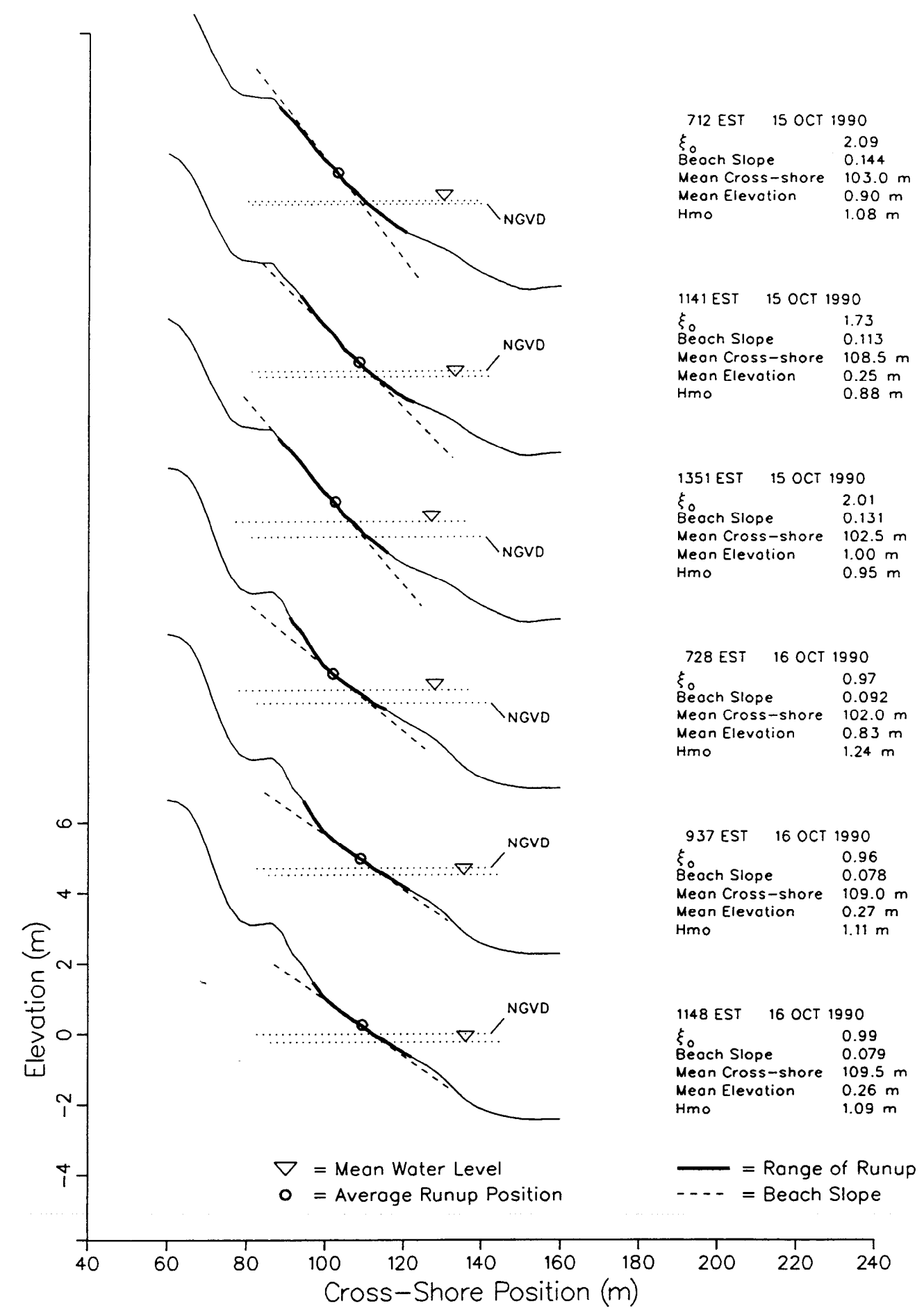

Figure A2. (Sheet 6 of 8 ) 


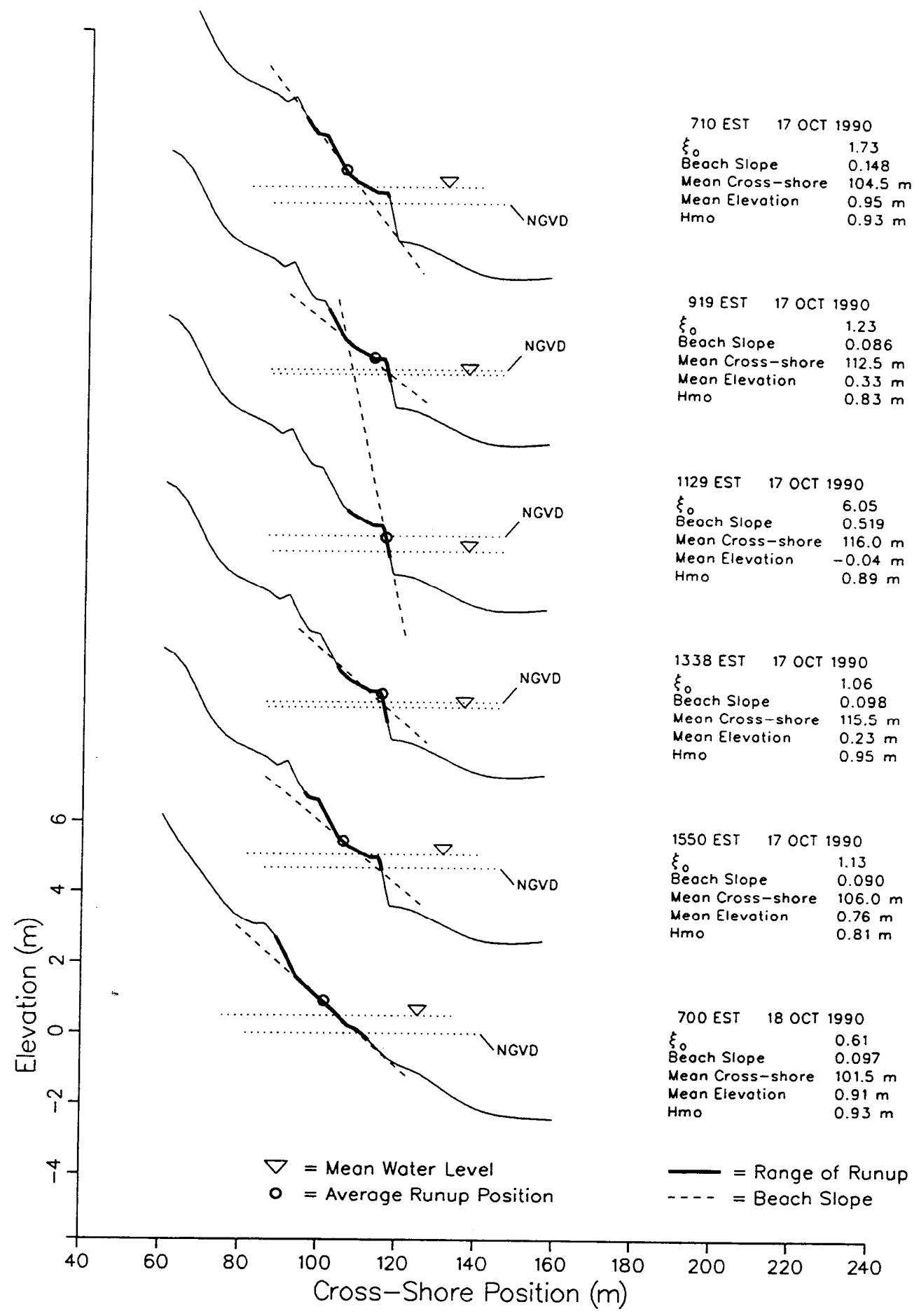

Figure A2. (Sheet 7 of 8 ) 


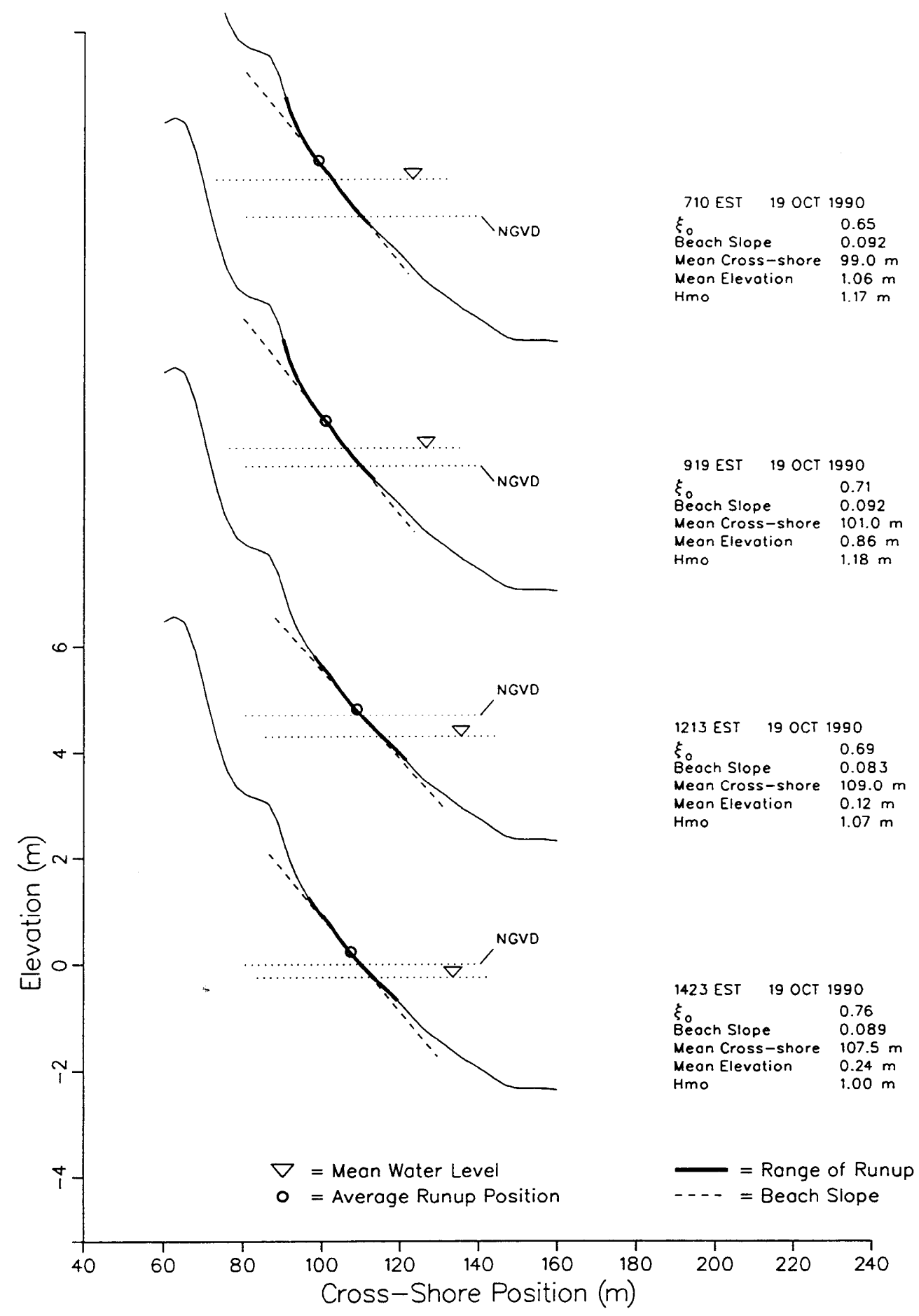

Figure A2. (Sheet 8 of 8 ) 


\section{Appendix B Photogrammetry}

The technique of using video images to determine ground topography is straightforward and has been described by Lippmann and Holman (1989) ${ }^{1}$ and Holland et al. (1997). A summary of this photogrammetric method is presented here to demonstrate the use of video to measure subaerial beach profiles (following Holman et al. 1991). This method is essentially the same as that for the video measurement of swash oscillations, except in reversed order. The fundamental problem is that since video is two-dimensional and ground topography is three-dimensional, the transformation is underdetermined. If one more piece of information is known, then the transformation from video to ground coordinates can be resolved, assuming that the camera geometry is known (i.e., camera position and view angles). For example, if one coordinate of an object is known, such as its longshore position, then a solution exists for cross-shore and vertical positions. Thus, if a line was made to cross the beach at a known angle, as with a beam of light or a shadow, then the profile along that line could be determined.

The photogrammetry of oblique images and labeling conventions used in the rectification process are illustrated in Figure B1. Coordinates in the image plane are denoted with lower case letters $(\mathrm{x}, \mathrm{y})$ and with upper case letters $(\mathrm{X}, \mathrm{Y}, \mathrm{Z})$ for ground coordinates. The camera is located at point $\mathrm{O}$ and height $\mathrm{Z}_{\mathrm{c}}$ above the horizontal (X-Y) reference plane, assumed to be MSL in this application. The camera nadir line passes through this reference plane at the nadir point $N$. The camera's focal length $f_{c}$ is the distance between the point $O$ and the $x-y$ focal plane. The camera's tilt $\tau$ is measured as the angle between the nadir and to principal point $\mathrm{p}$, the point where the optical axis intersects the center of the focal plane. The camera azimuthal angle $\phi$ is relative to the positive $y$-axis (longshore direction). A point on the ground at $Q\left(X_{Q}, Y_{Q}, Z_{Q}\right)$ and corresponding image coordinates $\mathrm{q}\left(\mathrm{x}_{\mathrm{q}}, \mathrm{y}_{\mathrm{q}}\right)$ will have the same angles $(\alpha$ and $\gamma$ ) to their respective principal lines (the line passing through principal point and nadir).

\footnotetext{
1 References cited in this appendix are located at the end of the main text.
} 


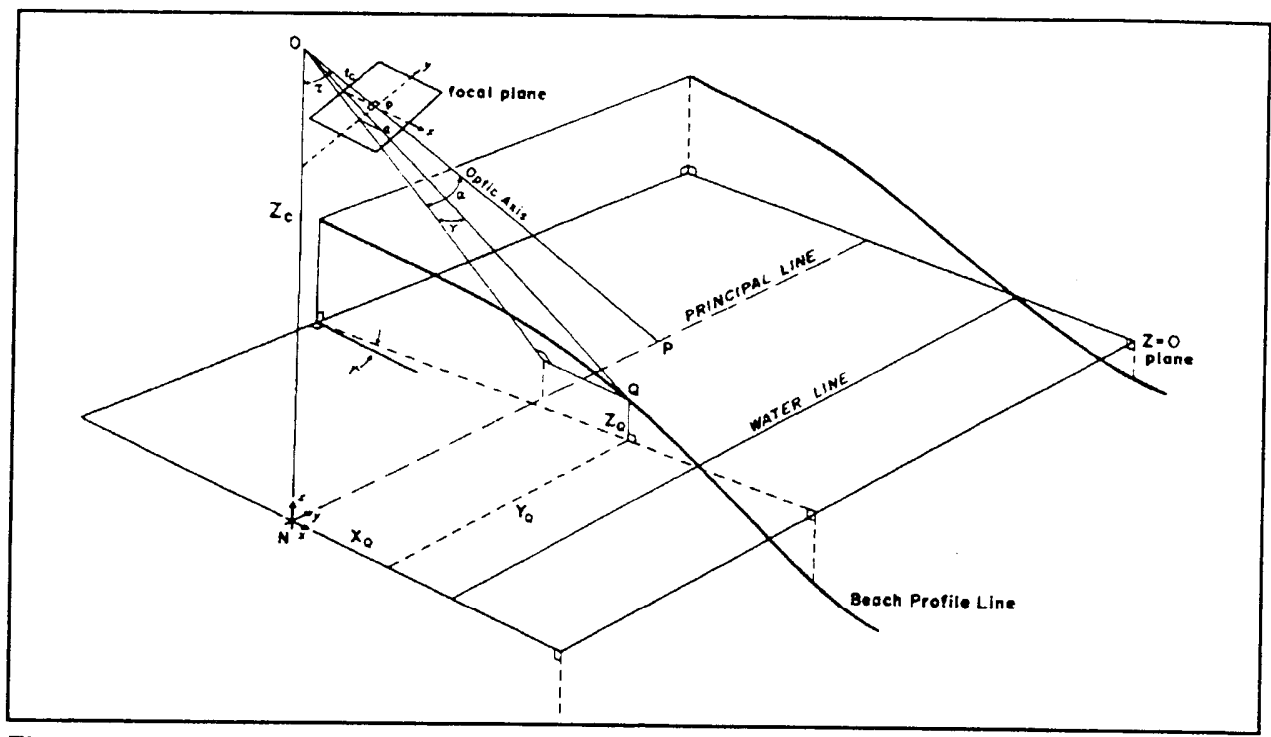

Figure B1. Photogrammetric transformation

The ground coordinates for the point $\mathrm{Q}$ can be found from image coordinates by

$$
\begin{aligned}
X & =\left(Z_{c}-Z\right)[\tan (\tau+\alpha) \sin \phi-\sec (\tau+\alpha) \tan \gamma \cos \phi] \\
& =Z^{\prime} F_{1}(\alpha, \gamma) \\
Y & =\left(Z_{c}-Z\right)[\tan (\tau+\alpha) \cos \phi-\sec (\tau+\alpha) \tan \gamma \sin \phi] \\
& =Z^{\prime} F_{2}(\alpha, \gamma)
\end{aligned}
$$

where $Z^{\prime}=\left(Z_{c}-Z\right)$ and $F_{1}$ and $F_{2}$ are functions of the camera parameters and image geometry $f_{c},(\alpha, \gamma, \tau$, and $\phi)$. The angles $\alpha$ and $\gamma$ are defined as

$$
\alpha=\tan ^{-1}\left(\frac{y_{q}}{f_{c}}\right)
$$

and 


$$
\gamma=\tan ^{-1}\left(\frac{x_{q}}{\sqrt{y_{q}^{2}+f_{c}^{2}}}\right)
$$

The unknowns $f_{c}$, $\tau$, and $\phi$ are determined with the use of targets at known image and ground coordinates, known as ground control points. An iterative procedure is used to calculate these unknown parameters. If two targets are used, then a solution can be obtained, but additional targets will provide more accurate estimations by computing a least-squares solution of the camera geometry. Lippmann and Holman (1989) found typical errors in estimates of $\tau, \phi$, and $f_{c}$ to be less than $0.25^{\circ}, 0.5^{\circ}$, and 0.5 percent, respectively.

At this point the functions $F_{1}$ and $F_{2}$ can be evaluated, but we are still left with three unknowns in Equations B1 and B2. One unknown can be eliminated if there is a line across the beach at a known angle $\mu$, described by the line

$$
Y_{L}=Y_{0 L}+X_{L} \tan \mu
$$

where the subscript $\mathrm{L}$ indicates points on the line and $Y_{0 L}$ is the intercept of the $\mathrm{Y}$-axis. Using this, Equations $\mathrm{B} 1$ and $\mathrm{B} 2$ reduce to a problem with two unknowns

$$
\begin{aligned}
& X_{L}=Z_{L} F_{1}\left(\alpha_{L}, \gamma_{L}\right) \\
& Y_{L}=Z_{L} F_{2}\left(\alpha_{L}, \gamma_{L}\right)
\end{aligned}
$$

rearranging in terms of the unknowns $X_{L}$ and $Z_{L}$, gives

$$
\begin{gathered}
X_{L}=Y_{0 L}\left(\frac{F_{2}\left(\alpha_{L}, \gamma_{L}\right)}{F_{1}\left(\alpha_{L}, \gamma_{L}\right)}-\tan \mu\right)^{-1} \\
Z_{L}=\frac{X_{L}}{F_{1}\left(\alpha_{L}, \gamma_{L}\right)}
\end{gathered}
$$

One application would be the measurement of a cross-shore profile ( $\tan \mu$ $=0)$ at a known longshore coordinate $\left(Y_{O L}=Y_{L}\right)$, say for instance a light beam cast across the beach. Functions $F_{1}$ and $F_{2}$ are computed from a measured $\alpha_{L}$ and $\gamma_{L}$, then the other two ground coordinates $\left(X_{L}\right.$ and $\left.Y_{L}\right)$ are found using Equations B6 and B7. Repeating this for all video pixels $\left(\alpha_{L}\right.$ and $\gamma_{L}$ values) 
lying on a cross-shore profile results in an estimate of the three-dimensional profile.

Nevertheless, the primary use for the system has been runup measurements, very similar to measuring a profile. Camera geometry is determined from ground control points in the manner described above. A measured beach profile $(\mathrm{X}, \mathrm{Y}, \mathrm{Z})$ is transformed into corresponding video coordinates. Pixel intensities are recorded along the video profile in a single video frame, each pixel having an associated ground coordinate. A typical sampling rate would be $6 \mathrm{~Hz}$, with postprocessing decimation to $2 \mathrm{~Hz}$. Pixel intensities on each profile are scanned for an abrupt change in intensity, detecting the swash edge, at which point the measured video coordinate is transformed to a runup elevation (Equation B9).

In principle, video measurement of runup could be automated to include routine measurement of beach profiles, reducing errors associated with temporal changes (i.e., difference between actual and assumed profiles). This method of using video to measure subaerial beach profiles was demonstrated by Holman et al. (1991) to have vertical accuracies of approximately $\pm 1 / 2$ pixel, or about $\pm 5 \mathrm{~cm}$ at $100 \mathrm{~m}$ from the camera. This technique would allow for routine collection of long time series of subaerial profiles and runup to study beach climatology.

A present limitation with this system is that video runup measurements are typically done in daylight hours, whereas profile measurements (done by casting a light beam) would be done under low light conditions. Night-time runup measurements could be done along the lighted profile at night, but the lighted profile would be difficult to see in the daytime. Stereo-photography would be one method of making daytime measurements of beach profiles (over the swash excursion) and runup without beach surveys or "light beams." 


\section{Appendix C Notation}

\begin{tabular}{|c|c|}
\hline$a$ & Edge wave shoreline amplitude \\
\hline$c$ & Edge wave celerity \\
\hline$c_{g}$ & Incident wave group velocity \\
\hline$C$ & Correlation coefficient \\
\hline$f$ & Wave frequency \\
\hline$f_{c}$ & Camera focal length \\
\hline$F_{\text {MAX }}$ & Peak frequency in energy spectra \\
\hline$F_{1}, F_{2}$ & Functions of camera parameters and image geometry \\
\hline$g$ & Acceleration of gravity \\
\hline$h$ & Water depth \\
\hline$H_{m o}$ & Characteristic wave height based on a wave energy spectrum \\
\hline$J_{0}$ & Zeroth order Bessel function \\
\hline$k$ & Wave number \\
\hline$k_{x}$ & Cross-shore wave number \\
\hline$k_{y}$ & Longshore wave number \\
\hline$L_{n}$ & Laguerre polynomial of order $n$ \\
\hline
\end{tabular}


$Q, q \quad$ Three-dimensional ground coordinate and corresponding twodimensional image coordinate in photogrammetry

$S_{x x}(t) \quad$ Radiation stress

$S\left(f_{r}, \theta_{m}\right) \quad$ Discrete wave energy frequency-direction spectrum

$t \quad$ Time, $\mathrm{s}$

$T_{p} \quad$ Peak period in energy spectra

$u, v \quad$ Cross-shore and longshore edge wave velocity components

$U(x, y, t) \quad$ Total current vector

$V_{\max } \quad$ Peak longshore current

V Mean longshore current

$x$ Cross-shore coordinate, 0 at shoreline, positive offshore for wave measurements; image plane coordinate for photogrammetry

$y \quad$ Longshore coordinate for wave measurements, image plane coordinate for photogrammetry

$X, Y, Z \quad$ Cross-shore, longshore, and vertical ground coordinates used in photogrammetry

$Z_{c} \quad$ Camera height above $\mathrm{X}-\mathrm{Y}$ plane

$\alpha, \gamma, \tau \quad$ Camera view angles in photogrammetry

$\beta \quad$ Beach slope

$\beta_{+k_{y}}, \beta_{-k_{y}} \quad$ Effective beach slope for edge waves in the presence of a longshore current

$\eta \quad$ Surface elevation from still-water level

$\mu \quad$ Angle of line on beach relative to cross-shore axis

$\xi_{0} \quad$ Iribarren number

$\rho \quad$ Water density 
$\phi \quad$ Cross-shore amplitude function for shallow-water edge waves; camera view angle in photogrammetry

$\chi \quad$ Nondimensional offshore distance

$\omega \quad$ Radial wave frequency, $\sec ^{-1}$ 
Public reporting burden for this collection of information is estimated to average 1 hour per response, including the time for reviewing instructions, searching existing data sources, gathering and maintaining the data needed, and completing and reviewing the collection of information. Send comments regarding this burden estimate or any other aspect of this collection of information, including suggestions for reducing this burden, to Washington Headquarters Services, Directorate for Information Operations and Reports, 1215 Jefferson Davis Highway, Suite 1204, Artington, VA 22202-4302, and to the Office of Management and Budget, Paperwork Reduction Project (0704-0188), Wastington, DC 20503.

\begin{tabular}{|l|l|l|l}
\hline 1. AGENCY USE ONLY (Leave blank) & 2 $\begin{array}{l}\text { REPORT DATE } \\
\text { September } 1998\end{array}$ & $\begin{array}{l}\text { 3. REPORT TYPE AND DATES COVERED } \\
\text { Final report }\end{array}$
\end{tabular}

\section{TTLE AND SUBTITLE}

Infragravity Waves in the Nearshore Zone

5. FUNDING NUMBERS

\section{AUTHOR(S)}

Kent K. Hathaway, Joan Oltman-Shay, Peter Howd, Rob A. Holman

7. PERFORMING ORGANIZATION NAME(S) AND ADDRESS(ES)

See reverse.

8. PERFORMING ORGANIZATION REPORT NUMBER

Technical Report CHL-98-30

9. SPONSORINGMONTTORING AGENCY NAME(S) AND ADDRESS(ES)

U.S. Army Corps of Engineers

Washington, DC 20314-1000

11. SUPPLEMENTARY NOTES

Available from National Technical Information Service, 5285 Port Royal Road, Springfield, VA 22161.
10. SPONSORINGMONTORING AGENCY REPORT NUMBER 12b. DISTRIBUTION CODE
Approved for public release; distribution is unlimited.

12a. DISTRIBUTIONAVALLABILTYY STATEMENT

\section{ABSTRACT (Maximum 200 words)}

This report summarizes the present state of knowledge on infragravity wave motions (nominally $0.003 \mathrm{to} 0.05 \mathrm{~Hz}$ ). Theoretical and observational studies are presented. Most of the studies discussed herein have been published elsewhere, however a few studies discussed in chapter 4 are presented for the first time in this report. Measurements of nearshore waves and currents have shown that a significant amount of the total energy can be contained in the infragravity band, and on highly dissipative beaches the infragravity wave variance often dominates over energy in the incident wave band $(0.05$ to $0.3 \mathrm{~Hz})$. An 8-month data set of infragravity variance measured at 8 -m depth at the shoreline (runup) was compared with incident wave variance. Analysis of the 8-m-depth data showed that high mode edge waves account for about 50 percent of the total infragravity variance, and as high as 80 percent at times. Significant edge wave heights greater than $20 \mathrm{~cm}$ were observed at the $8-\mathrm{m}$ depth. Infragravity wave variance was shown to have a higher correlation with swell variance $(C=0.95)$ than with sea variance $(C=0.61)$. This report was motivated, in part, by the need to determine the significance of infragravity waves on coastal erosion and structure damage and by the desire to improve coastal engineering solutions to problems associated with nearshore processes.

\begin{tabular}{|c|c|c|c|c|}
\hline \multicolumn{5}{|c|}{ 14. SUBJECT TERMS } \\
\hline & Infragravity waves & Leak & wave & Rur \\
\hline & Edge waves & Shear & waves & $w$ \\
\hline & Bound waves & Beacl & morphology & $\mathrm{Sa}$ \\
\hline 17. & $\begin{array}{l}\text { SECURITY CLASSIFICATION } \\
\text { OF REPORT }\end{array}$ & 18. & $\begin{array}{l}\text { SECURTY CLA } \\
\text { OF THIS PAGE }\end{array}$ & ITION \\
\hline & UNCLASSIFIED & & UNCLASSI & \\
\hline
\end{tabular}

NSN 7540-01-280-5500
15. NUMBER OF PAGES 89

16. PRICE CODE
19. SECURITY CLASSIFICATION OF ABSTRACT

20. UMITATION OF ABSTRACT 
7. (Concluded).

U.S. Army Engineer Waterways Experiment Station 3909 Halls Ferry Road, Vicksburg, MS 39180-6199;

Northwest Research Associates

14508 NE 20th Street, Bellevue, WA 98009;

Department of Marine Science, University of South Florida

140 7th Avenue South, St. Petersburg, FL 33701-5016;

College of Oceanography, Oregon State University

Corvallis, OR 97331-5503 